\title{
Schädigung respiratorischer Epithelzellen nach allogener Stammzelltransplantation in einem Zellkulturmodell der Graft-versus-Host Reaktion
}

Dissertation zur Erlangung des Doktorgrades der Naturwissenschaften (Dr. rer. nat.) der naturwissenschaftlichen Fakultät III - Biologie und Vorklinische Medizin -

der Universität Regensburg

vorgelegt von

Kirsten Krätzel

aus Miltenberg

2008 
Promotionsgesuch eingereicht am: 24.06.2008

Die Arbeit wurde angeleitet von: Prof. Dr. Hauska

Prüfungsauschuss:

Vorsitzender: $\quad$ Prof. Dr. Schneuwly

Erstgutachter: $\quad$ Prof. Dr. Hauska

Zweitgutachter: PD Dr. Schulz

Dritter Prüfer: $\quad$ Prof. Dr. Warth 


\section{Abkürzungsverzeichnis}

APC Antigenpräsentierende Zelle, antigene presenting cell

A549(IFN- $\gamma) \quad$ mit IFN- $\gamma(24 \mathrm{~h}, 200 \mathrm{U} / \mathrm{ml})$ vorstimulierte A549-Zellen

CFSE Carboxyfluorescein Succinimidyl Ester

CTL

zytotoxische T-Zelle, cytotoxic T-lymphocyte

$\mathrm{CD}$

Cluster of Differentiation

cDNA komplementäre DNA (complementary desoxyribonucleic acid)

DMSO Dimethylsulfoxid

dNTP Desoxyribonucleosidtriphosphat

ELISA Enzyme-linked Immunosorbent Assay

FACS fluorescence activated cell sorter

FBS fötales Kälberserum, fetal bovine serum

FITC Fluoresceinisothiocyanat

FSC Vorwärtsstreulicht, foreward scatter

GvHD Spender-gegen-Empfänger Reaktion, graft-versus-host disease

GvL Spender-gegen-Leukämie Reaktion, graft-versus-leukaemia effekt

IFN- $\gamma \quad$ Interferon $\gamma$

Ig Immunglobulin

IL-2 Interleukin 2

MFI mittlere Fluoreszenzintensität, mean fluorescence intensity

MHC Haupthistokompatibilitätskomplex, major histokompatibility complex

OD optische Dichte

oligo-dT oligo-Desoxythymidin

PBEC primäre bronchiale Epithelzellen, primary bronchial epithelial cells

PBEC $^{(\mathrm{IFN}-\gamma)}$ mit IFN- $\gamma(24 \mathrm{~h}, 200 \mathrm{U} / \mathrm{ml})$ vorstimulierte PBEC

PBMC mononukleäre Zellen des peripheren Blutes, peripheral blood

mononuclear cells

PBS Phosphat-gepufferte Salzlösung, phosphate buffered saline

PCR Polymerase-Ketten-Reaktion, Polymerase-Chain-Reaction 
PE Phycoerythrin

PI Propidium Iodid

SEB Staphylokokken-Enterotoxin B

SSC Seitwärtsstreulicht, sideward scatter

SZT Stammzelltransplantation

ICAM Interzelluläres Adhäsionsmolekül, intercellular adhesion molecule

MIC A/B MHC class I chain-related gene A und B

NKG2D natural-killer group 2, member D 


\section{Inhaltsverzeichnis}

1 Einleitung $\quad 1$

1.1 Allogene Knochenmark- und Stammzelltransplantation . . . . . . . . . . 1

1.2 Nebenwirkungen der Stammzelltransplantation . . . . . . . . . . . . . . . 2

1.3 Grundlegende Mechanismen der GvHD . . . . . . . . . . . . . . . . 6

2 Motivation und Fragestellung $\quad 11$

3 Material und Methoden 13

3.1 Material . . . . . . . . . . . . . . . . . . . . . . 13

3.2 Grundlegende zellkulturelle Arbeitsmethoden . . . . . . . . . . . . . . . . 17

3.2.1 Zellkulturbedingungen und Subkultivierung . . . . . . . . . . 17

3.2.2 Zentrifugation von Zellen . . . . . . . . . . . . . . . . . 18

3.2 .3 Kryokonservierung . . . . . . . . . . . . . . . 18

3.2.4 Vitalitätsprüfung und Zellzahlbestimmung . . . . . . . . . . 18

3.3 Kultivierung und Charakterisierung der Zelllinien . . . . . . . . . . . . . 19

3.4 Kultivierung und Charakterisierung primärer bronchialer Epithelzellen . 20

3.5 Isolation, Stimulation und Aktivierung von $\mathrm{CD}^{+}$T-Zellen . . . . . . . . 21

3.6 Vorbehandlung/-stimulation von Epithelzellen . . . . . . . . . . . . . . . 24

3.7 Semiquantitative RNA-Bestimmung . . . . . . . . . . . . . . . . . 24

3.7.1 RNA-Isolation . . . . . . . . . . . . . . . . . 25

3.7.2 reverse Transkription der mRNA zu cDNA . . . . . . . . . . 25

3.7.3 relative Quantifizierung der Genexpression: Real-Time PCR . . . 26

3.8 Bestimmung löslicher Zytokine im ELISA . . . . . . . . . . . . . . . . . 28

3.9 Durchflusszytometrie und Zellsortierung . . . . . . . . . . . . . . . . 28

3.10 Proliferationsbestimmung mittels CFSE-Färbung . . . . . . . . . . . . 30

3.11 Funktionaler Zytotoxizitätstest: ${ }^{51} \mathrm{Cr}$-Release Assay . . . . . . . . . . . . 31

3.12 Statistische Auswertungen . . . . . . . . . . . . . . . . 33 
4 Ergebnisse

4.1 Phänotypische Charakterisierung der primären bronchialen Epithelzellen 35

4.2 Charakterisierung der Oberflächenexpression respiratorischer Epithelzellen 37

4.2.1 Expression von Oberflächenmolekülen auf Transkriptionsebene . . 37

4.2.2 Expression von Oberflächenmolekülen auf Proteinebene . . . . . . 39

4.2.3 Steigerung der Oberflächenexpression durch IFN- $\gamma$-Vorstimulierung 39

4.3 Charakterisierung der isolierten $\mathrm{CD} 8^{+} \mathrm{T}$-Zell-Population . . . . . . . . . 41

4.4 Allogene Aktivierung der CD8 ${ }^{+} \mathrm{T}$-Zellen . . . . . . . . . . . . . . . . 42

4.4.1 IFN- $\gamma$-Produktion . . . . . . . . . . . . . . . . . . . . . 42

4.4.2 Aktivierungsmarker-Expression . . . . . . . . . . . . 45

4.5 Proliferation der CD8 ${ }^{+}$T-Zellen . . . . . . . . . . . . . . . . . . 49

4.6 Zytotoxizität aktivierter CD8 ${ }^{+}$T-Zellen gegen respiratorische Epithelzellen 52

4.6.1 Kontrolltargets: Bestätigung von Alloreaktivität und Target-Spezifität der Zytotoxizität aktivierter CD8 ${ }^{+}$T-Zellen . . . . . . . . . 55

4.6.2 Cold-Target-Inhibition: Bestätigung der Target-Spezifität der Zytotoxizität aktivierter $\mathrm{CD} 8^{+} \mathrm{T}$-Zellen . . . . . . . . . . . 57

4.7 Mechanismus der Lyse von BEAS-2B . . . . . . . . . . . . . . . 58

4.7.1 Granzym B oder FAS/FAS-Ligand? . . . . . . . . . . . . . . . 59

4.7.2 Einfluss von MHC I auf die Lyse von BEAS-2B . . . . . . . . . 60

4.7.3 Einfluss von NKG2D und dessen Liganden auf die BEAS-2B-Lyse 62

4.8 Zytotoxizität aktivierter $\mathrm{CD}^{+}$T-Zellen gegen primäre bronchiale Epi-

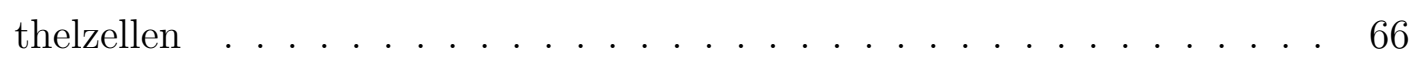

5 Diskussion $\quad 71$

5.1 Zellkulturmodell der GvHD . . . . . . . . . . . . . . 71

5.2 Aktivierung CD8 ${ }^{+}$T-Zellen durch respiratorische Epithelzellen . . . . . . 73

5.3 Zytotoxizität CD8 ${ }^{+}$T-Zellen gegen respiratorische Epithelzellen . . . . . 75

5.4 IFN- $\gamma$-Vorstimulation der schwachen Stimulatoren A549 und PBEC . . . 78

5.5 Mechanismus der Lyse bronchialer Epithelzellen . . . . . . . . . . . 79

$\begin{array}{lll}6 & \text { Zusammenfassung } & 83\end{array}$

$\begin{array}{lll}7 & \text { Anhang } & 85\end{array}$ 


\section{Abbildungsverzeichnis}

1.1 Klassische immunologische Wechselwirkungen . . . . . . . . . . . . 7

3.1 Lichtmikroskopische Aufnahme bronchialer Epithelzellen: Zelllinie BEAS-2B 19

3.2 Lichtmikroskopische Aufnahme alveolärer Epithelzellen der Zelllinie A549 19

3.3 Prinzip der Zellseparation mittels magnetischer Partikel . . . . . . . . . . 22

3.4 Wirkungsweise des Superantigens Staphylokokken-Enterotoxin B . . . . . 24

3.5 DNA-Schmelzkurven der Produkte einer real-time PCR . . . . . . . . . . 27

4.1 Lichtmikroskopische Aufnahme primärer bronchialer Epithelzellen . . . . 35

4.2 Charakterisierung der primären bronchialen Epithelzellen . . . . . . . . 36

4.3 mRNA-Expression von Oberflächenmarkern in BEAS-2B, A549 und PBEC 38

4.4 Expression von Oberflächenmarkern auf BEAS-2B, A549 und PBEC . . . 40

4.5 Phänotyp der isolierten T-Zellen . . . . . . . . . . . . . . . . . . . . . 42

4.6 IFN- $\gamma$-Ausschüttung durch stimulierte $\mathrm{CD} 8^{+}$T-Zellen . . . . . . . . . . . 43

4.7 IFN- $\gamma$-Ausschüttung durch $\mathrm{CD}^{+}$T-Zellen nach BEAS-2B-Stimulation . 44

4.8 IFN- $\gamma$-Ausschüttung durch $\mathrm{CD}^{+}$T-Zellen nach A549-/PBEC-Stimulation 44

4.9 Aktivierungsmarkerexpression auf T-Zellen nach BEAS-2B-Stimulation . 48

4.10 Proliferation CD8 ${ }^{+}$T-Zellen . . . . . . . . . . . . . . . . 49

4.11 Anteile proliferierender $\mathrm{CD}^{+} \mathrm{T}$-Zellen . . . . . . . . . . . . . 52

4.12 BEAS-2B-Lyse . . . . . . . . . . . . . . . . . 53

4.13 A549-Lyse . . . . . . . . . . . . . . . . . . . 54

4.14 Spezifische lytische Aktivität BEAS-2B-aktivierter CTL . . . . . . . . . . 56

4.15 BEAS-2B- und K562-Lyse in Abhängigkeit von der Stimulationsdauer . 56

4.16 Cold-Target-Inhibition . . . . . . . . . . . . . . . 58

4.17 Granzym B-Ausschüttung BEAS-2B-aktivierter CTL . . . . . . . . . . . 59

4.18 Einfluss eines FAS- oder TNF-vermittelten Apoptosesignals auf die Lyse 60

4.19 Einfluss von MHC I auf die BEAS-2B-Lyse . . . . . . . . . . . . . . . . 61

4.20 NKG2D-Expression auf CD8 ${ }^{+}$T-Zellen . . . . . . . . . . . . . 63 
4.21 Regulation der NKG2D-Expression auf CD8 ${ }^{+}$T-Zellen . . . . . . . . . . 63

4.22 MIC A/B-Expression auf BEAS-2B . . . . . . . . . . . . . . . . 63

4.23 Einfluss von NKG2D auf die BEAS-2B-Lyse . . . . . . . . . . . . . 64

4.24 NKG2D-Expression auf CTL nach BEAS-2B-Stimulation . . . . . . . . . 65

4.25 Abhängigkeit der BEAS-2B-Lyse von der NKG2D-Expression auf CTL . 65

4.26 Spezifische Lyse von PBEC durch PBEC-stimulierte CTL . . . . . . . . . 67

4.27 Einfluss einer IFN- $\gamma$-Vorbehandlung auf die Lyse von PBEC . . . . . . . 68

4.28 Einfluss von MHC I bzw. NKG2D auf die PBEC-Lyse . . . . . . . . . . . 70

4.29 Einfluss von MIC auf die PBEC-Lyse . . . . . . . . . . . . . . . . . 70 


\section{Einleitung}

\subsection{Allogene Knochenmark- und Stammzelltransplantation}

Die Stammzelltransplantation (SZT) ist heute eine weltweit anerkannte, etablierte und oft die einzige kurative Behandlungsmethode von einer Reihe maligner oder nichtmaligner, lebensbedrohlicher Krankheiten, die auf einer abnormalen Blutbildung oder Funktion der Immunzellen beruhen. Beispiele hierfür sind Leukämien, Lymphome, hämatopoetische Neoplasien oder genetische Erkrankungen, die mit einer gestörten Hämatopoese und Funktion zusammenhängen (z. B. Thalassämie). Das Prinzip der SZT beruht darauf, dass die kranken, entarteten Blut- oder Vorläuferzellen zerstört und anschließend durch gesunde Stamm- oder Knochenmarkzellen mit normaler Funktion ersetzt werden, die in der Folge die normale Blutbildung und Funktion des Immunsystems übernehmen. Anfangs wurden die zu transplantierenden Stammzellen aus dem Knochenmark gewonnen. In neuerer Zeit werden Stammzellen aber zunehmend auch aus dem peripheren Blut isoliert, nachdem sie zuvor aus dem Knochenmark mobilisiert wurden [1]. Auch aus Nabelschnurblut können Stammzellen gewonnen werden, aufgrund des geringen Blutvolumens und der damit verbundenen kleinen Zellmenge eignet sich diese Methode allerdings nur zur Transplantation bei Kindern.

Je nach der Herkunft der transplantierten Stammzellen unterscheidet man zwischen autologer, syngener und allogener SZT [1]. Bei der autologen SZT werden dem Patienten vor Therapiebeginn eigene Stammzellen entnommen und nach Strahlen- oder Chemotherapie wieder zugeführt, was den Vorteil hat, dass dieser nicht auf einen passenden Fremdspender angewiesen ist und auch keine immunologischen Komplikationen zu erwarten hat. Allerdings können im Transplantat auch maligne Zellen enthalten sein, sodass das Rezidivrisiko erhöht ist. Bei der syngenen SZT werden Stammzellen von einem eineiigen Zwilling transplantiert. Die häufigste Form ist jedoch die allogene SZT, bei der ein geeignetes (HLA-identisches, s.u.) Familienmitglied oder ein geeigneter (HLA-kompatibler, s.u.) Fremdspender für die Gewinnung der zu transplantierenden Stammzellen gefunden 
werden muss, was nicht immer leicht ist. Ein großer Nachteil dieser Methode ist außerdem das häufige Auftreten immunologisch bedingter Reaktionen, die gegen den Körper des Empfängers und seine Organe gerichtet sind (wie die Transplantat-gegen-Empfänger Reaktion, die graft-versus-host disease (GvHD), die später genauer betrachtet wird) $[2,3,4,5]$.

Eine SZT läuft in zwei Schritten ab. Während der ersten Phase der Therapie, noch vor der eigentlichen Transplantation, wird der Patient konditioniert, d.h. immunsuppressiv vorbehandelt. Dabei wird durch Chemotherapie und/oder Ganzkörperbestrahlung der größte Teil der eigenen Immun- und Knochenmarkzellen zerstört. Damit werden zum einen die kranken bzw. bösartigen Zellen vernichtet und dadurch das Anwachsen des Transplantats im frei werdenden Knochenmarksraum gefördert [6]. Zum anderen wird dadurch die spätere Abstoßung des Transplantats durch körpereigene intakte Immunzellen verhindert. Im zweiten Schritt gelangen dann die neuen Stammzellen des Spenders durch Transfusion in den Blutkreislauf und finden von dort ihren Weg in den Knochenmarkraum des Empfängers. Im Idealfall übernehmen sie nach ein bis drei Wochen die neue Blutbildung und Immunabwehr des Patienten, bis wieder ein größtenteils normal funktionsfähiges Immunsystem aufgebaut ist, dauert jedoch ca. sechs Monate, manche feineren Abwehrfunktionen brauchen sogar bis zu zwei Jahre zur vollständigen Erholung. Weiterhin bekämpfen mit dem Transplantat übertragene T-Zellen des Spenders auch zurückgebliebene maligne Zellen des Empfängers - ein wichtiges Therapieprinzip der SZT, das auch Spender-gegen-Leukämie Effekt (graft-versus-leukaemia effekt = GvL) genannt wird $[7,8]$.

\subsection{Nebenwirkungen der Stammzelltransplantation}

Die SZT bietet heutzutage hohe Heilungschancen, bis zu $60 \%$ aller behandelten Patienten können mindestens zehn Jahre nach der Transplantation überleben. Trotzdem kommt es aber immer noch oft zu schweren Nebenwirkungen, die je nach Stadium der Erkrankung und in Abhängigkeit von vorliegenden Risikofaktoren bei $15 \%$ bis über $30 \%$ der Patienten im ersten Jahr nach Transplantation letztlich zum Tod führen $[2,4,9,10]$.

Allgemein können Komplikationen nach SZT auf verschiedene Ursachen zurückgeführt werden: zum einen auf die direkte Schädigung v.a. sich schnell teilender Gewebe wie Schleimhäute, Haare und Spermien durch Konditionierungsmaßnahmen, v.a. Bestrahlung, zum anderen auf Infektionen als Folge der Immunsuppression und auf nichtinfektiös bedingte immunologische Reaktionen. 


\section{Nebenwirkungen an der Lunge}

Neben Leber, Haut und Darm ist die Lunge das Organ, an dem sich die meisten und schwerwiegendsten Komplikationen manifestieren. So tritt z. B. der sogenannte diffuse Lungenschaden bei $25 \%$ bis $55 \%$ aller SZT-Empfänger auf und kann für ca. $50 \%$ der Mortalität nach Transplantation verantwortlich gemacht werden $[11,12,13,14,15,16$, $17]$.

Viele Erreger v.a. des Respirationstraktes, die bei Gesunden nur ausnahmsweise lebensbedrohliche Krankheiten verursachen, führen bei immunsupprimierten Patienten zu erhöhter Morbidität und so stellen Infektionen besonders in der frühen Posttransplantationsphase ein großes Problem dar. Aufgrund des erfolgreichen Einsatzes antibiotischer Prophylaxe treten aber in den letzten Jahren infektiöse Ursachen, die früher noch für die Hälfte der pulmologischen Komplikationen verantwortlich waren, immer mehr in den Hintergrund, so dass akute sowie chronische nichtinfektiös bedingte Nebenwirkungen an Gewicht gewinnen [12, 16, 18, 19, 20]. So fanden Schwarer et al. [21] in einer Studie an 143 Patienten nach SZT bereits 1992 bei 20 \% chronische Symptome an der Lunge wie Husten, Dyspnoe (Atemnot) und starke Reduzierung des Lungenvolumens, ohne dass es Anhaltspunkte für Infektionen gab. Daneben reagiert die Lunge sehr empfindlich auf direkte strahlungsinduzierte Schäden besonders durch die Anwendung von Ganzkörperbestrahlung während der Konditionierungsphase, sowie auch auf indirekte, über proinflammatorische Zytokine wirkende, toxische Effekte der Konditionierungsmaßnahmen [12]. Eine Veränderung der Transplantationsmethoden weg von konventioneller intensiver Konditionierung und hin zu reduzierter Konditionierungsintensität sowie die Verwendung von Stammzellen aus Blut anstatt aus Knochenmark tragen zwar zu einem Absinken der direkten konditionierungsbedingten Organschäden und damit auch der frühen, toxischen Lungenschäden in der akuten Phase bei. Gleichzeitig ist aber eine Verschiebung hin zu chronischen oder „verspäteten akuten“ Komplikationen ab 100 Tagen nach der Transplantation zu beobachten [8], so dass die Gesamthäufigkeit von Lungenkomplikationen durch die veränderten Konditionierungsmethoden nicht weiter abnimmt.

Eine verbreitete Lungenschädigung, die bei $5 \%$ bis $25 \%$ der Patienten nach SZT in der akuten oder chronischen Phase zu beobachten ist, wird als Idiopathisches Pneumonie Syndrom (IPS) bezeichnet und ist als das Auftreten einer pulmonalen Inflammation (Entzündung) und Fibrose nach SZT in Abwesenheit einer Infektion definiert [18, 22]. Das IPS tritt mit einem breiten Spektrum klinischer Symptome auf, von denen z. B. Lungenentzündung (Pneumonie) und eine abnormale Lungenfunktion diagnostisch sind und 
ist histopathologisch u.a. mit einem diffusen Alveolarschaden, lymphozytärer Bronchitis und „bronchiolitis obliterans organizing pneumonia“ (BOOP) assoziiert [12, 17, 20, 23]. Das am häufigsten auftretende Krankheitsmuster ist jedoch die interstitielle Pneumonitis (IP), die in der Frühphase nach SZT in Assoziation mit dem diffusen Alveolarschaden auftritt und zu späteren Zeitpunkten auch von bronchiolärer Entzündung sowie Epithelschäden begleitet ist [11, 24, 25]. Als Risikofaktoren und potentielle Ursachen für das IPS gelten neben versteckten Infektionen und direkten und indirekten toxischen Effekten der Konditionierungsmaßnahmen vor allem die Freilassung inflammatorischer Zytokine sowie das Auftreten einer akuten GvHD [12, 17, 26]. Möglicherweise muss das IPS tatsächlich als das Ergebnis eines additiven oder synergistischen Zusammenwirkens von direkter bestrahlungsinduzierter Lungenschädigung und einer GvHD gesehen werden $[22]$.

\section{GvHD als immunologische Nebenwirkung der SZT}

Als GvHD, Spender-gegen-Empfänger Reaktion (graft-versus-host disease, GvHD) werden allgemein nichtinfektiöse immunologisch bedingte Komplikationen nach allogener SZT bezeichnet, die heutzutage generell das Hauptproblem nach SZT darstellen [27]. Die GvHD tritt in akuter Form bei 30 \%-80 \% der Patienten in den ersten drei Monaten auf und ist für eine hohe Frühmortalität nach allogener SZT verantwortlich [22, 27, 28], eine chronische GvHD dagegen tritt erst nach mehr als 100 Tagen, oft auch erst nach vielen Monaten oder Jahren nach SZT in Erscheinung und ist bei insgesamt 30 \%-60 \% der Patienten zu beobachten.

Die Ursache der GvHD liegt darin, dass bei der allogenen SZT zusammen mit den Stammzellen und dem hämatopoetischen System auch bereits immunkompetente, d.h. reife T-Zellen übertragen werden, deren Funktion im gesunden Immunsystem in der Unterscheidung zwischen körpereigen und fremd und damit in der Bekämpfung von Erregern oder entarteten Körperzellen besteht. Diese transplantierten Zellen des Spenders sind nach SZT zum einen auch für den therapeutisch wichtigen GvL Effekt verantwortlich, zum anderen können sie aber auch gesunde Körperzellen des Empfängers als fremd erkennen, woraufhin sie aktiviert werden und diese dann zerstören [28].

\section{GvHD auch an der Lunge?}

Die Lunge galt im Gegensatz zu Leber, Haut und Darm bisher nicht als klassisches Zielorgan der GvHD, zahlreiche experimentelle Beobachtungen deuten aber darauf hin, dass spezifische alloreaktive Spender-T-Lymphozyten und eine Alloreaktion im Sinne 
einer GvHD auch in die Pathogenese von akuten und chronischen Lungenschäden nach SZT involviert sind [12, 28, 29, 30, 31, 32]. So wird vielfach eine klinische, zeitliche Assoziation von IPS mit GvHD beobachtet bzw. GvHD geht dem IPS oft voran, was einen kausalen Zusammenhang wahrscheinlich oder zumindest möglich erscheinen lässt $[12,14,16,17,18,19,21,25,30,33,34,35]$. Auch in experimentellen Studien an Tieren wurden z. B. bei Nagern mit akuter, systemischer GvHD pathologische Lungenveränderungen beschrieben [22, 32, 36, 37]. Zusätzlich unterstützen experimentelle Mausmodelle eine Theorie, nach der die Schädigung der Lunge nach SZT hauptsächlich auf zwei unterschiedlichen, miteinander gekoppelten, immunvermittelten Wegen beruht: einer inflammatorischen, durch Zytokine ausgelösten und einer durch T-Zellen hervorgerufenen Reaktionskette. Somit wird ein akuter Lungenschaden also weniger als ein idiopathisches klinisches Syndrom betrachtet, sondern die Lunge als Target eines Alloantigenspezifischen, immunvermittelten Angriffs gesehen, für den letztlich mehrere verschiedene und ineinander greifende Prozesse verantwortlich sind: zunächst führt die direkte konditionierungsbedingte Schädigung der Empfänger-Gewebe und die damit verbundene Freisetzung löslicher inflammatorischer Zytokine auf der einen Seite zur Ansammlung von Makrophagen und T-Lymphozyten in der Lunge, auf der anderen Seite zu einer Voraktivierung des Gewebes, d. h. z. B. zu verstärkter Expression von MHC- und Adhäsionsmolekülen, was wiederum zur verstärkten Aktivierung inflammatorischer Immunzellen beiträgt. Zusätzlich führt die Interaktion von Spender-T-Zellen mit Empfänger-Gewebe und antigenpräsentierenden Zellen zu deren Aktivierung mit Proliferation, Differenzierung und Zytokinproduktion. Diese aktivierten T-Lymphozyten schließlich tragen zum einen als Effektorzellen direkt zur Schädigung des Gewebes bei und verstärken zum anderen zusätzlich durch erneute Produktion proinflammatorischer Zytokine wie Interferon- $\gamma$ (IFN- $\gamma$ ) und Interleukin-2 (IL-2) ihrerseits die Makrophagen- und T-Zell-Aktivierung $[2,3,11,12,22]$.

Die Aktivierung von Lymphozyten im Allgemeinen und damit die Entstehung einer GvHD hängen von Interaktionen zwischen Empfänger-APCs (antigen-präsentierenden Zellen) und Spender-T-Zellen ab [38, 39], welche auch im alveolären und bronchialen Kompartment stattfinden können. So wurden z. B. in BAL (broncho-alveolar lavage, Lungenspülungs)-Flüssigkeiten von Patienten nach einer Lungentransplantation spezifische, gegen respiratorische Epithelzellen reaktive zytotoxische T-Zellen gefunden [40]. Und auch im Mausmodell konnten sechs Wochen nach allogener SZT alloreaktive DonorT-Zellen in BAL-Flüssigkeiten nachgewiesen werden, die in vitro auf den Kontakt mit Empfänger-Antigenen hin proliferierten und IFN- $\gamma$ produzierten. Dies war selbst in Ab- 
wesenheit einer systemischen GvHD der Fall, so dass die Lunge möglicherweise sogar als ein Refugium für alloreaktive, d.h. Empfängerantigen-spezifische T-Zellen gesehen werden muss [37]. Auch Apoptose (=programmierter Zelltod) von Epithelzellen, die üblicherweise auf eine T-Zell-vermittelte Schädigung zurückgeht, gilt als pathognomonisch für die GvHD [28] und wird zwar nicht bei allen Stammzelltransplantierten mit Lungenschäden, aber zumindest bei einem Teil der Patienten mit IPS beobachtet [12, 30, 25].

Bei Epithelzellen handelt es sich nicht um klassische antigen-präsentierende Zellen, dies sind v.a. Dendritische Zellen und Makrophagen (s.u.). Auch für andere Zelltypen, wie z. B. Endothelzellen wurde jedoch bereits die Fähigkeit zu Antigenpräsentation und Aktivierung von alloreaktiven $\left(\mathrm{CD}^{+}\right)$T-Zellen in vitro und in vivo nachgewiesen $[41,42]$. Ebenso konnte in vitro gezeigt werden, dass auch humane respiratorische Epithelzellen eine Population von überwiegend zytotoxischen (d.h. CD8 ${ }^{+}$) antigenspezifischen T-Zellen aus mononucleären Zellen des peripheren Blutes (PBMCs) generieren können, die dann in der Lage waren, respiratorische Epithelzellen zu lysieren [43].

Während die Bedeutung alloreaktiver T-Zellen des Spenders für die Lungenschäden nach allogener Transplantation im Mausmodell des Idiopathischen Pneumoniesyndroms (IPS) bereits gesichert ist, steht beim Patienten der Nachweis einer spezifischen Alloreaktion gegen pulmonale Targetstrukturen in der Pathophysiologie pulmonaler Komplikationen nach allogener SZT nach wie vor noch aus.

\subsection{Grundlegende Mechanismen der GvHD}

\section{Selbst-Fremd-Erkennung, MHC Klasse I}

Bereits in den 40/50er Jahren wurde im Rahmen von Hauttransplantationen eine Gruppe von Genen entdeckt, die für Abstoßungsreaktionen bzw. die Verträglichkeit von Geweben (=Histokompatibilität) verantwortlich gemacht wurden [44]. Erst später wurde ihre zentrale Bedeutung für die Antigenerkennung durch T-Zellen und damit auch generell für die selbst-fremd-Erkennung und die Induktion einer GvHD erkannt. Da es sich um mehrere, gekoppelte, polymorphe Gene handelt, die hauptsächlich die Histokompatibilität festlegen, wurden sie als Haupthistokompatibilitätskomplex bezeichnet (major histokompatibility complex $=\mathrm{MHC}$ ) oder beim Menschen gleichbedeutend auch Human Leucocyte Antigen (HLA)-Gene. Der MHC kodiert für membrangebundene Glykoproteine, deren Hauptaufgabe es ist, Peptidfragmente, die z. B. von Pathogenen stammen, zu binden und auf der Zelloberfläche zu präsentieren, damit sie dort von T-Zellen erkannt werden können [1]. Diese MHC-Antigene werden in zwei Klassen aufgeteilt, die sich in 
Aufbau sowie Funktion unterscheiden. MHC Klasse II (MHC II) -Moleküle präsentieren überwiegend Peptidfragmente extrazellulärer Pathogene, die von T-Helferzellen (charakterisiert durch ihren sog. CD4-Korezeptor) erkannt werden. MHC Klasse I (MHC I) -Moleküle dienen dagegen der Präsentation von Peptidfragmenten aus dem Zytosol, das können bei infizierten Zellen Antigene intrazellulär lebender Viren sein, oder zelleigene Peptide im Fall von nichtinfizierten Zellen. MHC I-Moleküle werden auf allen kernhaltigen Körperzellen exprimiert. Zytotoxische T-Zellen sind durch den CD8-Korezeptor auf ihrer Oberfläche charakterisiert. Sie können nach Selektion und Reifung im Thymus durch ihren T-Zell-Rezeptor (TCR) in Verbindung mit dem CD8-Korezeptor die MHC I-Moleküle und die darauf präsentierten eigenen oder fremden Peptidfragmente spezifisch erkennen (vgl. Abbildung 1.1) [1]. Entsprechend können auch transplantierte $\mathrm{CD}^{+}$T-Zellen in dem ihnen fremden Körper des Empfängers sowohl dessen spezifische MHC I-Moleküle als auch die darauf präsentierten empfängerspezifischen Antigene als für sie fremd (=allogen) erkennen und die Körperzellen des Empfängers in der Folge zerstören. Damit es nicht sofort zu schweren Immunreaktionen nach Transplantation kommt, müssen Empfänger und Spender histokompatibel bzw. HLA-kompatibel sein, das heißt, möglichst wenige Unterschiede im MHC aufweisen, oder im Idealfall HLAidentisch sein, was z. B. bei Familienmitgliedern der Fall sein kann.

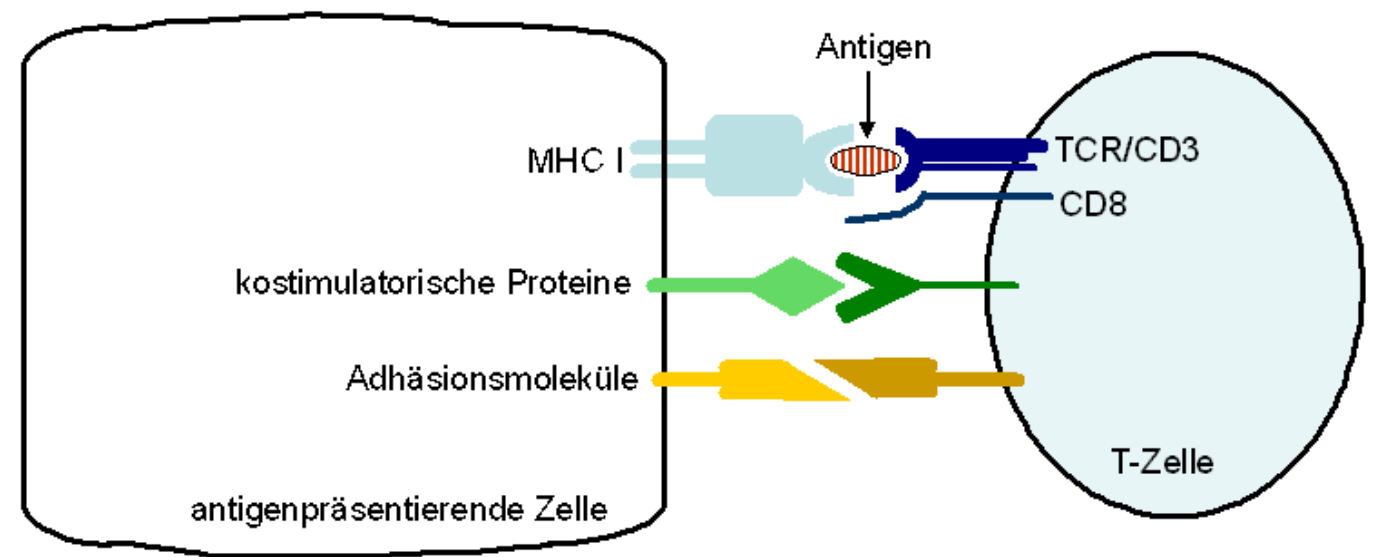

\begin{abstract}
Abbildung 1.1: Klassische immunologische Wechselwirkungen zwischen einer T-Zelle (rechts) und einer antigen-präsentierenden Zelle (links) mit dem spezifischen, TCRMHC-vermittelten Aktivierungssignal (oben), dem zweiten kostimulatorischen Aktivierungssignal (mitte) und zusätzlicher Stabilisierung der Zell-Zell-Interaktion durch Adhäsionsmoleküle (unten).
\end{abstract}




\section{T-Zell-Aktivierung}

Damit eine naive T-Zelle aktiviert wird, muss sie zunächst ein an ein Selbst-MHCMolekül gebundenes fremd-Antigen erkennen. Dies alleine reicht jedoch nicht aus, um Proliferation und Differenzierung zu induzieren. Zusätzlich ist ein zweites, kostimulierendes Signal notwendig, das klassischerweise z. B. durch die Bindung eines Liganden an das Oberflächenmolekül CD28 auf der T-Zelle entsteht. Als Liganden für CD28 kommen die Oberflächenmoleküle CD80 oder CD86 auf der selben Zelle, auf der die T-Zelle ihr spezifisches Antigen erkennt, in Frage [45, 46]. Außerdem müssen Adhäsionsmoleküle (wie z. B. ICAM-1) den Zell-Zell-Kontakt zunächst initiieren und die Interaktion dann stabilisieren (vgl. Abbildung 1.1). Als professionelle antigenpräsentierende Zellen (APC = antigen presenting cell) fungieren in der Regel B-Zellen, Dentritische Zellen und Makrophagen, die alle entscheidenden kostimulatorischen Moleküle auf ihrer Oberfläche tragen und deren Aufgabe damit die Aktivierung von T-Zellen ist [1].

Ist eine (Allo-) Aktivierung der naiven $\mathrm{CD}^{+}$T-Zelle erfolgreich initiiert, so wird als eine der ersten sichtbaren bzw. messbaren Reaktionen deren Proliferation, also klonale Expansion mit bis zu mind. fünf bis neun Zellteilungen ausgelöst und sie differenziert innerhalb einiger Tage zu einer bewaffneten Effektorzelle aus, der sog. zytotoxischen T-Zelle (CTL = cytotoxic T-lymphocyte), welche Effektormoleküle produziert und speichert [47]. Im Zuge ihres Aktivierungs- und Reifungsprozesses produzieren aktiverte T-Zellen außerdem verschiedene Zytokine. Dazu gehört z. B. Interferon $\gamma($ IFN- $\gamma$ ), das die Virusreplikation hemmen kann, das gleichzeitig aber auch die Expression von MHCMolekülen auf antigenpräsentierenden Zellen und damit die Wahrscheinlichkeit erhöht, dass eine Zelle mit fremd-Antigen als Zielzelle erkannt werden kann. Ebenso wird auch der T-Zell-Wachstumsfaktor Interleukin 2 (IL-2) produziert, und zwar gleichzeitig mit einer hochaffinen Form des IL-2-Rezeptors (CD25). Darüberhinaus wird die Expression von einer Reihe weiterer Oberflächenmoleküle (sog. Aktivierungsmarker) gesteigert, welche eine auto- und/oder parakrine Stimulation der Zellen ermöglichen bzw. verstärken. Wie alle Oberflächenmoleküle werden sie überwiegend nach dem sog. Cluster of Differentiation (CD) mit Nummern benannt. Zu diesen Aktivierungsmarkern auf T-Zellen gehört z. B. CD30, das über verschiedene Wege T-Zell-Antwort und -Überleben reguliert, indem es z. B. Aktivierungsantigene und Adhäsionsmoleküle wie ICAM-1 (CD54) sowie die metabolische Aktivität und Proliferationsrate steigern aber auch Apoptose auslösen kann [48, 49, 50, 51]. Desweiteren zählen dazu auch der Transferrinrezeptor CD71, der den besonders erhöhten Eisenbedarf der proliferierenden T-Zellen deckt, sowie CD69 als sog. ,early activation inducing molecule“, dessen genaue Funktionen noch nicht bekannt 
ist und Moleküle wie CD54, CD70, CD80, CD86, die die Immunantwort als Adhäsionsund kostimulatorische Moleküle aufrechterhalten und regulieren [52]. Trifft eine auf diese Weise aktivierte CTL erneut auf eine Körperzelle mit ihrem spezifischen (Allo-)Antigen, kommt es zum Immunangriff und die Zielzelle wird abgetötet, indem in ihr durch Effektormoleküle der CTL der programmierte Zelltod (Apoptose) ausgelöst wird. Dieser Vorgang läuft in der Regel unabhängig von einer Kostimulation ab. CD8 ${ }^{+}$zytotoxische T-Zellen töten ihre Zielzellen vor allem durch Perforin und Granzym, das sind Proteasen, die nach der TCR-Erkennung aus lytischen Granula gezielt in die Richtung der Zielzelle freigesetzt werden. Perforin bildet dabei Poren in der Membran der Zielzelle, durch welche die Granzyme ins Zellinnere eindringen können. Außerdem kann auch der membranständige FAS-Ligand der CTL durch Bindung an FAS (CD95) auf der Zielzelle in dieser ein Apoptoseprogramm auslösen. Eine weitere, kontaktunabhängige Möglichkeit der Apoptoseinduktion kann durch Bindung des von CTLs sezernierten Zytokins Tumor Nekrose Faktor (TNF) an den TNF-Rezeptor auf der Zielzelle vermittelt werden $[1,53,54,55]$.

Zusätzlich zu diesem klassischen Weg der TCR-MHC I-vermittelten T-Zell-Aktivierung und Induktion von Alloreaktionen wurden vor allem für CD8 ${ }^{+}$T-Zellen auch zunehmend verschiedene alternative Wege entdeckt [46, 56, 57]. So ist für Endothel- sowie Epithelzellen bereits die Fähigkeit beschrieben, dass sie als „semiprofessionelle APCs“ allogene $\mathrm{CD}^{+}$T-Zellen direkt und unabhängig stimulieren können [38, 42, 43]. Ebenso sind überwiegend aus Studien nach soliden Organtransplantationen auch von einer klassischen Kostimulation unabhängige Beispiele von Abstoßungsreaktionen bekannt, sowie auch durch CD70-, CD95- oder NKG2D-vermittelte kostimulatorische Signale, die in zytotoxischen T-Zellen nachgewiesen werden konnten [46, 58, 59, 60, 61]. Yamada [62] zeigte, dass im Tiermodell eine Blockade von CD70 das Transplantatüberleben unabhängig von einer CD80/86-CD28-Interaktion verlängerte, eine CD8 ${ }^{+}$T-Zell-vermittelte AbstoBung verhinderte sowie die Proliferation und Aktivierung von $\mathrm{CD} 8^{+}$Effektor-T-Zellen blockierte und im humanen System die Zytotoxizität von CTLs durch CD70 verstärkt wird. In weiteren Studien wurde außerdem die Bedeutung einer Interaktion von CD95 (FAS) mit FAS-Ligand für eine maximale Alloantigen-spezifische Proliferation zytotoxischer T-Lymphozyten und Abstoßungsreaktionen beschrieben [58, 63].

Neuere Untersuchungen haben auch die Bedeutung einer NKG2D-Signalübertragung für die Aktivierung und Funktion von $\mathrm{CD}^{+}$T-Zellen gezeigt. NKG2D (natural-killer group 2, member D) ist ein klassischer und unabhängig wirkender, aktivierender Rezeptor auf natürlichen Killerzellen (NK-Zellen), der aber auch auf (überwiegend CD8 ${ }^{+}$) 
T-Zellen konstitutiv exprimiert wird und nach neuen Untersuchungen eine Rolle bei deren Aktivierung spielt. Die Kostimulierung durch NKG2D führte bei CD8 ${ }^{+}$T-Zellen in mehreren verschiedenen Studien zu besserem Überleben, verstärkter Proliferation, Aktivierungsmarkerexpression, Zytokinproduktion und/oder Zytotoxizität [64, 65, 66, 67, 68, 69]. Welche dieser Effekte jeweils nachgewiesen werden konnten, hing sowohl vom Aktivierungszustand der T-Zellen als auch von den Kulturbedingungen der jeweiligen Studien ab [69]. Als Liganden für NKG2D sind MIC A, MIC B (MHC class I chainrelated gene A und B) und ULBP1-5 (UL-16 (herpes simplex virus I unique long genom region-16) binding proteins) bekannt, die auf vielen verschiedenen Zelltypen kostitutiv und unter Stress sogar verstärkt exprimiert werden [70, 71, 72]. 


\section{Motivation und Fragestellung}

Wie in Kapitel 1 beschrieben können heute durch antibiotische Prophylaxe früher oft tödliche Infektionen des Respirationstraktes nach SZT größtenteils verhindert werden. Darüberhinaus können neuere, weniger toxische Strategien des Konditionierungsregimes, v.a. die Bestrahlung mit reduzierter Intensität, direkte strahlungsbedingte Schädigungen reduzieren, nicht jedoch insgesamt die Häufigkeit pulmonaler Komplikationen. Die Lunge bleibt deshalb eines der Organe, die nach SZT am häufigsten und am schwerwiegendsten von nichtinfektiösen Nebenwirkungen betroffen sind, welche nach wie vor für einen großen Teil der Todesfälle nach SZT verantwortlich sind. Deshalb ist es dringlich, die Beteiligung einer GvHD bei der Entstehung dieser akuten und chronischen Lungenschäden nach allogener SZT sowie deren Ursachen und Mechanismen zu verstehen, um Maßnahmen entwickeln zu können, die solche schweren Komplikationen verhindern können. Hierzu soll die vorliegende Arbeit einen Beitrag leisten.

\section{Zellkulturmodell der GvHD}

Um die Bedingungen und Interaktionen zwischen den verschiedenen an einer GvHD beteiligten Zelltypen imitieren und untersuchen zu können, wurde im Rahmen dieser Arbeit ein Zellkulturmodell entwickelt, in dem respiratorische Epithelzellen mit allogenen CD8 ${ }^{+}$T-Zellen in Kokultur gebracht wurden.

Zytotoxische CD8 ${ }^{+}$T-Zellen sind die klassischen Effektorzellen, die für die Entstehung einer GvHD, also einer zytotoxisch vermittelten Schädigung von Empfängergewebe verantwortlich gemacht werden. Da deren Beteiligung isoliert von anderen Effekten, wie z.B. durch Helfer-T-Zellen oder natürliche Killerzellen untersucht werden soll, wurden in den Versuchen auf der einen Seite isolierte CD8 ${ }^{+}$T-Zellen eingesetzt. Auf der anderen Seite soll besonders die Schädigung des Lungenepithels betrachtet werden. Da dabei sowohl das alveoläre Kompartment, besonders beim IPS in der frühen Phase, als auch das bronchiale Kompartment, z.B. bei der lymphozytiären Bronchitis in der späteren Phase, betroffen sein können [11, 24, 25], sollen die Versuche zunächst mit je einer alveolären und einer bronchialen Epithtelzelllinie durchgeführt werden. Um eine Epithelzellspezifität beobachteter Reaktionen besser erkennen und von eventuellen Zelllinienartefakten 
unterscheiden zu können, sollen im Anschluss primäre bronchiale Epithelzellen (PBEC), die im Rahmen von Bronchoskopien bei klinischen Untersuchungen frisch gewonnen werden können, kultiviert und in das Kokulturmodell eingesetzt werden.

Die Fragestellung gliedert sich zusammenfassend in die folgenden Unterpunkte:

$\triangleright$ Können respiratorische Epithelzellen als nichtklassische, „nichtprofessionelle Antigenpräsentierende Zellen" fungieren und zytotoxische CD8 ${ }^{+}$T-Zellen direkt und ohne professionelle Hilfe von APCs oder CD4 ${ }^{+}$T-Zellen (allo)aktivieren?

$\triangleright$ Sind diese (allo)aktivierten $\mathrm{CD}^{+}$T-Zellen dann in der Lage, respiratorische Epithelzellen spezifisch als Targets zu erkennen und zu zerstören?

$\triangleright$ Welche Mechanismen liegen dem Aktivierungsvorgang und dem zytotoxischen Verhalten zugrunde? 


\section{Material und Methoden}

\subsection{Material}

\section{Zellen}

A549 alveoläre Epithelzellen, CCL-185, ATCC, Manassas, VA, USA

BEAS-2B bronchiale Epithelzellinie, CRL-9609, ATCC, Manassas, VA, USA

BLCL Eppstein-Barr-Virus-transfizierte B-Zellen als autologe Kontrolltargets [73]

K562 chronic myeloid leukemia cell line, CCL-243, ATCC, Manassas, VA, USA

PBEC primäre bronchiale Epithelzellen von gesunden Spendern

PBMC mononukleäre Zellen des peripheren Blutes

HMEC Endothelzellinie, human vascular endothelial cells [73];

als Kontrollzellen für die Überprüfung der Funktion des anti-MHC I-Antikörpers W6/32 eingesetzt; zur Verfügung gestellt von der Klinik für Hämatologie/Onkologie des Uniklinikums Regensburg

\section{Medien und Medienzusätze}

RPMI1640 mit L-Glutamin und 25 mM Hepes Gibco BRL, Paisley, UK AECBM (airway epithelial cell basal medium) Promo Cell, Heidelberg Amphotericin B $(250 \mu \mathrm{g} / \mathrm{ml})$ Gibco BRL, Paisley, UK fötales Rinderserum (FBS Gold) PAA Laboratories, Pasching, A

Penicillin (10000 units/ml) Gibco BRL, Paisley, UK

Streptomycin $(10000 \mu \mathrm{g} / \mathrm{ml})$ Gibco BRL, Paisley, UK

komplettes RPMI: RPMI1640 versetzt mit 10 \% hitzeinaktiviertem FBS, 100 U/ml Penicillin und $100 \mu \mathrm{g} / \mathrm{ml}$ Streptomycin

AECGM (airway epithelial cell growth medium): AECBM versetzt mit den folgenden Zusätzen (Promo Cell): Rinderhypophysenextrakt (0,4 \%), epidermaler Wachstumsfaktor $(10 \mathrm{ng} / \mathrm{ml})$, Insulin $(5 \mu \mathrm{g} / \mathrm{ml})$, Hydrokortison $(0,5 \mu \mathrm{g} / \mathrm{ml})$, Epinephrin $(0,5 \mu \mathrm{g} / \mathrm{ml})$, Triiodothyronin $(6,7 \mathrm{ng} / \mathrm{ml})$, Transferrin $(10 \mu \mathrm{g} / \mathrm{ml})$, Retinolsäure $(0,1 \mathrm{ng} / \mathrm{ml})$ sowie 
$100 \mathrm{U} / \mathrm{ml}$ Penicillin, 100 pg/ml Streptomycin und 250 ng/ml Amphotericin B IL-2-Medium: komplettes RPMI1640 versetzt mit 100 U/ml IL-2

Einfriermedium: FBS versetzt mit $10 \%$ DMSO

\section{Chemikalien und Lösungen}

Accutase

Aceton

bovines Serumalbumin (BSA) 5 \%-Lösung

Carboxyfluorescein Succinimidyl Ester (CFSE)

Natrium $\left[{ }^{51} \mathrm{Cr}\right]$ chromat $(100 \mu \mathrm{Ci})$

Dispase II $(2,4 \mathrm{U} / \mathrm{ml})$

DMSO

dNTP (100 mM, 25 pmol)

EDTA

Ficoll-Paque Plus $(<0,012 \mathrm{ng} / \mathrm{ml})$

Interleukin 2, human recombinant aus E. coli

Interferon- $\gamma$, human recombinant aus E. coli

M-MLV Reverse Transciptase

oligo-dT (oligothymidylic acid)

$\mathrm{PBS}$ without $\mathrm{Ca} / \mathrm{Mg}$

Propidium Iodid (PI)

Reverse Transciptase Reaktions-Puffer

RNasin ${ }^{\circledR}$ Ribonuclease Inhibitor

Staphylokokken-Enterotoxin B (SEB)

Trypanblau 0,4 \%-Lösung
PAA Laboratories, Pasching, A

Roth/Merck

Sigma-Aldrich, Steinheim

Invitrogen, Karlsruhe

Hartmann Analytics, Braunschweig

Roche, Mannheim

Sigma-Aldrich, Steinheim

Fermantas

Sigma-Aldrich, Steinheim

Amersham, Uppsala, S

Sigma-Aldrich

Roche, Mannheim

Promega

Sigma-Aldrich, Steinheim

PAA Laboratories, Pasching, A

Sigma-Aldrich, Steinheim

Promega

Promega, Madison, WI, USA

Sigma-Aldrich, Deisenhofen

Sigma-Aldrich, Steinheim

\section{Kits (human)}

$\mathrm{CD}^{+} \mathrm{T}$ cell Isolation Kit II

Granzyme B ELISA Kit

High Pure RNA Isolation Kit

Human IFN- $\gamma$ ELISA Kit

QuantiTect $^{T M}$ SYBR $^{\circledR}$ Green PCR Kit

Simultest IMK-Lymphocyte
Miltenyi Biotec, Bergisch Gladbach

Hoelzel Diagnostics, Köln

Roche, Mannheim

Pierce Endogen, Rockford, IL, USA

Qiagen, Hilden

BD Biosciences, San Jose, CA, USA 


\section{Antikörper (anti-human)}

$\begin{array}{lll}\text { Antikörper } & \text { Klon } & \text { Hersteller } \\ \text { CD25 (FITC) } & \text { M-A251 } & \text { BD Biosciences, Heidelberg } \\ \text { CD30 (FITC) } & \text { BerH8 } & \text { BD Biosciences, Heidelberg } \\ \text { CD31 } & \text { 1A10 } & \text { Dianova } \\ \text { CD45 } & \text { Ab-3 } & \text { Dianova } \\ \text { CD54 } & \text { HA58 } & \text { BD Biosciences } \\ \text { CD69 (FITC) } & \text { L78 } & \text { BD Biosciences, Heidelberg } \\ \text { CD70 } & \text { Ki-24 } & \text { BD Biosciences, Heidelberg } \\ \text { CD71 (FITC) } & \text { YDJ1.2.2 } & \text { immunotech, Marseille, F } \\ \text { CD80 } & 3771.11 & \text { R\&D Systems, Minneapolis, MN, USA } \\ \text { CD86 } & 37301.111 & \text { R\&D Systems, Minneapolis, MN, USA } \\ \text { CD90 } & \text { ASO2 } & \text { Dianova } \\ \text { CD95 } & \text { ZB4 } & \text { immunotech, Marseille, F } \\ \text { NKG2D (PE) } & \text { 1D11 } & \text { ebioscience } \\ \text { NKG2D } & \text { 1D11 } & \text { Biolegend } \\ \text { HLA-DR } & \text { B8.12.2 } & \text { immunotech, Marseille, F } \\ \text { MHC I } & \text { W6/32 } & \text { Hybridomakultur-Überstand } \\ \text { MIC A/B } & \text { 6D4 } & \text { BD Biosciences, Heidelberg } \\ \text { MIC A } & \text { 159227 } & \text { R\&D Systems, Minneapolis, MN, USA } \\ \text { Panzytokeratin } & \text { KL-1 } & \text { Dianova }\end{array}$

\section{Sekundärantikörper}

anti-Maus Immunglobuline, F(ab')2 Fragment (FITC) Dako, Glostrup, DK

\section{Isotypkontrollen}

$\begin{array}{lll}\text { Antikörper } & \text { Klon } & \text { Hersteller } \\ \text { IgG1 } & \text { MG1-45 } & \text { Biolegend (blockierend) } \\ \text { IgG1, } \kappa & \text { MOPC-21 } & \text { BD Biosciences, Heidelberg } \\ \text { IgG1, } \kappa(\text { FITC) } & \text { MOPC-21 } & \text { BD Biosciences, Heidelberg } \\ \text { IgG2a } & \text { G155-178 } & \text { BD Biosciences, Heidelberg } \\ \text { IgG2b } & \text { MPC-11 } & \text { BD Biosciences, Heidelberg }\end{array}$




\section{Primer (human)}

$\begin{array}{lll}\text { Gen } & \text { Richtung } & \text { Sequenz } \\ \beta \text {-Aktin } & \text { vorwärts } & \text { 5'-CGCCCCAGGCACCAGGGC-3' } \\ \beta \text {-Aktin } & \text { rückwärts } & \text { 5'-GGCTGGGGTGTTGAAGGT-3' } \\ \text { CD80 } & \text { vorwärts } & \text { 5'AGGGAACATCACCATCCAAG-3' } \\ \text { CD80 } & \text { rückwärts } & \text { 5'-TGCCAGTAGATGCGAGTTTG-3' } \\ \text { CD86 } & \text { vorwärts } & \text { 5'-GTATTTTGGCAGGACCAGGA-3' } \\ \text { CD86 } & \text { rückwärts } & \text { 5'ATTCCTGTGGGCTTTTTGTG-3' } \\ \text { CD95 } & \text { vorwärts } & \text { 5'ATAAGCCCTGTCCTCCAGGT-3' } \\ \text { CD95 } & \text { rückwärts } & \text { 5'-GACAAAGCCACCCCAAGTTA-3' }\end{array}$

\section{Verbrauchs- und sonstige Materialien}

Filterspitzen (10, 20, 100, 200, 1000 pl)

Neubauer-Zählkammer improved

LightCycler Kapillaren

Magnet OctoMACS Seperator

Zellkulturflaschen (belüftet)

Zellkulturflaschen (Cell+ Wachstumsoberfläche)

Kammerobjektträger

96-Lochplatten, U-Boden (TC Microwell 96U)

96-Lochplatten Luma-Plate-96

1,5 ml Reagiergefäße

FACS-Röhrchen (Rundboden, $5 \mathrm{ml}$ )

Polystyrol-Kulturröhrchen (Rundboden, $10 \mathrm{ml}$ )

15 und 50 ml-Röhrchen

Separationssäulen (MS Columns)

Serologische Pipetten (2, 5, 10, $25 \mathrm{ml})$

Spitzen $(100,1000 \mu \mathrm{l})$

Sterilfiltereinheit $(250 \mathrm{ml})$

TopSeal-A (Abdeckfolie für Luma-Plate-96)
Biozym, Hessisch Oldendorf

Brand, Wertheim/Main

Roche, Mannheim

Miltenyi Biotech, Berg. Gladbach

Greiner, Frickenhausen

Sarstedt, Nümbrecht

Falcon

Nunc, Roskilde, DK

Perkin Elmer, Boston, MA, USA

Sarstedt, Nümbrecht

Falcon, Le Pont de Claix, F

Greiner, Frickenhausen

Sarstedt, Nümbrecht

Miltenyi Biotech, Berg. Gladbach

Sarstedt, Nümbrecht

Sarstedt, Nümbrecht

Sartorius, Göttingen

PerkinElmer, Boston, MA, USA 


\section{Geräte}

Brutschrank HeraCell

Durchflusszytometer FACSCalibur

Durchflusszytometer FACSAria (Cell-Sorter)

Gamma-Bestrahlungsgerät IBL 437C

Heizblock

Lichtmikroskop Axiovert 25

LightCycler

Photometer Molecular Devices

Photometer GeneQuant pro

Sterilbank HeraSafe

TopCount Microplate Scintillation Counter

Zentrifuge

Zentrifuge

\section{Statistiksoftware}

SigmaPlot

SigmaStat

CellQuest analysis software, BD Biosciences, Heidelberg

WinMDI
Heraeus, Hanau

BD Biosciences, Heidelberg

BD Biosciences, Heidelberg

cis bio international

Eppendorf, Hamburg

Zeiss, Oberkochen

Roche, Mannheim

MWG Biotech

Amersham, Uppsala, S

Heraeus, Hanau

Perkin Elmer, Boston, MA, USA

Heraeus, Hanau

Eppendorf, Hamburg

\subsection{Grundlegende zellkulturelle Arbeitsmethoden}

\subsubsection{Zellkulturbedingungen und Subkultivierung}

Alle Arbeiten zur Kultivierung der Zellen erfolgten unter sterilen Bedingungen unter einer Sterilbank. Die Zellen wurden unter Standardbedingungen bei $37{ }^{\circ} \mathrm{C}$, einer Luftfeuchtigkeit von $95 \%$ und bei $5 \% \mathrm{CO}_{2}$ kultiviert. Als Medium für die Zelllinien diente komplettes RPMI 1640, für die Primärzellen airway epithelial growth (AECG)-Medium. Nach Erreichen einer etwa 90 \%-igen Konfluenz wurden die Zellen jeweils gesplittet, d. h. vereinzelt. Das war bei den Zelllinien zwei- bis dreimal pro Woche der Fall, bei den PBEC aufgrund deutlich geringerer Proliferationsrate seltener. Wenn seltener gesplittet wurde, wurde zumindest zweimal pro Woche das entsprechende Medium der Zellen gewechselt. Zur Vermeidung größerer Variationen fanden nur Zellen der „Passagen“ 10 bis 20 Verwendung in den Versuchen, PBEC wurden maximal bis „Passage“ drei eingesetzt. 
Zum Splitten bzw. Ernten von Zellen für Versuche wurden die adhärenten Zelllinien und Primärzellen nach einmaligem Spülen mit PBS mit Accutase von der Wachstumsfläche abgelöst. Dieses Enzym mit proteo- und collagenolytischer Aktivität vereinzelt die Zellen besonders schonend und lässt die Struktur und Funktionalität der Zellmembran und ihrer Oberflächenproteine intakt. Die Zellsuspension wurde anschließend mit Medium aus den Kulturflaschen gespült, abzentrifugiert und zur Weiterkultivierung in einer Konzentration von ein bis zwei Millionen Zellen pro $75 \mathrm{~cm}^{2}$ Wachstumsfläche ausgesät. Suspensionskulturen wurden bei Erreichen der Konfluenz durch Verdünnen mit frischem Medium subkultiviert.

\subsubsection{Zentrifugation von Zellen}

Sofern nicht anders angegeben, wurden Zellen der Zelllinien sowie PBEC bei Raumtemparatur für sechs bis acht Minuten bei 250-facher Erdbeschleunigung zentrifugiert, PBMC sowie T-Zellen bei 300-facher Erdbeschleunigung.

\subsubsection{Kryokonservierung}

Überschüssige Zellen der Zelllinien (oder isolierten PBMC) wurden in Einfriermedium (FBS $+10 \%$ DMSO) suspendiert und Aliquots bis zur späteren Verwendung in Kryoröhrchen in flüssigem Stickstoff gelagert.

\subsubsection{Vitalitätsprüfung und Zellzahlbestimmung}

Alle Zellen wurden regelmäßig lichtmikroskopisch auf Wachstum, Vitalität und eventuelle Verkeimungen hin überprüft. Beim Subkultivieren und vor jedem Einsatz in Experimente wurden die Zellen mittels Trypanblaufärbung auf ihre Vitalität hin überprüft und ausgezählt. Ein Aliquot der jeweiligen Zellsuspension (bei adhärenten Zellen nach Ablösen) wurde im Verhältnis 1:1 mit einer 0,4 \% Trypanblaulösung gemischt und ein Aliquot davon in die Kammer einer Neubauerzählkammer überführt. Da nur tote Zellen aufgrund fehlender Membranintegrität durch Trypanblau blau angefärbt werden, konnten sie auf diese Weise lichtmikroskopisch von den lebenden unterschieden werden.

Gleichzeitig konnten die Zellen in den Quadraten der Neubauerzählkammer ausgezählt und die Konzentration an Zellen (Zellen/ml) nach folgender Formel berechnet werden:

$$
\frac{\text { Anzahl Zellen }}{m l}=\frac{\text { Anzahl gezählter Zellen }}{\text { Anzahl ausgezählter Großquadrate }} \times \text { Verdünnungsfaktor } \times 10000 \text {. }
$$




\subsection{Kultivierung und Charakterisierung der Zelllinien}

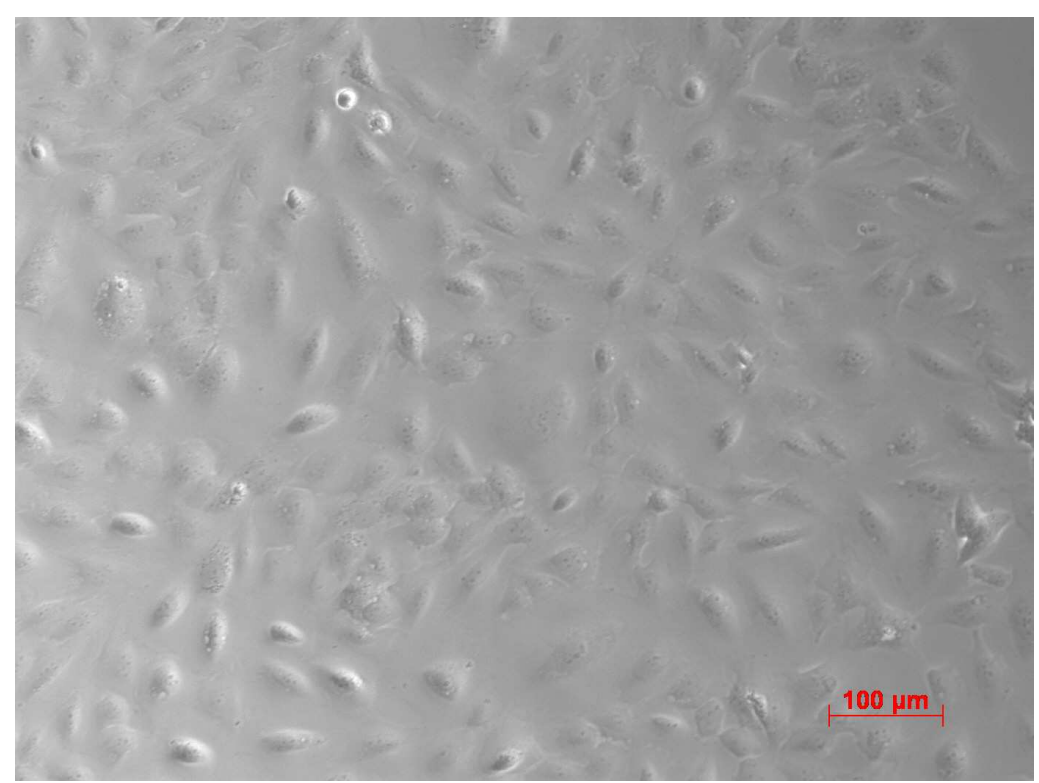

Abbildung 3.1: Humane bronchiale Epithelzellen der Zelllinie BEAS-2B. Adhärent wachsender Monolayer bronchialer Epithelzellen in der lichtmikroskopischen Aufnahme.

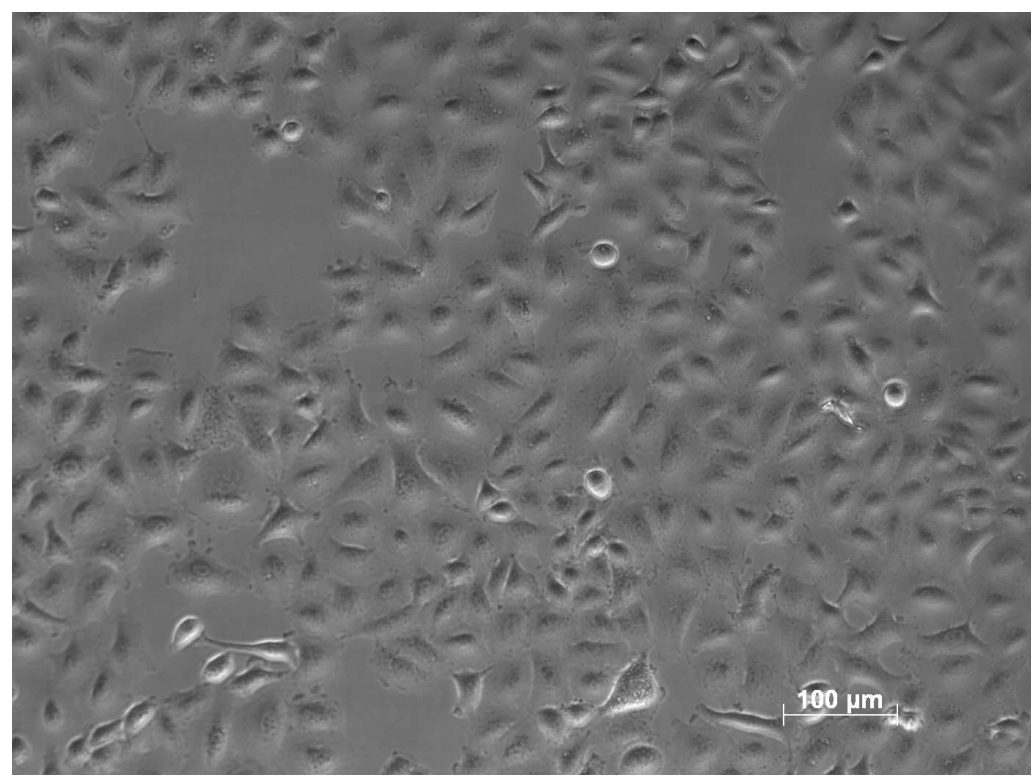

Abbildung 3.2: Humane Pneumozyten der Zelllinie A549. Adhärent wachsender Monolayer alveolärer Epithelzellen in der lichtmikroskopischen Aufnahme.

Bei der Zelllinie BEAS-2B (ATCC CRL-9609) handelt es sich um humane bronchiale Epithelzellen, die von einem gesunden Spender gewonnen und durch Transfektion mit 
einem Adenovirus 12-SV40 Virus-Hybrid immortalisiert worden waren [74]. Die Zellen behielten dabei weitgehend ihre epithelialen Eigenschaften wie die typische Morphologie des Epithels [75], Wachstum und Zytokeratinexpression [76, 77] bei. Die adhärent wachsenden BEAS-2B bilden auf unbehandelten Plastikwachstumsflächen einen Zellrasen (Monolayer) aus (Abbildung 3.1).

A549-Zellen (ATCC CCL-185) sind humane Tumorzellen, die morphologische sowie funktionelle Charakteristika von Typ II-Pneumozyten aufweisen. Sie wurden aus dem Alveolarzellkarzinom eines 58-jährigen männlichen Kaukasiers entnommen [78, 79] und repräsentieren damit alveoläre Epithelzellen. Die adhärent wachsenden A549 bilden in Kultur auf unbehandelten Plastikwachstumsflächen einen Monolayer aus (Abbildung 3.2) und sind positiv für Zytokeratin nach Immunoperoxidasefärbung (LGC-Promochem).

K562 Zellen (ATCC CCL-243) stammen von einem Patienten mit chronisch myeloider Leukämie (CML) zum Zeitpunkt einer Blastenkrise und wachsen in Suspensionskultur. Es handelt sich weder um B- noch um T-Vorläuferzellen, aufgrund ihres geringen Differenzierungsgrades können sie jedoch nicht eindeutig weiter charakterisiert werden [80, 81, 82]. K562 exprimieren keine MHC I-Moleküle, können deshalb nicht von klassischen CD8 ${ }^{+}$T-Zellen, sondern nur von natürlichen Killerzellen als Zielzellen (Targets) erkannt und lysiert werden und dienen aus diesem Grund als NK-sensitive Kontrolltargets in den Versuchen [73, 83].

\subsection{Kultivierung und Charakterisierung primärer bronchialer Epithelzellen}

Zusätzlich zu den Zelllinien wurde mit Kulturen humaner primärer bronchialer Epithelzellen (PBEC) gearbeitet. Diese wurden wie bei Schulz et al. [84] beschrieben aus gesunden Bereichen der Lunge von Patienten, die sich einer Bronchoskopie unterzogen, durch mehrfaches vorsichtiges Bürsten einzelner Segment- und Subsegmentbronchien mittels gedeckter Bürste und unter direkter Sicht gewonnen (die Zustimmung zur Entnahme von bronchialen Epithelzellen seitens der Ethikkommission der Universität Regensburg liegt vor, Ethikantrag Nr.03/180). Die Bürsten wurden anschließend direkt in steriles

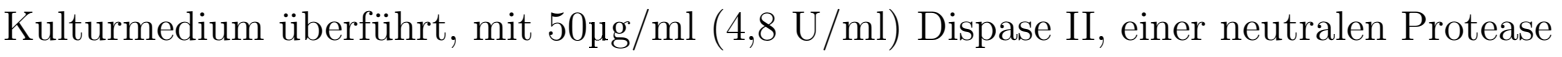
versetzt, die speziell zur Disaggregation von Geweben geeignet ist, gut gevortext und anschließend für ca. zwei Stunden bei $37^{\circ} \mathrm{C}$ inkubiert. Die Epithelzellen wurden dabei aus dem Gewebeverband gelöst und separiert, während ihre Vitalität und Viabilität erhalten blieb. Nach erneutem guten Vortexen wurde das Medium mit den nun suspendierten 
Zellen komplett von der zurückbleibenden Bürste abpipettiert, in ein neues Röhrchen überführt, einmal mit Medium gewaschen und erneut in AECG- (airway epithelial cell growth) Medium suspendiert. Zellzahl sowie Vitalität der so gewonnenen Epithelzellen wurde immer lichtmikroskopisch mittels Trypanblaufärbung eines Zellaliquots ermittelt, bevor die Zellen in AECG-Medium mit einer Dichte von ca. 6000/ $\mathrm{cm}^{2}$ in CELL+ Kulturflaschen ausgesät wurden. Pro Patient konnten hierdurch ca. 100000 bis eine Million Zellen gewonnen werden. Der Median lag bei 215000 Zellen pro Patient.

Zur Charakterisierung der Epithelzellen wurden jeweils Aliquots der Zellsuspensionen auf Kammerobjektträger ausgesät, bei Erreichen der Konfluenz auf der Wachstumsfläche mit eiskaltem Aceton fixiert und anschließend immunologischen Kontrollfärbungen mit Antikörpern gegen Zytokeratin, CD90, CD31, CD45 unterzogen.

\subsection{Isolation, Stimulation und Aktivierung von $\mathrm{CD}^{+}$ T-Zellen}

Mononukleäre Zellen des peripheren Blutes (PBMC) von freiwilligen, gesunden Spendern wurden aus frischem Heparinblut oder aus von der Klinik zur Verfügung gestelltem Leukaphereseblut gewonnen. Die Isolation erfolgte nach Standardprotokoll mittels Dichtezentrifugation über Ficoll-Paque, einem nichtionischen, synthetischen Polymer aus Sucrose und Epichlorhydrin, welches mit einer Dichte von 1,077 g/ml zwischen der von Erythrozyten, Granulozyten, Thrombozyten und der von PBMC liegt und diese so von ersteren Zelltypen trennen kann. $25 \mathrm{ml}$ im Verhältnis 1:3 mit RPMI-Medium gemischtes Leukaphereseblut wurden dabei vorsichtig in einem 50 ml-Röhrchen über das vorgelegte Ficoll $(13 \mathrm{ml})$ geschichtet und für 20 min ohne Bremse bei $1800 \mathrm{rpm}$ zentrifugiert. Dadurch wurden Erythrozyten, Granulozyten, Thrombozyten und Fragmente toter Zellen, also die Teilchen mit der größten Dichte, durch das Ficoll hindurch auf den Boden des Röhrchens zentrifugiert. Aufgrund ihrer geringeren Dichte als Ficoll sammelten sich die Leukozyten in einem Ring über der Ficollschicht, aber noch unterhalb des Mediums bzw. Serums. Diese Interphase wurde anschließend abgenommen und dreimal mit je $30 \mathrm{ml} \mathrm{Me}-$ dium gewaschen. Überschüssige PBMC wurden für weitere Versuche aliquotiert und in Einfriermedium in flüssigem Stickstoff gelagert.

\section{$\mathrm{CD}^{+}$Separation mittels MACS (Magnetic Activated Cell Sorting)}

Da speziell die Rolle der CD8 ${ }^{+}$T-Zellen untersucht werden sollte, mussten diese mit größtmöglicher Reinheit eingesetzt werden. Dazu wurde die Methode der Negativselektion von $\mathrm{CD}^{+}$aus gesamt-PBMC durch Depletion der CD8 ${ }^{-}$Zellen mit Hilfe von kleinen, 
superparamagnetischen Partikeln, sogenannten Microbeads gewählt (CD8 ${ }^{+}$Separations Kit von Miltenyi; Abbildung 3.3). Das Zellgemisch der PBMC wurde dafür zunächst nach Protokoll und Mengenangaben des Herstellers mit Biotin-konjungierten, monoklonalen Antikörpern gegen nicht-CD8 ${ }^{+}$T-Zellen, also einem Cocktail aus CD4, CD14, CD16, CD19, CD36, CD56, CD123, TCR- $\gamma / \delta$ und Glycophorin A markiert, an den im nächsten Inkubationsschritt ein zweiter, Microbead-gekoppelter anti-Biotin-Antikörper gebunden wurde. Nach einem Waschschritt wurde die Zellsuspension über die Matrix einer Säule durch das starke Magnetfeld eines Permanentmagneten laufen gelassen. Die magnetisch markierten Zellen wurden durch das Magnetfeld in der Säule zurückgehalten, nur die unmarkierten, überwiegend $\mathrm{CD} 8^{+} \mathrm{T}$-Zellen können die Matrix passieren und wurden darunter aufgefangen.

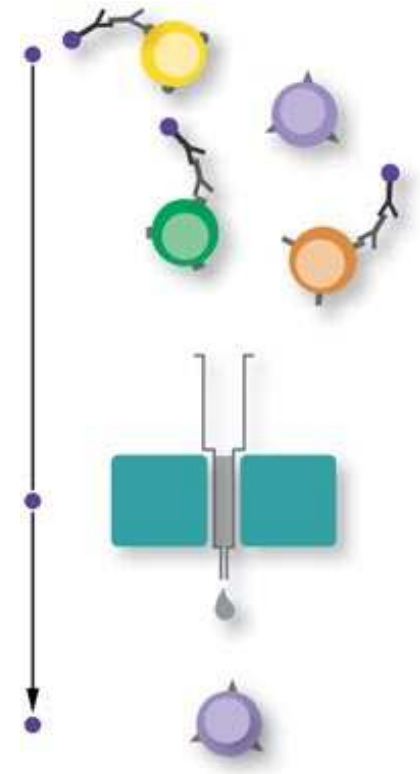

Abbildung 3.3: Prinzip der Separation CD8 ${ }^{+}$T-Zellen mittels Magnetic Activated Cell Sorting (MACS): Negativselektion CD8 ${ }^{+}$T-Zellen durch paramagnetische Markierung aller in PBMC enthaltenen $\mathrm{CD}^{-}$Zellen und Zurückhalten der markierten Zellen in einem Magnetfeld. Quelle: Miltenyi.

\section{Bestimmung der Reinheit der isolierten $\mathrm{CD}^{+}$Population}

Sowohl direkt nach der Separation als auch nach der anschließenden Stimulation wurde stets die Reinheit der Population CD8 ${ }^{+}$T-Zellen durch direkte (Zweifarben-) Immunfluoreszenzfärbungen und anschließende durchflusszytometrische Messung der Fluoreszenz überprüft. Mit den Fluorescein-Isothiocyanat (FITC)- bzw. Phycoerythrin (PE)markierten monoklonalen Antikörpern des Simultest IMK-Lymphozyte Kits (BD Bio- 
sciences) wurde der prozentuale Gehalt folgender reifer Leukozytenpopulationen bestimmt: $\mathrm{CD}^{+}{ }^{+} \mathrm{CD} 4^{+}$Helfer T-Zellen, $\mathrm{CD}^{+}{ }^{+} \mathrm{CD}^{+}$zytotoxische T-Zellen, CD3 ${ }^{+} \mathrm{CD} 19^{+}$ B-Zellen, $\mathrm{CD}^{-} \mathrm{CD}^{+} 6^{+}$und/oder CD3 ${ }^{-} \mathrm{CD}_{5}{ }^{+}$NK-Zellen, CD3 ${ }^{-}$CD45 ${ }^{+}$Monozyten.

\section{Aktivierung der $\mathrm{CD}^{+} \mathrm{T}-$ Zellen}

Die Stimulation der CD8 ${ }^{+}$T-Zellen wurde in vitro in einer Kokultur mit unterschiedlichen Stimulatorzellen durchgeführt, wobei sowohl die Aktivierbarkeit der T-Zellen als auch das Aktivierungspotential der eingesetzten Stimulatorzellen getestet werden konnte. Die MHC-Unverträglichkeit zwischen T-Zell-Spendern und den Stimulatorzellen der Zelllinien BEAS-2B und A549 war dabei durch eine HLA-Typisierung bestätigt worden.

Als Stimulatoren dienten Zellen der Zellinien BEAS-2B, A549 sowie PBEC, die zuvor jeweils durch Bestrahlung mit 30 Gy einer ${ }^{137} \mathrm{Cs}-$ Strahlenquelle stoffwechselinaktiviert wurden. Zur allogenen Aktivierung wurden naive CD8 ${ }^{+}$T-Zellen direkt nach der Isolation in einer Konzentration von $1 \times 10^{6}$ Zellen/ml im Verhältnis 1:1 mit den Stimulatorzellen gemischt und in kleinen Kulturflaschen in komplettem RPMI 1640 mit Zusatz von 100 U/ml IL-2 kultiviert. Diese Stimulationsphase dauerte in der Regel sieben Tage. Um zu testen, ob eine längere Stimulationsdauer zu spezifischeren oder stärkeren Reaktionen führte, wurde in einigen Versuchen eine zusätzliche Restimulationsphase angeschlossen, d. h. nach den ersten sieben Tagen wurde die Kokultur abzentrifugiert, neue Stimulatorzellen und neues IL-2-Medium in denselben Verhältnissen zugegeben und für weitere drei, sieben oder 14 Tage inkubiert, d. h. stimuliert. Zur Kontrolle wurden CD8 ${ }^{+}$ T-Zellen parallel unter denselben Kulturbedingungen ohne Stimulatorzellen also nur in IL-2-Medium kultiviert.

Staphylokokken-Enterotoxin B (SEB) führt als sog. Superantigen zu einer Überaktivierung des Immunsystems durch antigenunabhängige Überstimulierung der T-Zellen (vgl. Abbildung 3.4). Es wurde in einer Einsatzkonzentration von $10 \mu \mathrm{g} / \mathrm{ml}$ als Positivkontrolle zur Induktion einer maximalen Proliferationsantwort der T-Zellen eingesetzt.

Überstände der Stimulationsansätze wurden für spätere Analysen im ELISA gesammelt und bei $-20{ }^{\circ} \mathrm{C}$ weggefroren.

Die beiden Begriffe Aktivierung und Stimulation sind nicht immer klar auseinanderzuhalten, wenn auch nicht identisch. Im Allgemeinen bezeichnet aber „Stimulation“ im Folgenden den Vorgang, T-Zellen mit Stimulantien oder Stimulatorzellen anzuregen, während „Aktivierung“ bzw. „aktiviert“ den angeregten Zustand der T-Zellen nach erfolgreicher Stimulation beschreiben soll. 


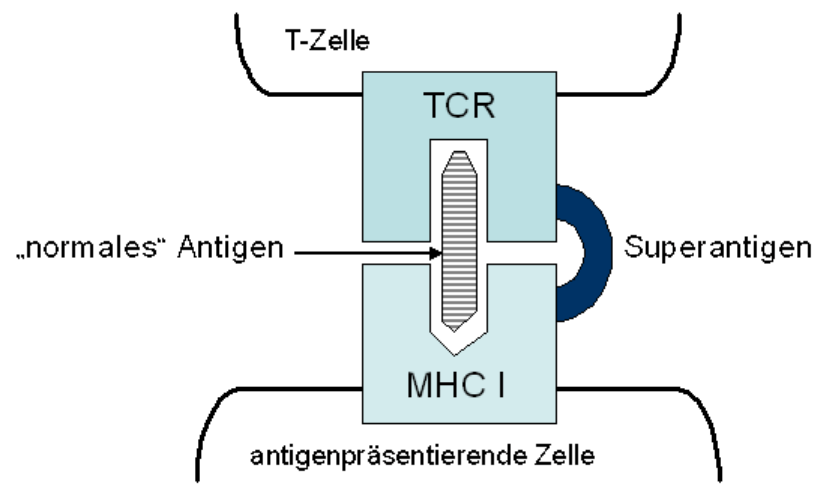

Abbildung 3.4: Antigenunabhängige Überstimulierung durch das Superantigen Staphylokokken-Enterotoxin B (SEB).

\subsection{Vorbehandlung/-stimulation von Epithelzellen}

In Vorexperimenten wurden für jede Behandlungsmethode zunächst Konzentrations-, Zeit- bzw. Dosis-Wirkungstests durchgeführt. Für die Experimente wurde dann jeweils die subletale Dosis mit maximaler Wirkung gewählt und angewandt. Zur allogenen Aktivierung von T-Zellen durch Stimulatorzellen, sollten letztere zwar unverändert ihre Oberflächenantigene präsentieren, selbst jedoch nicht mehr aktiv sein, Stoffwechsel betreiben oder proliferieren. Deshalb wurden Zellen, die als Stimulatoren dienten, zuvor mittels einer ${ }^{137}$ Cs-Strahlenquelle mit einer Dosis von 30 Gy bestrahlt und dadurch inaktiviert.

Für einige Versuche wurden Zellen der Zelllinie A549 sowie PBEC mit IFN- $\gamma$ vorstimuliert, um die Expression von Oberflächenantigenen sowie stimulatorischen und/oder kostimulatorischen Molekülen zu erhöhen. In den Vorarbeiten haben sich maximale Änderungen der Oberflächenantigenexpression bei 48 Stunden Stimulationszeit und $200 \mathrm{U} / \mathrm{ml}$ ergeben, weshalb für die folgenden Experimente diese Größen eingesetzt wurden.

\subsection{Semiquantitative RNA-Bestimmung}

Die Genexpression folgender stimulatorischer und kostimulatorischer Moleküle respiratorischer Epithelzellen wurde zunächst auf transkriptioneller Ebene gemessen: ICAM-1, CD70, CD80, CD86, CD95. Dafür wurde die Gesamt-RNA aus den Zellen isoliert und die messenger RNA (mRNA) daraus in komplementäre DNA (cDNA) umgeschrieben. 
Diese konnte dann mittels Polymerasekettenreaktion (PCR), die auf einer exponentiellen Vermehrung der DNA basiert, quantifiziert werden. Alle Arbeiten mit RNA wurden unter RNase-freien Bedingungen und mit RNase-freien Geräten durchgeführt.

\subsubsection{RNA-Isolation}

Mit dem High Pure RNA Isolation Kit wurde direkt nach dem Ernten die Gesamt-RNA aus Aliquots der Zelllinien BEAS-2B und A549 sowie von PBEC nach Anleitung des Herstellers isoliert. Dabei wurden die Zellen zunächst mit einem Guanidin Hydrochlorid $(\mathrm{HCl})$-haltigen Puffer lysiert. Dieser inaktiviert einerseits RNAsen und gleichzeitig binden die freigesetzten Nukleinsäuren in Anwesenheit des chaotropen Salzes Guanidin $\mathrm{HCl}$ an eine Glasfasermembran, durch die die entstandene Lösung anschließend zentrifugiert wurde. Alle anderen Zellbestandteile wurden in einem darunter befindlichen Auffanggefäß gesammelt und verworfen. Es folgte ein DNA-Verdau mit DNase I auf der Membran, sowie anschließendes zweimaliges Waschen zur Reinigung von Salzen, Proteinen und anderen PCR-inhibitorischen Kontaminationen, bevor die RNA dann mit reinstem Wasser wieder aus der Membran in ein frisches 1,5 ml-Reagiergefäß eluiert wurde. Diese RNA-Lösung wurde bis zur weiteren Verwendung bei $-80{ }^{\circ} \mathrm{C}$ gelagert.

Zur Quantifizierung der RNA wurde die optische Dichte eines Aliquots der Lösung bei $260 \mathrm{~nm}\left(\mathrm{OD}_{260 \mathrm{~nm}}\right)$ in einem Photometer (GeneQuant pro) bestimmt. Daraus lässt sich dann nach folgender Formel die Konzentration der RNA in der Lösung berechnen, wobei der Multiplikationsfaktor für einzelsträngige RNA 40 beträgt:

Konzentration der RNA $=\mathrm{OD}_{260 \mathrm{~nm}} \times$ Verdünnung $\times$ Multiplikationsfaktor $\quad\left[\frac{\mathrm{ng}}{\mathrm{\mu l}}\right]$.

Zusätzlich wurde stets auch die optische Dichte der Lösung bei $280 \mathrm{~nm}$ gemessen. Das Verhältnis $\mathrm{OD}_{260 \mathrm{~nm}} / \mathrm{OD}_{280 \mathrm{~nm}}$ lag immer zwischen 1,8 und 2,0, sodass dadurch eine Kontamination der RNA durch Proteine ausgeschlossen werden konnte.

\subsection{2 reverse Transkription der mRNA zu cDNA}

Mit Hilfe von oligo-dT-Primern, die den poly-A-Schwanz der mRNA erkennen und daran hybridisieren, wurde anschließend pro Probe die mRNA aus 1 gg Gesamt-RNA nach folgendem Protokoll in cDNA umgeschrieben: Das entsprechende Volumen der RNALösung, welches 1 gg Gesamt-RNA enthielt, wurde zunächst mit 1 ll oligo-dT-Primer zusammenpipettiert, mit Wasser auf $10 \mu$ l aufgefüllt und, damit sich die oligo-dT-Primer 
anlagern konnten, $3 \mathrm{~min}$ bei $70{ }^{\circ} \mathrm{C}$ inkubiert. Anschließend wurden $1 \mu \mathrm{l}$ RAsin, $1 \mu \mathrm{M}$ MLV Reverse Transkiptase, $4 \mu \mathrm{l}$ 5xPuffer und $4 \mu \mathrm{l}$ dNTP (Einsatzkonzentration 2,5 mM) zugegeben und $1 \mathrm{~h}$ bei $37{ }^{\circ} \mathrm{C}$ inkubiert. Zum Abstoppen dieser Synthesereaktion bzw. zur Inaktivierung der Enzyme wurde der Ansatz anschließend 2 min auf $95{ }^{\circ} \mathrm{C}$ erhitzt und das Reaktionsvolumen $(20 \mu \mathrm{l})$ für den weiteren Einsatz in die quantitative PCR auf $150 \mu$ l aufgefüllt, die entstandene cDNA also 1:7,5 verdünnt.

\subsection{3 relative Quantifizierung der Genexpression: Real-Time PCR}

Die relative Quantifizierung der mRNA in den Zellen erfolgte indirekt über die in der Probe enthaltenen cDNA mittels real-Time PCR im Light Cycler mit Hilfe des Fluoreszenzfarbstoffs SYBR ${ }^{\circledR}$ Green I. Dieser lagert sich in die kleine Grube doppelsträngiger DNA ein, wodurch seine Fluoreszenz stark zunimmt. In jedem Zyklus der PCR wird diese, durch blaues Licht (470 nm) einer LED (light-emitting diode) angeregte Fluoreszenz in jeder Probe detektiert (Messung bei $530 \mathrm{~nm}$ ). Die Intensität des Fluoreszenzsignals ist direkt proportional zur bis dahin bereits entstandenen doppelstrang-DNA-Menge. Der Zyklus der PCR, in dem diese Fluoreszenzintensität, also die DNA-Menge, einen bestimmten Schwellenwert überschreitet, wird als sogenannter crossing point bezeichnet. Je mehr DNA anfänglich bereits in die PCR eingesetzt wurde, also in einer Probe vorhanden war, desto eher wird dieser Schwellenwert erreicht. Anhand einer cDNAVerdünnungsreihe (unverdünnt, 1:10, 1:100, 1:1000), die für jedes Gen mitgeführt wurde, konnte dieser crossing point durch die LightCycler Software in einen Wert (calculated value $=$ relative Konzentration) umgerechnet werden, der im Folgenden zum Vergleich zwischen den Proben herangezogen wurde. Zusätzlich wurde in jeder Probe parallel zu der des Zielgens auf dieselbe Weise die Expression eines Referenzgens (= Haushaltsgens) bestimmt, das möglichst keiner Regulation unterliegt, also in allen Zellen eines Typs in gleicher Menge vorliegt. Dadurch können auch Unterschiede in den berechneten Werten, die ausschließlich auf unterschiedlichen Effizienzen der vorangegangen Schritte (RNA Isolation, Reverse Transkriptase Reaktion, PCR) beruhen, eliminiert werden. Als Haushaltsgen wurde beta-Aktin herangezogen und die calculated values der DNA-Menge des Zielgens als Vielfaches der des Haushaltsgens berechnet und angegeben. An diese eigentliche PCR schloss sich immer eine Schmelzkurvenanalyse mit dem Light-Cycler an, für die die Temperatur der Proben langsam von $65{ }^{\circ} \mathrm{C}$ auf $95{ }^{\circ} \mathrm{C}$ erhöht wurde. An ihrem spezifischen Schmelzpunkt (die Temperatur, bei der $50 \%$ der DNA einzelsträngig vorliegt) wurde die entstandene doppelstrang-DNA in Einzelstränge aufgespaltet, was zu einem plötzlichen Abfall der Fluoreszenz führte. Zu niedrige Schmelzpunkte sind dabei 
Hinweise auf Primerdimere, die sich während der PCR gebildet haben, was z. B. passieren kann, wenn keine DNA des zu untersuchenden Gens in der Probe vorhanden ist, ein Fluoreszenzabfall, also Aufschmelzen der entstandenen DNA, in mehreren Schritten deutet darauf hin, dass während der PCR verschiedene DNA-Produkte in einer Probe entstanden sind (Abbildung 3.5). Versuche mit solchen Hinweisen auf einen unsauberen Verlauf der PCR wurden nicht zur Auswertung herangezogen.

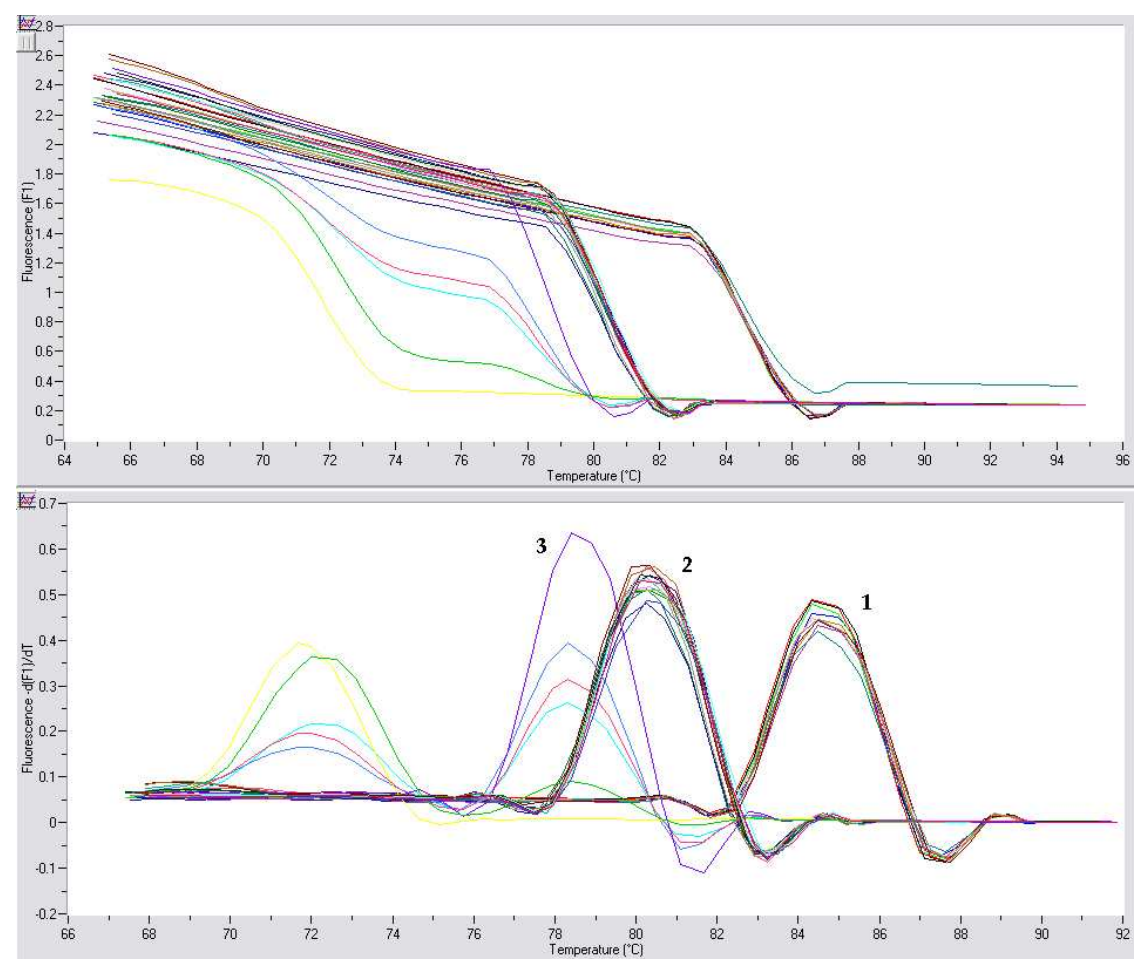

Abbildung 3.5: DNA-Schmelzkurven der Produkte einer real-time PCR. Die Amplifikation von Primerdimeren mit sehr niedrigen Schmelzpunkten (unteres Bild ganz links) ist ein Hinweis darauf, dass die DNA-Menge in der eingesetzten Probe unter der Nachweisgrenze lag. Diese Proben wurden ebensowenig in die Auswertung einbezogen, wie solche, in denen unsaubere, aus mehreren Einzelprodukten bestehende, PCR-Produkte entstanden, die in mehreren Schritten aufschmelzen (unteres Bild (3)). (1) Schmelzkurven der CD95-Produkte, (2) Schmelzkurven der CD80- bzw. $\beta$-Aktin-Produkte.

Für die Quantifizierung wurden die Reagenzien des QuantiTect ${ }^{T M}$ SYBR $^{\circledR}$ Green PCR Kit wie folgt eingesetzt: pro Probe wurden zu 5 ul der zu untersuchenden cDNALösung je 0,5 $\mu$ l des 1:10 vorverdünnten Vorwärts- und Rückwärtsprimers gegeben, dazu 10 pl des QuantiTect ${ }^{T M}$ SYBR $^{\circledR}$ Green PCR Master Mix gemischt, der neben dem Farbstoff SYBR ${ }^{\circledR}$ Green I auch die DNA Polymerase (HotStaTaq DNA Polymerase), einen dNTP Mix und einen optimierten Puffer enthält, und mit 4 l Wasser aufgefüllt. 
Dieses Gesamtreaktionsvolumen von $20 \mu \mathrm{l}$ wurde in eine Light Cycler Kapillare pipettiert und zentrifugiert und in dieser die PCR im LightCycler nach folgendem Protokoll durchgeführt: Denaturierung: $900 \mathrm{~s} 95{ }^{\circ} \mathrm{C}$; Amplifikation (mit 45 Widerholungen): $15 \mathrm{~s}$ $95{ }^{\circ} \mathrm{C}, 20$ s Annealingtemperatur $56-58{ }^{\circ} \mathrm{C}, 25$ s $72{ }^{\circ} \mathrm{C}$, Fluoreszenzmessung bei $72{ }^{\circ} \mathrm{C}$; Schmelzkurve: $1 \mathrm{~s} 95{ }^{\circ} \mathrm{C}, 15 \mathrm{~s} 65{ }^{\circ} \mathrm{C}$, Temperaturerhöhung mit $0,1{ }^{\circ} \mathrm{C} / \mathrm{s}$ auf $95{ }^{\circ} \mathrm{C}$, dabei kontinuierliche Fluoreszenzmessung.

Die verwendeten Primer wurden mit Hilfe der im Internet zugänglichen NucleotideDatabase (http://www.ncbi.nlm.nih.gov/sites/entrez?db=Nucleotide) entworfen und in hochreiner Form (high salt purified) von MWG-Biotech (Ebersberg) bezogen.

\subsection{Bestimmung löslicher Zytokine im ELISA}

Zur quantitativen Bestimmung der durch aktivierte T-Zellen produzierten und ausgeschütteten Zytokine bzw. von während der Lyse freigesetztem Granzym B wurden colorimetrische Sandwich-ELISA herangezogen. Dazu wurden fertige ELISA-Kits, die sowohl mit Antikörpern gegen das nachzuweisende Antigen (Zytokin oder Granzym B) vorbeschichtete Platten als auch die zugehörigen Reagenzien enthielten, nach angegebenem Protokoll des Herstellers angewandt.

\subsection{Durchflusszytometrie und Zellsortierung}

Der Phänotyp der untersuchten Epithel- sowie T-Zellen wurde durchflusszytometrisch im FACS mittels Immunfluoreszenzfärbung bestimmt. Die mit fluoreszenzfarbstoffgekoppelten Antikörpern gegen bestimmte Oberflächenantigene markierten Zellen durchlaufen dabei einzeln in einem Flüssigkeitsstrom den Lichtstrahl eines Argon-Ionen-Lasers der Wellenlänge 488 nm. Dadurch wird der auf der Zelle gebundene Farbstoff zur Fluoreszenz angeregt und emittiert Licht einer bestimmten Wellenlänge, welches von entsprechenden Photodetektoren gemessen und quantifiziert wird. Man erhält darüber zum einen die Information, ob eine Zelle das entsprechende Antigen trägt bzw. wie viele Prozent der Zellen einer Population dieses tragen und zum anderen einen relativen Wert der Expressionsdichte (Fluoreszenzintensität), der angibt, wie viel des Antigens die Zelle auf ihrer Oberfläche exprimiert bzw. wie viel des Antigens die Zellen der Population im Mittel exprimieren (= mean fluorescence intensity, MFI). Als Fluoreszenzfarbstoffe wurden Fluorescein-Isothiocyanat (FITC, Emmissionswellenlänge $525 \mathrm{~nm}$ ) und Phycoerythrin (PE, Emmissionswellenlänge $576 \mathrm{~nm}$ ) eingesetzt. Zusätzlich und unabhängig von 
einer Fluoreszenzmarkierung wird ein Teil des Lichts des Laserstrahls beim Durchlaufen einer Zelle durch Beugung, Streuung oder Brechung an dieser in verschiedene Richtungen abgelenkt und ebenfalls detektiert. Dadurch erhält man Informationen über die Größe (entsprechend dem Vorwärtsstreulicht, foreward scatter = FSC) und Granularität (entsprechend Seitwärtsstreulicht, sideward scatter $=$ SSC) der einzelnen, vermessenen Zellen.

Die Fluoreszenzmarkierung der Zellen erfolgte stets auf Eis und im Dunkeln. Es wurden entweder direkt fluoreszenzmarkierte Antikörper verwendet oder unmarkierte primäre Antikörper, welche erst in einem zweiten Färbungsschritt durch ein spezifisches fluoreszenzmarkiertes Immunglobulin markiert wurden. $1 \times 10^{5}$ bis $5 \times 10^{5}$ Zellen wurden in einem Reaktionsvolumen von $50 \mu \mathrm{l}$ PBS + 5\% FBS resuspendiert und mit den Antikörpern in einer Endkonzentration von 10 pg/ml (oder nach Angaben des Herstellers) für ca. 30 min inkubiert. Überschüssige Antikörper wurden zwischen und nach den Inkubationsschritten durch einmaliges Waschen mit PBS $+5 \%$ FBS entfernt und die Zellen für die Messung in einer Endkonzentration von mind. $1 \times 10^{6}$ Zellen/ml erneut gut resuspendiert und zur Messung in FACS-Röhrchen überführt. Zur Diskriminierung toter Zellen wurde Propidium Iodid (PI) in einer Endkonzentration von $200 \mathrm{ng} / \mathrm{ml} \mathrm{zu}-$ gegeben. Dieser Letalfarbstoff dringt nur in tote Zellen durch deren nicht mehr intakte Membran ein, kann dort in die DNA interkalieren woraufhin er nach Anregung durch das Laserlicht fluoresziert und detektiert werden kann. Tote Zellen wurden von der Analyse ausgeschlossen. Messung und Auswertung erfolgten unmittelbar nach der Färbung der Zellen in einem FACSCalibur und mit der Software CellQuest (BD Biosciences) oder der frei im Internet zugänglichen Auswertungssoftware WinMDI.

Eine Kontrollfärbung mit den entsprechenden Isotypen wurde parallel zu allen Antikörperfärbungen mitgeführt, um unspezifische Bindungen der Antikörper ausschließen zu können.

Auf den Epithelzellen wurde auf diese Weise die Expression von MHC I, MHC II, MIC A/B sowie folgender stimulatorischer und kostimulatorischer Oberflächenmoleküle gemessen: CD54 (ICAM-1), CD70, CD80, CD86, CD95.

Die Reinheit der isolierten $\mathrm{CD}^{+}$T-Zell-Population wurde direkt nach der Isolation sowie nach der Stimulationszeit von $7 \mathrm{~d}$ bzw. $7+3 \mathrm{~d}$ anhand von Doppelfärbungen mit folgenden Antikörpern des Simultest IMK-Lymphocyte kits überprüft: CD3-CD4, CD3CD8, CD3-CD16/56, CD3-CD19.

Außerdem wurde der Aktivierungszustand der CD8 ${ }^{+}$T-Zellen nach 7- bzw. 7+3-tägiger Stimulierung durch Färbung mit Antikörpern gegen folgende Aktivierungsmarker 
bestimmt: CD25, CD30, CD54 (ICAM-1), CD69, CD70, CD71, CD80, CD86, CD95, NKG2D.

Ein FACS-Gerät (FACSAria von BD Biosciences) wurde auch verwendet, um die wie beschrieben mit PE-markierten anti-NKG2D-Antikörpern markierte Zellen zu sortieren. Bei dieser Spezialanwendung der Durchflusszytometrie wird jede Zelle während der Fluoreszenzmessung mit einer elektrischen Ladung versehen. Gleichzeitig wird an eine von zwei neben dem Einzelzellstrom befindlichen Elektroden eine entgegengesetzte Ladung/Spannung angelegt, so dass die vermessene Zelle direkt im Anschluss an die Messung je nachdem, ob ihre Fluoreszenzintensität über oder unter einem vorher festgesetzten Schwellenwert liegt, nach rechts oder links in eines von zwei vorgelegten Auffanggefäßen mit FCS geleitet wird. Entsprechend wurde die gemessene Population dadurch in zwei Teilpopulationen sortiert, eine mit hoher, die andere mit niedriger Expression des untersuchten Antigens NKG2D.

\subsection{Proliferationsbestimmung mittels CFSE-Färbung}

Zellproliferation spielt eine zentrale Rolle im Zusammenhang mit der klonalen Expansion von T-Zellen während der T-Zell-Aktivierung. Zur Untersuchung der Proliferation wurde ein nichtradioaktiver, fluoreszenzfarbstoffbasierter Test herangezogen. Alle Arbeiten erfolgten im Dunkeln, damit der eingesetzte Farbstoff CFSE seine Fluoreszenzfähigkeit behielt. Frisch isolierte CD8 ${ }^{+}$T-Zellen wurden zunächst einmal mit PBS gewaschen, um Reste des Mediums zu entfernen, die die Färbung beeinträchtigen könnten. $10^{7}$ Zellen/ml wurden dann in einer Endkonzentration von $2 \mu \mathrm{M}$ mit CFDA, SE-Lösung in PBS für 4 min bei RT inkubiert. Das nichtpolare, zellmembrangängige Molekül Carboxyfluorescein Diacetat, Succinimidyl Ester (CFDA, SE) wird in der Zelle durch intrazelluläre Esterasen zum anionischen CFSE (Carboxyfluorescein Succinimidyl Ester) konvertiert. Durch spontane und irreversible (kovalente) Bindung an die Aminogruppen zellulärer Proteine entsteht eine (nach 24-stündiger Equilibrationszeit) stabile, langanhaltende Fluoreszenz, die dann durchflusszytometrisch gemessen werden kann [85, 86, 87]. Überschüssiges CFDA, SE wurde nach der Inkubationszeit durch zweimaliges Waschen mit PBS und Medium entfernt und die markierten Zellen anschließend wie für die Stimulierung beschrieben (s.o.) mit den entsprechenden Stimulatorzellen, IL-2 alleine oder SEB als Positivkontrolle in Kultur genommen. An den Tagen 1, 7 und $7+3$ nach Beginn der Stimulation wurden Aliquots der Zellen aus der Kultur entnommen und deren Fluoreszenz durchflusszytometrisch gemessen. Die Differenzierung von ruhenden und 
proliferierenden Zellen basiert dabei auf der Halbierung der Fluoreszenzintensität bei jedem Zellzyklus, da der an (Struktur-)proteine gebundene Farbstoff bei jeder Zellteilung gleichmäßig zwischen den beiden Tochtergenerationen verteilt wird [85, 86, 87].

\subsection{Funktionaler Zytotoxizitätstest: ${ }^{51} \mathrm{Cr}$-Release Assay}

Der 4h-Standard- ${ }^{51}$ Cr-Release Assay oder ${ }^{51} \mathrm{Cr}$-Freisetzungstest ist ein funktionaler Zytotoxizitätstest, der es erlaubt, das Ausmaß der Lyse von Target(Ziel-)zellen durch bestimmte Effektorzellen über die Freisetzung von ${ }^{51} \mathrm{Cr}$ aus den lysierten Targetzellen, also speziell eine T-Zell-vermittelte Zytotoxizität, direkt zu quantifizieren. Die Lyse wurde dabei jeweils in Doppelbestimmung bei verschiedenen Effektor/Target (E/T)-Verhältnissen ermittelt, beginnend mit 80:1 und in 1:2-Verdünnungsschritten bis minimal 2,5:1.

Die Effektoren wurden dazu zunächst in die Vertiefungen einer 96 well-RundbodenPlatte vorgelegt, je in einem Volumen von 100 pl komplettem RPMI 1640 und in abneh-

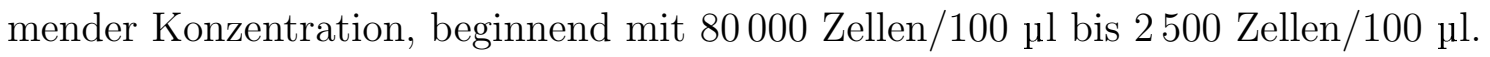

Gleichzeitig wurden $1 \times 10^{6}$ Targetzellen mit $50 \mu \mathrm{l}(2,3 \mathrm{MBq})$ Natrium $\left[{ }^{51} \mathrm{Cr}\right]$ chromat $\left(\mathrm{Na}_{2}\left({ }^{51} \mathrm{CrO}_{4}\right)\right)$ für 1,5 Stunden inkubiert und überschüssiges Natrium $\left[{ }^{51} \mathrm{Cr}\right]$ chromat anschließend durch zweimaliges Waschen entfernt. Jeweils 1000 Targets in einem Volumen von 100 pl komplettem RPMI 1640 wurden dann in jede Vertiefung der Platte zu den vorbereiteten Effektoren pipettiert und diese anschließend für $4 \mathrm{~h}$ bei $37{ }^{\circ} \mathrm{C}$ und $5 \% \mathrm{CO}_{2}$ kokultiviert. Anschließend wurden je $40 \mu \mathrm{l}$ des zellfreien Überstandes auf eine Luma-Platte übertragen, trocknen gelassen und die enthaltene Radioaktivität in einem gamma-Counter gemessen (Experimentalfreisetzung). Zusätzlich wurden für jedes Target zwei Vertiefungen ohne Effektoren mitgeführt. Aus der einen wurde parallel zum beschriebenen Vorgehen nach $4 \mathrm{~h}$ die entsprechende Menge zellfreien Überstandes entnommen, auf die Luma-Platte übertragen und daraus die spontane, ohne Einwirkung von Effektoren freigesetzte ${ }^{51} \mathrm{Cr}-$ Menge/Radioaktivität gemessen (Spontanfreisetzung). Aus der anderen Vertiefung wurden sofort nach dem hineinpipettieren $40 \mu \mathrm{l}$ der noch homogen gemischten Targetzellsuspension entnommen und deren Radioaktivität parallel zum beschriebenen Vorgehen auf der Luma-Platte gemessen. Diese Gesamtmenge im entsprechenden Ansatz enthaltener, also von den Targets zuvor aufgenommener Radioaktivität entspricht der maximal möglichen ${ }^{51}$ Cr-Freisetzung (maximale Freisetzung). Die relative spontane Freisetzung (spontane Freisetzung/maximale Freisetzung $\times 100$ ) ist ein Indikator für die Targetzellintegrität und muss entsprechend möglichst niedrig liegen. In allen in dieser Arbeit gezeigten Experimenten wurde ein Schwellenwert von 
$15 \%$ nicht überschritten.

Die relative, prozentuale spezifische Lyse der Targetzellen wurde aus den ermittelten Werten nach folgender Formel berechnet:

$$
\text { relative Lyse }=\frac{\text { Freisetzung im Experiment }- \text { spontane Freisetzung }}{\text { maximale Freisetzung }- \text { spontane Freisetzung }} \times 100 \quad[\%]
$$

Für Blockierungsexperimente wurden die Effektoren bzw. die Targets nach der Markierung mit ${ }^{51} \mathrm{Cr}$ je für 30min bei RT mit blockierenden (functional grade) Antikörpern in der Endkonzentration 20 pg/ml inkubiert und ohne anschließendes Waschen direkt in den ${ }^{51}$ Cr-Release Assay eingesetzt, so dass der Antikörper während der ganzen vierstündigen Kokulturphase anwesend war. Folgende Antikörper wurden verwendet: auf Targetseite anti-MHC I (W6/32), auf Effektorseite NKG2D (1D11) sowie IgG1 (MG1-45). Zum direkten Vergleich wurden immer gleichzeitig Kontrollansätze ohne blockierende Antikörper durchgeführt.

Zur Bestimmung des während der Lyse freigesetzten Effektormoleküls Granzym B wurden Zytotoxizitätsassays nach dem oben beschriebenen Protokoll in E/T-Verhältnissen von 0, 20:1 bzw. 40:1 angesetzt, nur mit dem Unterschied, dass die Targetzellen nicht radioaktiv markiert wurden. Nach der vierstündigen Inkubation/Kokultur wurde der Überstand aus den Vertiefungen der Platten gesammelt und nach Entfernung evtl. enthaltener Zellen durch Zentrifugation bis zur späteren ELISA-Analyse bei $-20{ }^{\circ} \mathrm{C}$ gelagert.

\section{Cold-Target-Inhibition}

Da durch BEAS-2B vorstimulierte CD8 ${ }^{+}$T-Zellen nicht immer nur BEAS-2B, sondern, wenn auch nur in geringerem Ausmaß, auch andere Targetzellen (K562) lysiert wurden, sollten sogenannte „cold target inhibition“-Experimente genauere Aussagen über die Spezifität der gefundenen Lyse und die Eigenschaften der Effektorpopulation erlauben. Dazu wurden beide Zelltypen, die einzeln jeweils lysiert wurden, den Effektoren gleichzeitig als Targets in einem Standard- ${ }^{51}$ Cr-Release Assay angeboten. Die Versuche wurden bei einem konstanten E/T-Verhältnis von 10:1 durchgeführt, da die Lyse in diesem Bereich überwiegend linear verlief.

Die eigentlichen Targetzellen, deren Ausmaß an Lyse untersucht werden sollte, wurden dabei wie beschrieben ${ }^{51} \mathrm{Cr}$-markiert (=hot Targets). Die anderen blieben unmarkiert (=cold Targets =Inhibitoren/Kompetitoren), wurden zusätzlich zu Ersteren in steigendem cold/hot-Verhältnis von 1:1 bis 40:1 in den ${ }^{51}$ Cr-Release Assay eingesetzt, und dienten so als Kompetitoren. Konkret wurden zunächst die cold Targets, in abnehmen- 
der Anzahl von 80000 bis 2500 in je $50 \mu$ l komplettem RPMI 1640 in Doppelbestimmung in die Vertiefungen einer 96-Well-Rundbodenplatte vorgelegt, anschließend wurden 2000 Zellen der wie beschrieben ${ }^{51} \mathrm{Cr}$-markierten hot Targets in jede Vertiefung dazugemischt (so dass sich cold/hot-Verhältnisse von 40:1 bis ca. 1:1 ergaben). Zuletzt wurden in jede Vertiefung, außer in die für Spontan- und Maximalfreisetzung vorgesehenen, 20000 aktivierte CTL in $100 \mu \mathrm{l}$ komplettem RPMI 1640 als Effektoren hinzupipettiert und der

${ }^{51}$ Cr-Release Assay nach oben beschriebenem Protokoll inkubiert und ausgewertet. Die Kontrolllyse in Abwesenheit von Kompetitoren wurde immer parallel mitbestimmt.

Sofern die selben Zellen der Effektorpopulation die unmarkierten Zellen ebenso als Targets erkennen und lysieren wie die eigentlichen ${ }^{51} \mathrm{Cr}$-markierten Targetzellen, kommt es aufgrund der mit zunehmenden cold/hot-Verhältnissen im Überschuss vorliegenden Inhibitoren zur kompetitiven Hemmung der Lyse der ${ }^{51} \mathrm{Cr}$-markierten Targets, sodass dann im Überstand des Assays entsprechend weniger Radioaktivität messbar ist. Wenn die Inhibitoren von den Effektorzellen nicht als Targets erkannt werden oder falls unterschiedliche lytisch aktive Zelltypen einer Effektor-Mischpopulation die Inhibitoren bzw. die Targets lysieren, wird die Lyse der Targetzellen und somit die ${ }^{51} \mathrm{Cr}$-Freisetzung durch Anwesenheit von Inhibitoren nicht beeinflusst.

\subsection{Statistische Auswertungen}

Berechnungen und Tests wurden mit dem Programm SigmaStat (San Jose, California, USA) durchgeführt. Soweit nicht anderweitig aufgeführt, wurden mind. vier unabhängige Experimente durchgeführt und die Mittelwerte \pm Standardfehler aufgetragen.

Mittelwerte zwischen zwei Gruppen wurden soweit Varianzengleichheit und Normalverteilung der Daten gewährleistet waren, mit dem Student's t-test auf Unterschiede getestet, andernfalls mit dem nichtparametrischen Mann-Whitney Rangsummentest. Mittelwerte zwischen drei Gruppen wurden mittels ANOVA (mit anschließendem Dunn's oder Tukey's post-hoc test) auf Unterschiede getestet.

Da die Lyse in den ${ }^{51} \mathrm{Cr}$-Release Assays von Versuch zu Versuch selbst unter gleichen Versuchsbedingungen relativ starken Schwankungen unterlag (hohe „inter-assaydifferences“), konnten die Werte verschiedener Bedingungen innerhalb eines Versuchs nicht als unabhängig angesehen werden. Zu jedem Versuch wurden deshalb die entsprechenden Kontrollen immer im selben Ansatz mitgeführt und Mittelwerte verschiedener Bedingungen wurden mit dem t-test für verbundene Stichproben auf Unterschiede getestet. 


\section{Ergebnisse}

\subsection{Phänotypische Charakterisierung der primären bronchialen Epithelzellen}

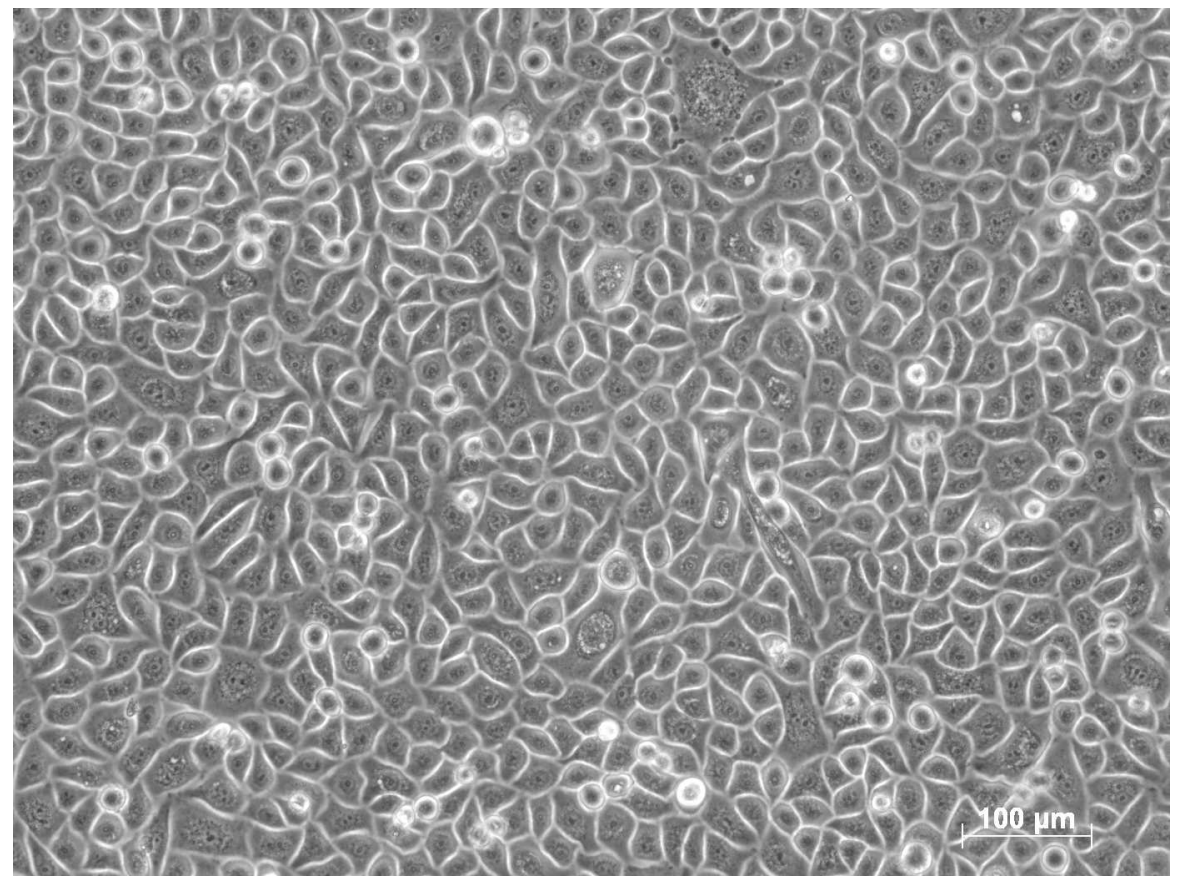

Abbildung 4.1: Fast konfluent gewachsene PBEC-Kultur in der lichtmikroskopischen Aufnahme.

Primäre bronchiale Epithelzellen (PBEC) wurden direkt nach deren Gewinnung aus der Lunge von Patienten und der anschließenden Separation und Isolierung aus den dazu herangezogenen Bürsten in AECG-Medium ausgesät. Während ein- bis mehrwöchiger Kultur wuchsen die Zellen langsam heran, konnten dabei bis zu zweimal gesplittet werden und bildeten schließlich einen dichten Monolayer aus epithelzelltypisch backsteinmusterartig nebeneinander liegenden Zellen aus. Die PBEC waren in der lichtmikroskopischen Betrachtung mehr oder weniger einheitlich granulär und flächig. Langspindelförmige, fibroblastenartige Zellen waren nicht darunter zu finden (Abbildung 4.1). Der epitheliale 


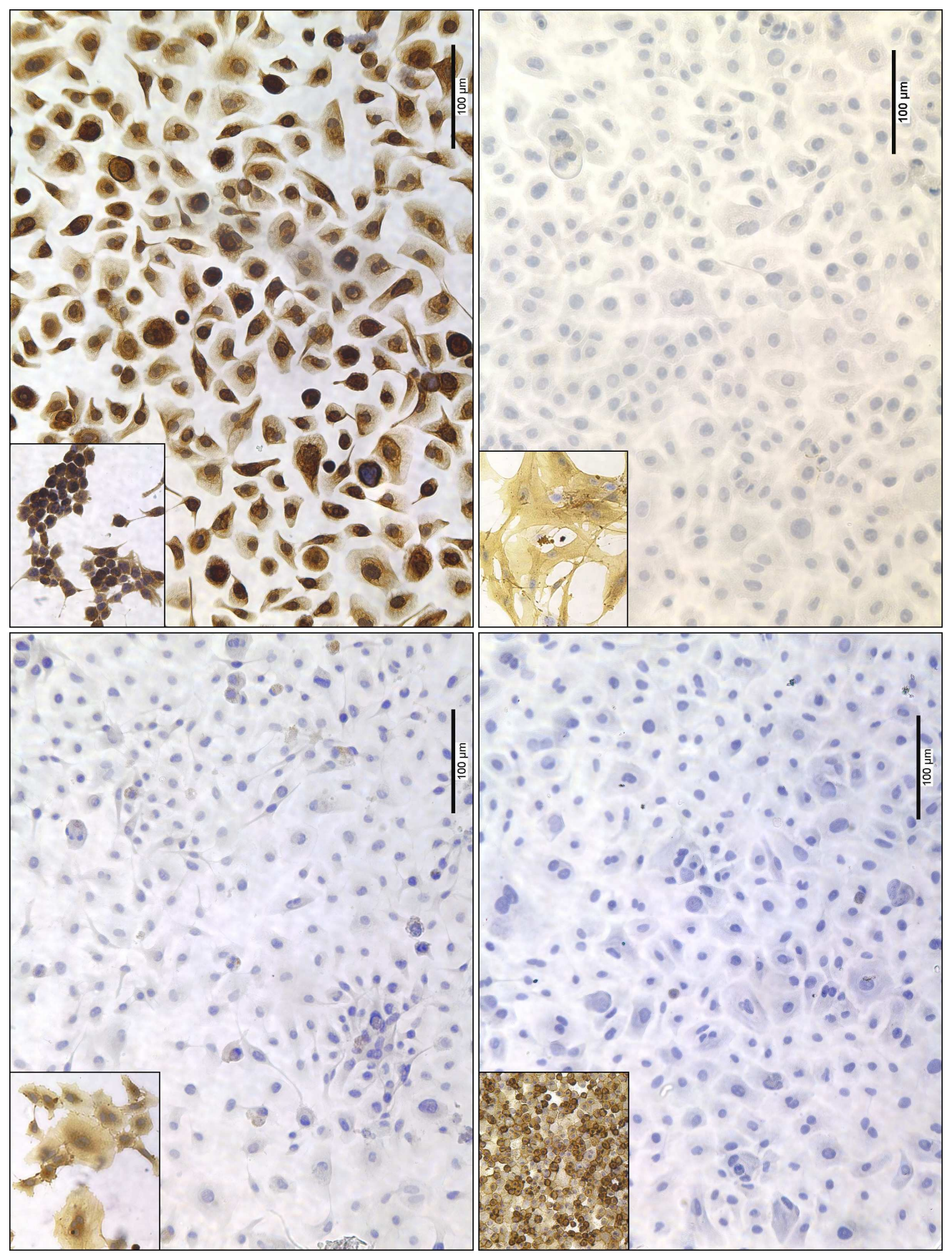

Abbildung 4.2: Charakterisierung der primären bronchialen Epithelzellen: angefärbtes Zytokeratinskellet in PBEC (oben links), PBEC sind negativ für den Fibroblastenmarker CD90 (oben rechts), den Endothelzellmarker CD31 (unten links) und den Panleukozytenmarker CD45 (unten rechts). Fixierte PBEC wurden mit Antikörpern gegen Zytokeratin (Epithelzellmarker), CD90, CD31 bzw. CD45 immunhistologisch gefärbt. Jeweils in kleinem Bild: analog behandelte Positivkontrolle. 
Charakter der kultivierten Zellen wurde durch die positve Zytokeratinfärbung der Kulturen mit einem Panzytokeratin-spezifischen Antikörper (KL-1) bestätigt (Abbildung 4.2, mit der humanen Brustkrebszelllinie BT474 als Positivkontrolle). Gleichzeitig konnte eine Kontamination der Kulturen mit Fibroblasten durch negative Färbungsergebnisse mit dem spezifischen Fibroblasten-Antikörper CD90 (Klon ASO2; Abbildung 4.2) ausgeschlossen werden sowie Endothelzellen bzw. Makrophagen durch negative Färbungsergebnisse mit dem Endothelzellmarker CD31 bzw. Panleukozytenmarker CD45 (Abbildung 4.2) [88, 84].

\subsection{Charakterisierung der Oberflächenexpression respiratorischer Epithelzellen}

Ebenso wie Endothelzellen sind auch Epithelzellen keine klassischen antigenpräsentierenden Zellen. Für Endothel ist die Fähigkeit zur Antigenpräsentation und die Aktivierung von alloreaktiven $\mathrm{CD}^{+}$T-Zellen in vitro und in vivo jedoch bereits nachgewiesen [42]. Auch für respiratorische Epithelzellen wurde diskutiert, dass sie in vitro allospezifische $\mathrm{CD}^{+}$T-Zellen aktivieren [41] bzw. antigenspezifische T-Zellen aus PBMC generieren können [43]. Eine Voraussetzung dafür ist zunächst, dass sie diejenigen mit Antigenpräsentation assoziierten Oberflächenmoleküle exprimieren, die es ihnen erst ermöglichen, $\mathrm{CD}^{+} \mathrm{T}$-Zellen allogen zu stimulieren. In früheren Arbeiten wurde bereits gezeigt, dass BEAS-2B wie auch PBEC in großer Dichte MHC I tragen, ebenso exprimieren sie in unterschiedlicher Menge auch Adhäsions- und ko- bzw. stimulatorische Moleküle wie ICAM-1, CD70 und B7-H1-3, die klassischen kostimulatorischen Moleküle CD80 und CD86 wurden auf BEAS-2B und PBEC dagegen als in nur sehr geringer Menge oder nicht exprimiert beschrieben [89, 90, 91, 92, 93, 94].

\subsubsection{Expression von Oberflächenmolekülen auf Transkriptionsebene}

Auch für die Zellen der für die folgenden Versuche herangezogenen Chargen der Zelllinien und der Patienten sollte die Expression folgender Oberflächenmoleküle zunächst mittels semiquantitativer real-time PCR auf Transkriptionebene bestätigt werden: CD54 (ICAM-1), CD80, CD86, CD95 sowie CD70 (nicht abgebildet, [93]). Die relativen Expressionswerte wurden in Abbildung 4.3 als prozentuale Anteile von denen des jeweils gleichzeitig mitbestimmten zytoplasmatischen Haushaltsgens $\beta$-Aktin berechnet, dessen 
Werte stabil waren.

Für ICAM-1 und CD95 war mRNA in allen drei Zelltypen nachweisbar, die Expression betrug aber jeweils weniger als ein Promille von der des Referenzgens $\beta$-Aktin. CD80 wurde in A549 jedoch so schwach transkribiert, dass die mRNA-Menge gerade an der Nachweisgrenze liegt, in BEAS-2B war die mRNA sogar für CD80 und CD86 nicht mehr zuverlässig nachweisbar. Die mRNA-Expressionsmuster unterschieden sich in den beiden Zelllinien auch in der Hinsicht, dass in BEAS-2B mehr ICAM-1, aber nur sehr wenig CD95 ( $<0,01 \%$ von $\beta$-Aktin) messbar war, in A549 jedoch ICAM-1-mRNA in vergleichbar geringer Menge vorlag, dagegen aber mehr CD95-mRNA. In den untersuchten PBEC lag die ICAM-1-mRNA-Menge wie bei A549 deutlich unter 0,01\% von $\beta$-Aktin und CD80 war nicht mehr zuverlässig nachweisbar. Auffällig war dagegen die im Gegensatz zu den beiden Zelllinien höhere CD86-Expression, ein Ergebnis, das im Gegensatz zu Kurosawa [94] steht, der in Northern Blot-Analysen zwar mRNA für CD80, nicht aber für CD86 auf PBEC von drei Spendern nachweisen konnte. Möglicherweise ist die Expression sehr abhängig von der Vorgeschichte der Spender oder der Gewinnung und Kultur der PBEC.

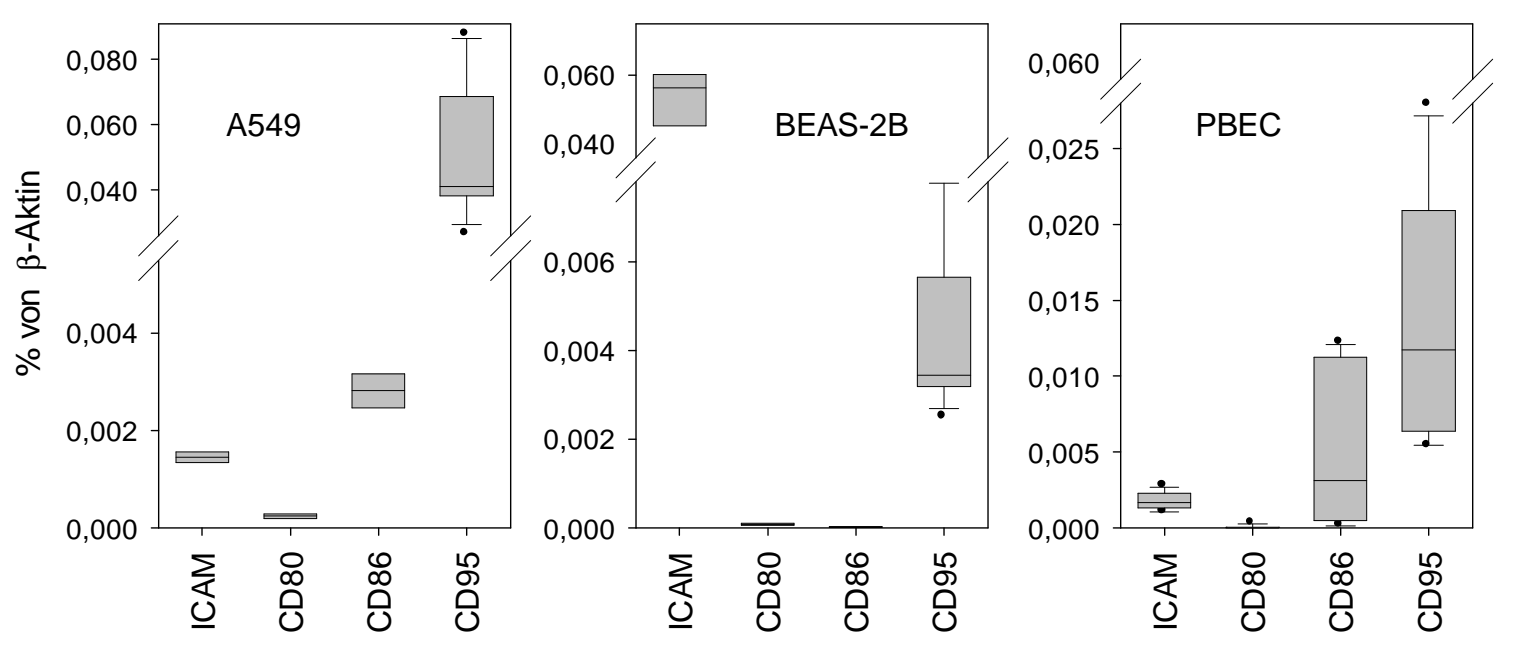

Abbildung 4.3: Expression von ICAM-1, CD80, CD86 und CD95 in A549, BEAS-2B und PBEC. Die relative mRNA-Menge wurde mittels Real-Time PCR ermittelt und ist in Prozent des Haushaltsgens $\beta$-Aktin angegeben. Zur besseren Darstellbarkeit der Balken wurden auf der y-Achse unterschiedliche Maßstäbe gewählt. 


\subsubsection{Expression von Oberflächenmolekülen auf Proteinebene}

Da die Synthese von mRNA für ein bestimmtes Molekül in der Zelle nicht zwangsläufig bedeutet, dass das entsprechende Protein auch gebildet und auf die Oberfläche der Zelle transportiert (bzw. sezerniert) und damit funktionsfähig wird, wurde im Folgenden durchflusszytometrisch überprüft, ob die genannten Moleküle sowie MHC I oder II tatsächlich auch auf der Zelloberfläche der respiratorischen Epithelzellen präsentiert werden. Diese Ergebnisse sind in Abbildung 4.4 zusammengestellt. Wie alle kernhaltigen Zellen trugen erwartungsgemäß je $100 \%$ der Zellen aller untersuchten respiratorischen Zelllinien sowie der PBEC aller Patienten MHC I auf ihrer Oberfläche. Auf BEAS-2B war MHC I in sehr hoher Dichte (MFI $830 \pm 160$ ) vertreten, im Gegensatz zu A549 und PBEC, die deutlich weniger MHC I trugen (MFI $138 \pm 15$ auf A549). MHC II dagegen war jeweils nur auf ca. $1 \%$ der Zellen aller drei untersuchter Zelltypen vorhanden und auf diesen positiven Zellen wurde es nur in geringer Dichte (MFI $24 \pm 1,5$ auf BEAS-2B) exprimiert. Nur auf BEAS-2B war das Adhäsionsmolekül ICAM-1 auf einem Großteil der Zellen $(83 \% \pm 11 \%$ ) in mittlerer Dichte (MFI $132 \pm 22$ ) exprimiert - nur $14 \%$ $( \pm 2 \%)$ der A549 waren positiv für ICAM-1 (MFI $23 \pm 3$ ). Umgekehrt war ein großer Teil der A549 positiv für CD95 (81 \% 土8 \%; MFI $138 \pm 15)$ - im Gegensatz zu BEAS-2B (52\% $\pm 8 \%$; MFI $41 \pm 2$ ). CD80 und CD86 konnte auf keinem der Zelltypen in relevanter Menge nachgewiesen werden $(<1 \%$ positive Zellen). Dieses Ergebnis sowie das Muster der ICAM-1- und CD95-Oberflächenexpression bestätigen die auf RNA-Ebene gemessenen Werte. Das für BEAS-2B bereits beschriebene CD70 [93] konnte auf beiden Zelllinien in etwa gleichem Umfang nachgewiesen werden (knapp 20 \% positiv, MFI 1525). PBEC ähnelten in ihrer Oberflächenexpression eher den A549, mit weniger ICAM-1 (11\% $\pm 3 \%$; MFI $46 \pm 8$ ) und auffallend viel CD95 (92\% $\pm 4 \%$; MFI $32 \pm 4$ ). CD80 und CD86 war auf den PBEC zwar auch nur auf je $1 \%$ der Zellen nachweisbar, im Mittel trugen diese positiven PBEC aber mehr davon als die Zellen der Linien (MFI $49 \pm 13$ bzw. $38 \pm 8)$.

\subsubsection{Steigerung der Oberflächenexpression durch IFN- $\gamma$-Vorstimulierung}

Da A549 und PBEC damit eine geringere Expression insbesondere von MHC I und ICAM-1 zeigten als BEAS-2B und darauf auch geringere Stimulator- und Zytotoxizitätinduzierende Eigenschaften zurückzuführen sein könnten, wurden diese beiden Zelltypen im Folgenden mit IFN- $\gamma$ vorstimuliert. Dieses proinflammatorische Zytokin erhöht 

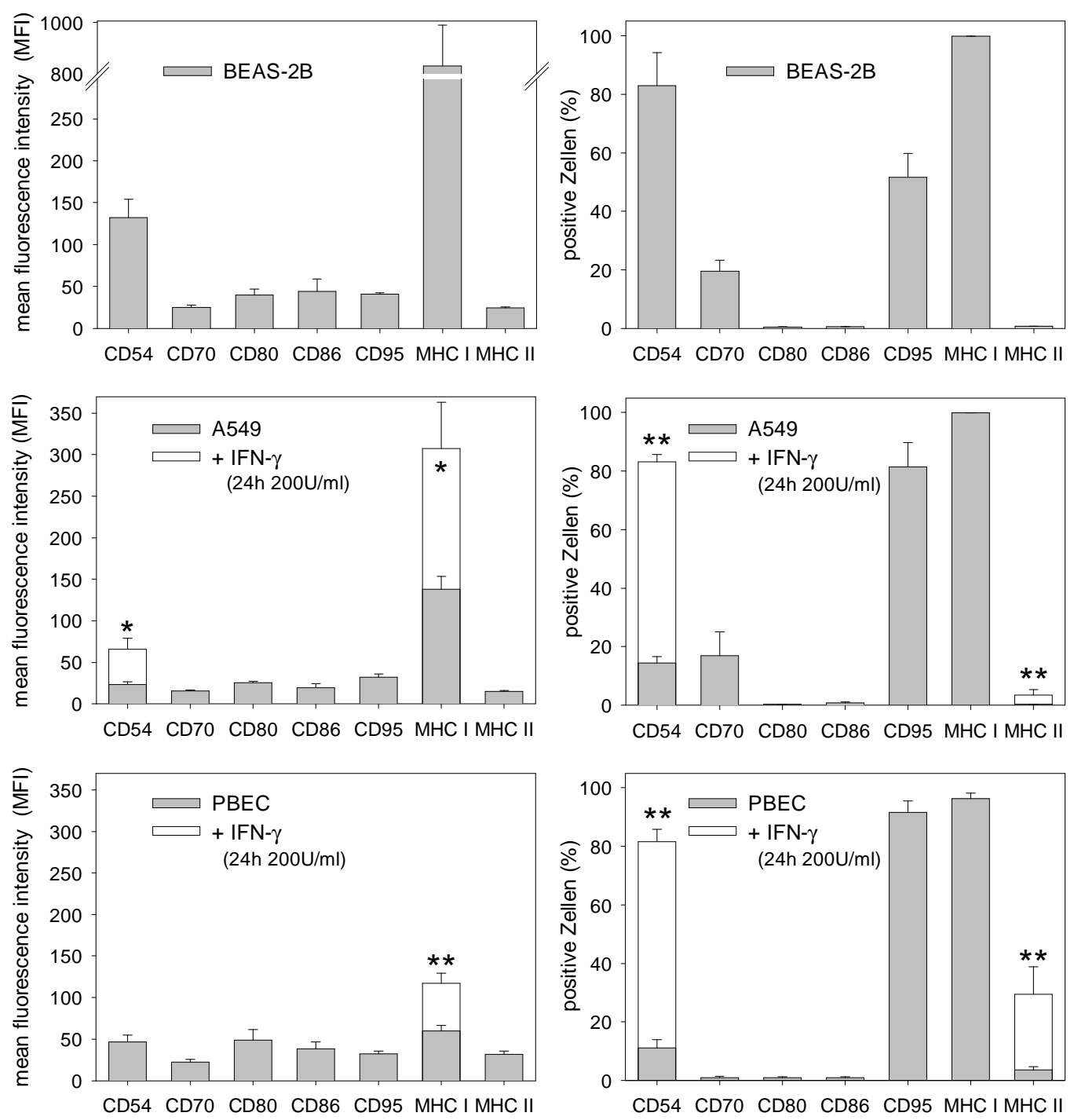

Abbildung 4.4: Expression stimulatorischer und kostimulatorischer Oberflächenmoleküle auf BEAS-2B, A549 und PBEC. Zellen der Zelllinien BEAS-2B (oben) und A549 (mitte) sowie PBEC (unten) wurden mit FITC-konjugierten Antikörpern gegen die untersuchten Oberflächenmoleküle markiert und der Anteil positiv gefärbter Zellen (rechte Reihe) sowie die mittlere Fluoreszenzintensität (linke Reihe) durchflusszytometrisch ermittelt. Eine signifikante Steigerung der Oberflächenexpression durch Vorstimulation von A549 und PBEC mit IFN- $\gamma$ ergab sich für CD54 (ICAM-1), MHC I und/oder MHC II (weiße Balken) gegenüber den basalen Zellen (graue Balken). Nicht signifikante Expressionsänderungen sind nicht dargestellt, BEAS-2B wurden nicht vorstimuliert untersucht. $* \mathrm{p}<0,05, * * \mathrm{p}<0,01$. 
die Expression von MHC I auf antigenpräsentierenden Zellen und auch eine ICAM-1Induktion auf BEAS-2B und PBEC konnte bereits nachgewiesen werden [92, 90]. Somit wäre auch eine Regulation der Expression der hier untersuchten, mit Antigenpräsentation assoziierten Oberflächenmoleküle auf den respiratorischen Epithelzellen ebenso denkbar, wie in der Folge stärkere Stimulatoreigenschaften. Tatsächlich war für A549 eine signifikante Steigerung der Anzahl ICAM-1 positiver Zellen $(\mathrm{p}<0,01)$ sowie der Dichte von ICAM-1 ( $\mathrm{p}=0,03)$ und MHC I $(\mathrm{p}=0,02)$ nachweisbar (Abbildung 4.4). Auch auf den PBEC war die Dichte von MHC I nach IFN- $\gamma$-Stimulation auf das doppelte erhöht $(\mathrm{p}<0,001)$. Ebenso nahm die Anzahl ICAM-1-positiver $(\mathrm{p}=0,003)$ und zusätzlich auch die MHC II-positiver $(\mathrm{p}=0,004)$ PBEC hochsignifikant zu. Eine proinflammatorische Vorstimulation konnte also die Rezeptorexpression und damit die Antigenität dieser Zellen erhöhen.

Diese durch proinflammatorische IFN- $\gamma$-Stimulation voraktivierten A549 bzw. PBEC wurden in der Folge in weiteren Tests eingesetzt und als A549 ${ }^{(\mathrm{IFN}-\gamma)}$ bzw. PBEC ${ }^{(\mathrm{IFN}-\gamma)}$ bezeichnet.

\subsection{Charakterisierung der isolierten $\mathrm{CD8}^{+}$ T-Zell-Population}

Die Population $\mathrm{CD}^{+}{ }^{+}$T-Zellen wurde direkt nach der Isolation aus PBMC, vor dem Einsatz in die jeweiligen Experimente auf ihre Reinheit bzw. Zusammensetzung überprüft, da möglichst wenige andere Zelltypen in den Ansätzen anwesend sein sollten. Charakterisiert nach Größe (entsprechend FSC) und Granularität (entsprechend SSC) ergaben die frisch isolierten T-Zellen eine einheitliche Population (Abbildung 4.5 oben links). Es handelte sich bei diesen frisch isolierten Zellen zu $89 \%$ ( $\pm 5 \%$ um $\mathrm{CD}^{+}{ }^{+} \mathrm{CD}^{+}$T-Zellen, mit nur $1,8 \%( \pm 1,7 \%) \mathrm{CD}^{+} \mathrm{CD}^{+}$T-Zellen und weniger als $1 \% \mathrm{CD}^{-} \mathrm{CD}^{-} 6^{+} 56^{+}$ NK-Zellen (Mittelwert \pm Standardabweichung). Damit entspricht die erreichte Reinheit der Isolation der vom Hersteller des Isolationskits (Miltenyi) angegebenen durchschnittlich erreichbaren Reinheit. Nach 7 Tagen Stimulation in Kultur unterschied sich die Population in diesen phänotypischen Eigenschaften nicht von der frisch isolierten. Im FSC-SSC-Diagramm, aufgetragen nach Größe und Granularität, ergab sich nach BEAS2B-Stimulation aber ein deutlich von der ursprünglichen Population verschiedenes Bild (Abbildung 4.5 unten links). Ein Teil der T-Zellen war größer als die frisch isolierten (weiter rechts im Diagramm), was typisch für aktivierte Lymphozyten ist. Ganz links im FSC-SSC-Diagramm ist eine ausgedehnte, verwaschene Wolke aus toten Zellen und dem 
Zellschrott der Stimulatorzellen zu sehen, der nicht in die Auswertung miteinbezogen wurde.
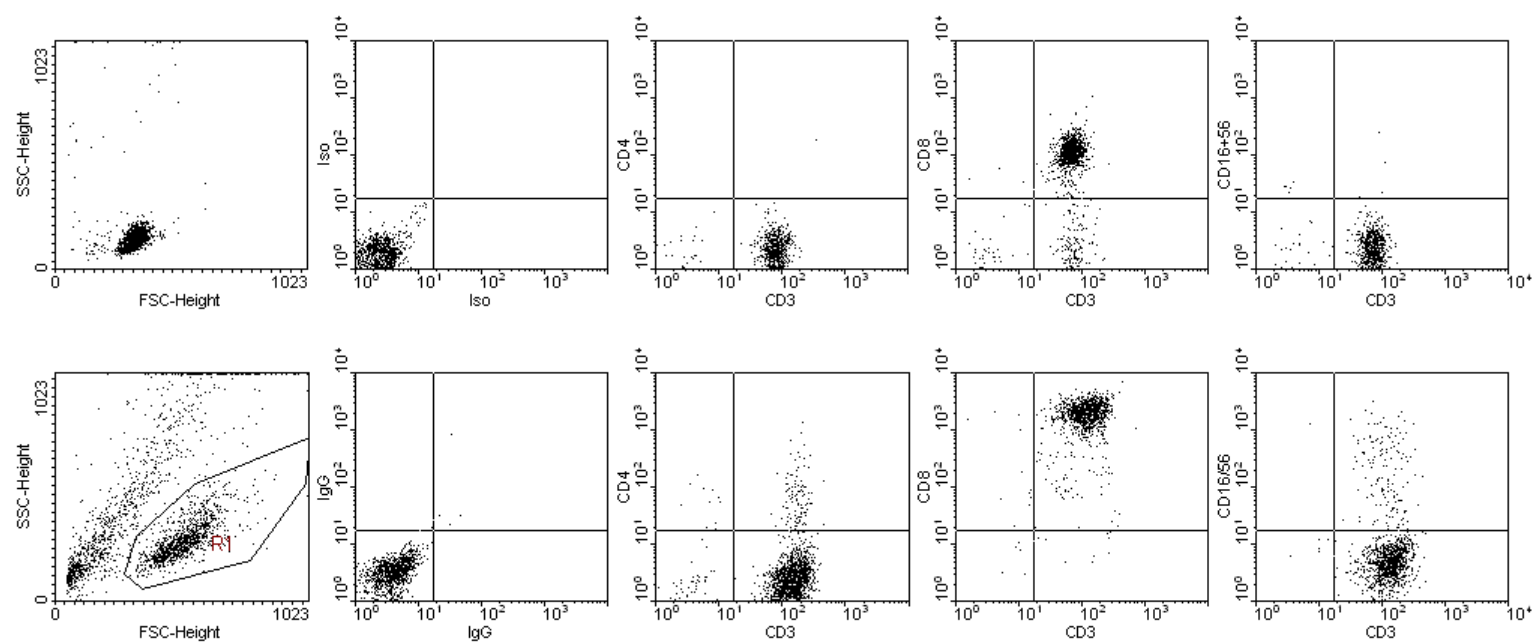

Abbildung 4.5: Phänotypische Charakterisierung der Population frisch isolierter TZellen (obere Reihe) und der Effektor-T-Zellen nach einwöchiger Stimulationsdauer (untere Reihe). Die T-Zellen wurden mit FITC- bzw. PE-konjugierten Antikörpern doppelt gefärbt und durchflusszytometrisch vermessen. Je $90 \%$ der Population war $\mathrm{CD}^{+}$, weniger als $1 \% \mathrm{CD}^{-} \mathrm{CD}^{+} 6^{+} 56^{+}$(NK-) Zellen waren enthalten.

\subsection{Allogene Aktivierung der $\mathrm{CD8}^{+} \mathrm{T}$-Zellen}

\subsubsection{IFN- $\gamma$-Produktion}

Eine der ersten (messbaren) Reaktionen in Folge einer Aktivierung von T-Zellen ist deren Produktion und Ausschüttung von IFN- $\gamma$. Im untersuchten Zellkulturmodell wurden wie beschrieben isolierte CD8 ${ }^{+}$T-Zellen mit HLA-differenten, bestrahlten Stimulatorzellen in Anwesenheit einer niedrigen Dosis IL-2 (100 U/ml) für eine Woche oder länger stimuliert. Als Kontrolle zur Ermittlung der basalen, unspezifischen Hintergrundproduktion von IFN- $\gamma$ dienten ohne Stimulatorzellen, nur in IL-2-Medium unter ansonsten denselben Bedingungen kultivierte $\mathrm{CD}^{+}$T-Zellen. Die IFN- $\gamma$-Konzentration wurde nach der Stimulationsdauer in den Überständen der Kulturen mittels ELISA bestimmt. Da die Stimulator-Epithelzellen zuvor durch Bestrahlung stoffwechselinaktiviert worden waren, sollten sie selbst nicht zum IFN- $\gamma$-Gehalt im Medium beitragen. Im Überstand einer $90 \%$ konfluenten BEAS-2B-Kultur konnten ebenfalls keine messbaren Mengen an IFN- $\gamma$ nachgewiesen werden. Im Gegensatz zu CD8 ${ }^{+}$T-Zellen, die völlig ohne Stimulantien nur 
in komplettem RPMI gehalten wurden, produzierten $\mathrm{CD}^{+}$T-Zellen während 7 Tagen in IL-2-Medium (IL-2-Kontrolle) bereits geringe IFN- $\gamma$-Mengen $(225 \pm 50 \mathrm{pg} / \mathrm{ml}$; p=0,013). BEAS-2B-stimulierte CD8 ${ }^{+}$T-Zellen sezernierten innerhalb derselben Stimulationsdauer fast viermal so viel IFN- $\gamma$ wie die CD8 ${ }^{+}$T-Zellen der IL-2-Kontrolle $(\mathrm{p}<0,001$; Abbildung 4.6). Eine Stimulierung von $\mathrm{CD}^{+}$T-Zellen mit bestrahlten A549 induzierte dagegen keine erhöhte IFN- $\gamma$-Produktion gegenüber der IL-2-Kontrolle. Ebenso waren auch bestrahlte PBEC-Stimulatoren nicht in der Lage, eine signifikante von der Kontrolle verschiedene IFN- $\gamma$-Produktion zu induzieren (Abbildung 4.6).

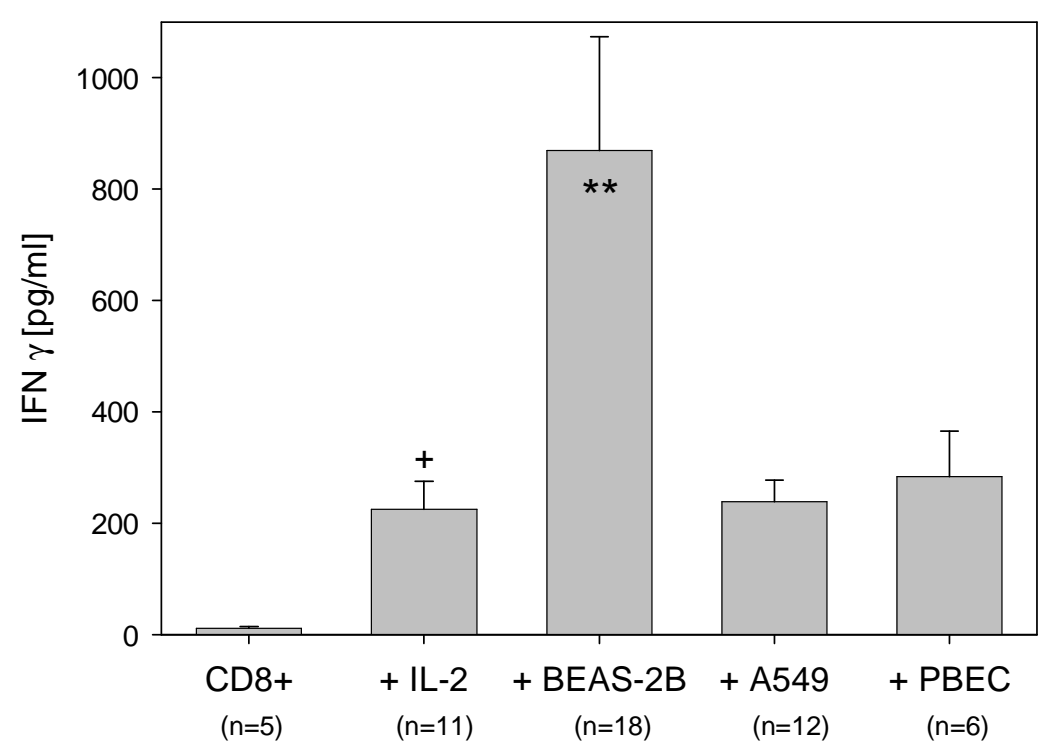

Abbildung 4.6: Produktion bzw. Ausschüttung des Zytokins IFN- $\gamma$ durch CD8 ${ }^{+}$TZellen als Zeichen ihrer Aktivierung. Die IFN- $\gamma$-Konzentration im Überstand 7-tägiger Kulturen vom $\mathrm{CD}^{+}$T-Zellen ohne oder mit dem T-Zell-Wachstumsfaktor IL-2 im Medium oder zusätzlich mit BEAS-2B-, A549- oder PBEC-Stimulatorzellen wurde mittels ELISA bestimmt. $+\mathrm{p}<0,05$ vs. CD ${ }^{+}$T-Zellen ohne IL-2, $* * \mathrm{p}<0,001$ vs. IL-2Kontrolle.

Einfluss der Stimulationsdauer auf die IFN- $\gamma$-Produktion der CD8 $^{+}$TZellen: Um zu testen, ob die gemessene IFN- $\gamma$-Produktion durch eine Restimulation noch erhöht werden kann, bzw. ob für eine messbare bzw. spezifische Aktivierung von A549 und PBEC die Stimulationsdauer von sieben Tagen lediglich zu kurz war, wurden die $\mathrm{CD}^{+}$T-Zellen im Anschluss an die erste 7-tägige Stimulationsdauer unter jeweils denselben Bedingungen für drei (oder mehr) zusätzliche Tage kultiviert.

Bereits die Restimulation der nur in IL-2-Medium und ohne Stimulatorzellen kulti- 


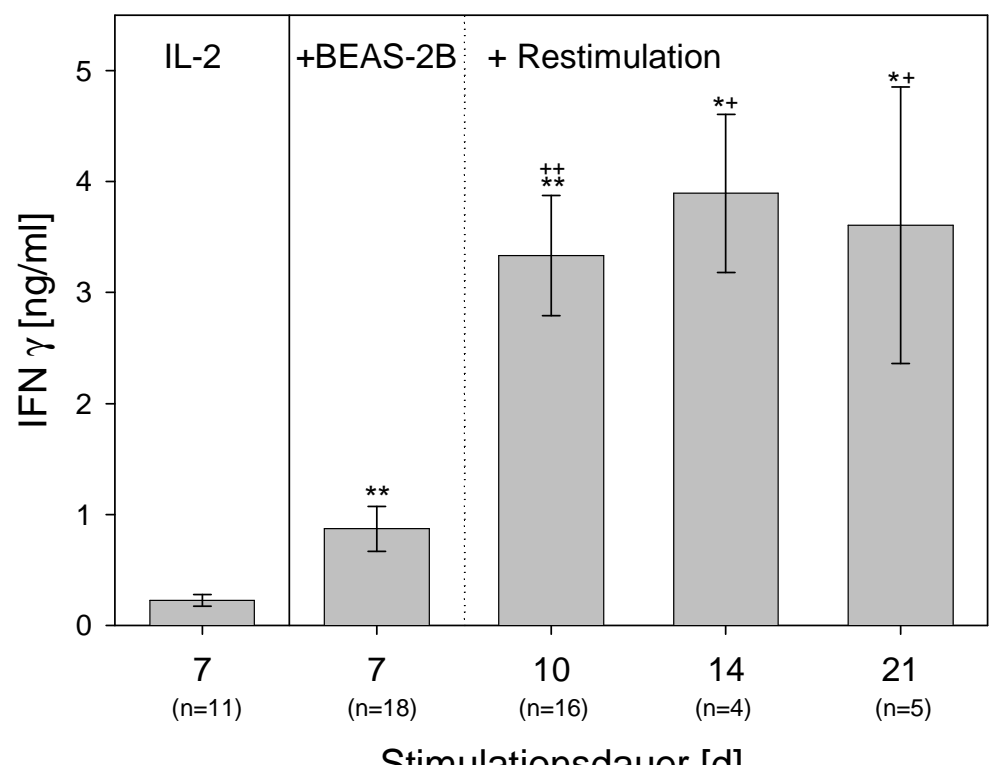

Abbildung 4.7: Ausschüttung des Zytokins IFN- $\gamma$ durch CD8 ${ }^{+}$T-Zellen nach BEAS2B-Stimulation in Abhängigkeit von der Stimulationsdauer. Die IFN- $\gamma$-Konzentration wurde im Überstand einer Kokultur aus CD8 ${ }^{+}$T-Zellen mit BEAS-2B-Stimulatorzellen nach 7 Tagen bzw. nach weiteren 3, 7 oder 14 Tagen Restimulation mittels ELISA bestimmt. Differenz vs. IL-2-Kontrolle: $* * \mathrm{p}<0,001, * \mathrm{p}<0,01$, Differenz vs. 7 Tage BEAS-2B-Stimulation: $++\mathrm{p}<0,001,+\mathrm{p}<0,01$.

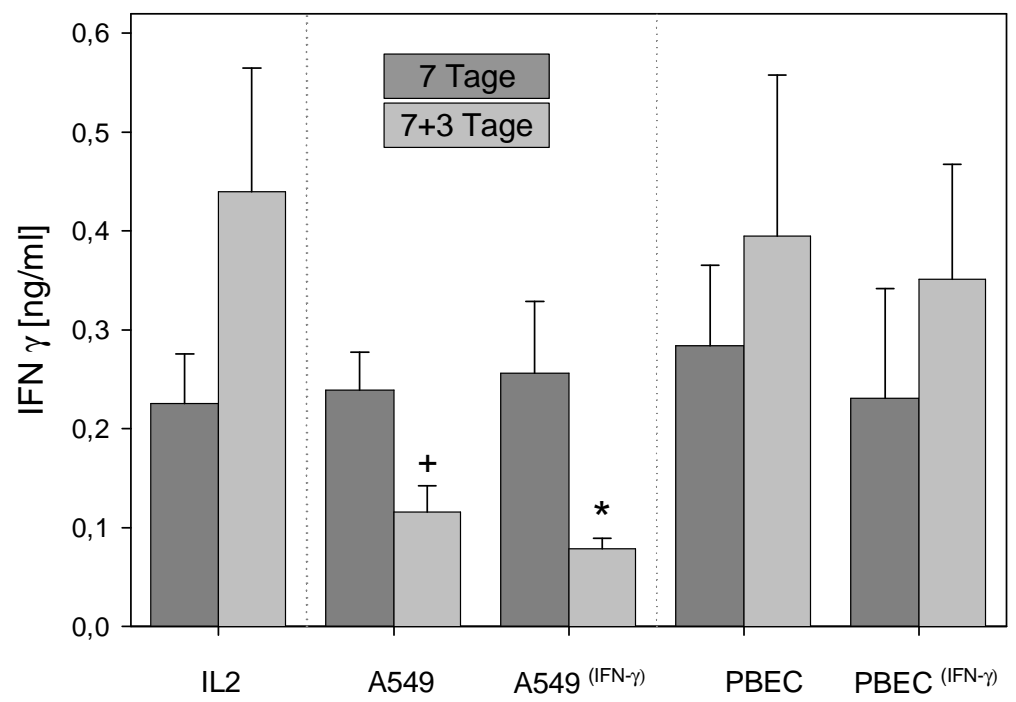

Abbildung 4.8: Ausschüttung des Zytokins IFN- $\gamma$ durch CD8 ${ }^{+}$T-Zellen nach A549bzw. PBEC-Stimulation in Abhängigkeit von Stimulationsdauer und Vorstimulation der Stimulatorzellen. Die IFN- $\gamma$-Konzentration wurde im Überstand einer Kultur aus CD8 ${ }^{+}$ T-Zellen in Il-2-Medium alleine $(n=12)$ oder mit Stimulatorzellen ohne (7 Tage) bzw. mit weiteren 3 Tagen Restimulation bestimmt. Als Stimulatorzellen dienten basale A549 $(\mathrm{n}=10)$ bzw. PBEC $(\mathrm{n}=6)$ oder entsprechende IFN- $\gamma$-vorstimulierte A549(IFN- $\gamma)$ bzw. PBEC $^{(\mathrm{IFN}-\gamma)}$. Differenz vs. IL-2-Kontrolle: $* \mathrm{p}<0,05$, Differenz vs. 7 Tage: $+\mathrm{p}<0,05$. 
vierten T-Zellen führte zu einer leichten, aber nicht signifikanten Erhöhung deren IFN$\gamma$-Ausschüttung. Die Restimulation des BEAS-2B-Ansatzes mit neuen Stimulatorzellen resultierte dagegen bereits nach zusätzlichen drei Tagen in einer starken Erhöhung der IFN- $\gamma$-Konzentration im Medium auf knapp das vierfache $(\mathrm{p}<0,001)$. Durch längere Restimulationsdauern (7 bzw. 14 Tage) konnte die IFN- $\gamma$-Produktion nicht weiter erhöht werden, blieb aber auf einem etwa gleichbleibend hohen Niveau (Abbildung 4.7). A549stimulierte $\mathrm{CD}^{+}$T-Zellen produzierten nach zusätzlicher dreitätiger Restimulation interessanterweise weniger IFN- $\gamma$ verglichen mit der einfachen 7 -tägigen Stimulationszeit $(\mathrm{p}=0,04)$, und damit sogar tendenziell, wenn auch nicht signifikant weniger als die CD8 ${ }^{+}$ T-Zellen des IL-2-Kontrollansatzes. Im Medium PBEC-stimulierter CD8 ${ }^{+}$T-Zellen war nach Restimulation mit neuen Stimulatorzellen keine Änderung der IFN- $\gamma$-Produktion messbar, sodass diese im PBEC-Ansatz auch nach Restimulation der im IL-2-Ansatz entsprach (Abbildung 4.8).

Einfluss einer IFN- $\gamma$-Vorstimulation der Stimulatorzellen auf die IFN- $\gamma$ Produktion der CD8 ${ }^{+}$T-Zellen: Wie gezeigt (Abbildung 4.4), steigerte eine IFN- $\gamma-$ Vorstimulation der respiratorischen Epithelzellen A549 und PBEC deren Oberflächenexpression von MHC I und ICAM-1 und damit potentiell auch ihre Allogenität. Diese A549 (IFN- $\gamma$-Stimulatorzellen bewirkten im Vergleich zu nicht vorstimulierten jedoch keinen Unterschied in der IFN- $\gamma$-Produktion durch CD8 ${ }^{+}$T-Zellen, weder nach sieben, noch nach $7+3$ Tagen. Der beobachtete Effekt, dass die IFN- $\gamma$-Konzentration im Medium der Kokultur nach 7+3 Tagen niedriger war als nach sieben Tagen, fiel mit A549(IFN- $\gamma)_{-}$ Stimulatorzellen allerdings etwas deutlicher aus. Damit lag die IFN- $\gamma$-Produktion der T-Zellen in diesem Ansatz mit A549 (IFN- $\gamma)$ nach $7+3$ Tagen signifikant unter der in der vergleichbaren IL-2-Kontrolle ( $\mathrm{p}=0,04)$ (Abbildung 4.8). Die IFN- $\gamma$-Vorstimulation der PBEC-Stimulatorzellen wirkte sich dagegen nicht messbar auf die durch sie induzierte IFN- $\gamma$-Freisetzung durch $\mathrm{CD}^{+}$T-Zellen aus, weder nach 7 noch nach $7+3$ Tagen Stimulationsdauer.

\subsubsection{Aktivierungsmarker-Expression}

Als eine weitere Reaktion in Folge der Aktivierung steigern $\mathrm{CD} 8^{+}$T-Zellen die Expression bestimmter Moleküle auf ihrer Zelloberfläche, sog. Aktivierungsmarker, die eine autound/oder parakrine Stimulation der Zellen ausüben bzw. verstärken können.

Durchflusszytometrisch wurde deshalb vor (naiv) und nach der Stimulationsdauer die Expression der Aktivierungsmarker CD25 (IL-2-Rezeptor), CD30, CD54 (ICAM-1), CD69, CD70, CD71, CD80, CD86, CD95 und HLA-DR gemessen. Diese Versuche konn- 
ten aufgrund mangelnder Zellzahlen nicht mit PBEC, sondern nur mit den Zelllinien durchgeführt werden. Dabei kann sich eine Expressionssteigerung sowohl darin bemerkbar machen, dass für das bestimmte Oberflächenmolekül zuvor negative Zellen dieses nach Stimulation exprimieren, wodurch die Anzahl positiver Zellen in der Population ansteigt, als auch in einer erhöhten Dichte der Moleküle auf der Oberfläche aller positiven Zellen (mean fluorescence intensity, MFI). Die alleinige Zunahme des Anteils positiver Zellen in der Population während der Stimulation kann allerdings ebenso gut nur auf einer Selektion dieser Zellen bzw. auf einem Absterben der für den Marker negativen Zellen beruhen und muss deshalb vorsichtig interpretiert werden. Die absoluten

\begin{tabular}{|l|c|c|c|c|l|}
\hline \multicolumn{6}{|l|}{ Fluoreszenzintensität } \\
\hline & naiv & IL-2 & BEAS-2B & A549 & A549 $9^{(\mathrm{IFN}-\gamma)}$ \\
\hline \hline CD25 & $30,03 \pm 6,65$ & $152,67 \pm 25,46^{* *}$ & $130,59 \pm 32,17^{* *}$ & $63,49 \pm 15,30^{* *}$ & $85,72 \pm 21,47^{*}$ \\
CD30 & $35,33 \pm 12,52$ & $61,46 \pm 9,80^{*}$ & $87,92 \pm 16,01^{*}$ & $21,97 \pm 1,59^{*}$ & $25,54 \pm 3,42^{*}$ \\
CD54 & $35,33 \pm 12,52$ & $61,46 \pm 9,80^{*}$ & $87,92 \pm 16,01^{*}$ & $21,97 \pm 1,59^{*}$ & $25,54 \pm 3,42^{*}$ \\
CD69 & $34,68 \pm 3,30$ & $89,50 \pm 12,19^{* *}$ & $78,97 \pm 15,35^{* *}$ & $26,33 \pm 4,11$ & $27,33 \pm 5,01$ \\
CD70 & $27,38 \pm 1,66$ & $122,68 \pm 33,56^{* *}$ & $135,28 \pm 14,02^{* *}$ & $21,00 \pm 1,90$ & $24,97 \pm 3,46$ \\
CD71 & $44,55 \pm 3,43$ & $310,26 \pm 26,06^{* *}$ & $625,99 \pm 188,11^{* *}$ & $32,44 \pm 5,81$ & $29,60 \pm 4,80$ \\
CD80 & $152,55 \pm 108,57$ & $66,53 \pm 12,53$ & $74,37 \pm 14,04$ & $27,06 \pm 3,44$ & $37,53 \pm 5,72^{*}$ \\
CD86 & $55,41 \pm 13,04$ & $146,36 \pm 52,40$ & $158,37 \pm 23,19^{*}$ & $34,37 \pm 8,30$ & $33,74 \pm 6,66$ \\
CD95 & $49,94 \pm 5,09$ & $81,23 \pm 17,30$ & $187,89 \pm 24,72^{* *}$ & $35,63 \pm 2,70$ & $36,76 \pm 2,80$ \\
HLA-DR & $104,11 \pm 10,38$ & $550,03 \pm 164,84^{*}$ & $1338,83 \pm 206,83^{* *}$ & $32,02 \pm 2,62$ & $33,97 \pm 4,07$ \\
\hline
\end{tabular}

\begin{tabular}{|c|c|c|c|c|c|}
\hline \multicolumn{6}{|c|}{ \%positive Zellen } \\
\hline & naiv & IL-2 & BEAS-2B & A549 & $\mathrm{A} 549^{(\mathrm{IFN}-\gamma)}$ \\
\hline CD25 & $1,04 \pm 0,09$ & $5,32 \pm 1,36^{* *}$ & $17,79 \pm 3,077^{* *}$ & $5,38 \pm 1,58 * *$ & $5,07 \pm 0,76^{* *}$ \\
\hline CD30 & $0,29 \pm 0,06$ & $1,14 \pm 0,27^{* *}$ & $2,89 \pm 0,55 * *$ & $0,85 \pm 0,24$ & $0,83 \pm 0,30$ \\
\hline CD54 & $67,18 \pm 3,14$ & $87,07 \pm 5,42 *$ & $83,35 \pm 2,47 * *$ & $92,27 \pm 2,85$ ** & $91,10 \pm 2,04 *$ \\
\hline CD69 & $10,77 \pm 6,54$ & $11,63 \pm 2,67$ & $30,33 \pm 6,79 *$ & $50,40 \pm 4,71^{* *}$ & $48,80 \pm 4,80 * *$ \\
\hline CD70 & $5,09 \pm 0,62$ & $12,94 \pm 1,21 * *$ & $24,35 \pm 4,95^{* *}$ & $12,44 \pm 2,63^{* *}$ & $12,16 \pm 1,77^{*}$ \\
\hline CD71 & $2,56 \pm 0,23$ & $8,63 \pm 2,35 *$ & $24,34 \pm 3,15^{* *}$ & $5,85 \pm 2,53$ & $3,94 \pm 0,42 *$ \\
\hline CD80 & $1,73 \pm 0,43$ & $4,52 \pm 1,10^{*}$ & $15,57 \pm 2,47^{* *}$ & $3,74 \pm 0,96$ & $5,21 \pm 0,76^{*}$ \\
\hline CD86 & $2,81 \pm 0,41$ & $4,50 \pm 1,39$ & $10,35 \pm 4,34$ & $3,26 \pm 0,91$ & $3,22 \pm 0,54$ \\
\hline CD95 & $80,63 \pm 2,70$ & $93,29 \pm 2,34^{*}$ & $93,50 \pm 1,88 * *$ & $94,89 \pm 2,50 *$ & $94,49 \pm 1,78^{*}$ \\
\hline HLA-DR & $44,61 \pm 7,17$ & $37,40 \pm 2,77^{*}$ & $41,74 \pm 7,18$ & $42,65 \pm 1,86 *$ & $35,69 \pm 3,87 *$ \\
\hline
\end{tabular}

Tabelle 4.1: Aktivierungsmarkerexpression auf $\mathrm{CD} 8^{+} \mathrm{T}$-Zellen direkt nach Isolation (naiv) und nach 7-tägiger Kultur in IL-2-Medium alleine oder mit BEAS-2B- oder A549Stimulatoren. Die CD8 ${ }^{+}$T-Zellen wurden mit spezifischen Antikörpern gegen die untersuchten Marker direkt oder indirekt fluoreszenzmarkiert, deren Fluoreszenzintensität durchflusszytometrisch gemessen und der Anteil der positiven Zellen (unten) sowie die mittlere Fluoreszenzintensität (oben) der Population daraus bestimmt. 
Messwerte von MFI und der Anzahl positiver Zellen (\%) sind basal und nach sieben Tagen Stimulationszeit für die untersuchten Zelltypen in Tabelle 4.1 zusammengefasst.

Frisch isolierte, naive CD8 ${ }^{+}$T-Zellen zeigten keine oder nur eine sehr niedrige Expression der untersuchten Oberflächenmoleküle. Nur CD54, CD95 und HLA-DR waren basal überhaupt auf über $10 \%$ der isolierten T-Zellen exprimiert. Bereits nach siebentägiger Stimulation mit IL-2 alleine stieg die Expressionsdichte von CD25, CD30, CD54, CD69, CD71 und HLA-DR auf den CD8 ${ }^{+}$T-Zellen und für alle untersuchten Aktivierungsmarker außer für CD86 zeigte sich eine signifikante, wenn auch geringe Erhöhung von entweder dem Anteil positiver Zellen oder der MFI (Tabelle 4.1). Nach der Stimulation mit bestrahlten BEAS-2B war die MFI dagegen bei allen Markern außer CD80 deutlich erhöht. Bei sieben der zehn untersuchten Marker war sogar beides, sowohl der Anteil positiver Zellen als auch die MFI der positiven Zellen signifikant gesteigert. Damit wurde die Expression aller Marker außer CD86 durch BEAS-2B-Stimulierung signifikant stärker gesteigert als durch IL-2 alleine (Abbildung 4.9). Die Expressionssteigerung der Marker CD25, CD30, CD69 und HLA-DR ist dabei besonders hervorzuheben, da sie mit Abstoßungsreaktionen bzw. allogener Aktivierung in Zusammenhang gebracht werden $[95,96,97,38,98]$.

Die Stimulierung CD8 ${ }^{+}$T-Zellen mit A549-Stimulatorzellen für 7 Tage führte zwar zu einem erhöhten Anteil CD69-positiver Zellen ( $\mathrm{p}=0,02$ vs. IL-2), diese trugen CD69 jedoch sogar in geringerer Antigendichte als nur IL-2-stimulierte T-Zellen $(p=0,01)$. Dies spricht eher dafür, dass während der Stimulationsdauer eine Selektion der CD69+ Zellen stattfindet, die Expression des Markers selbst aber nicht im eigentlichen Sinne verstärkt wurde. Ein Unterschied im Anteil positiver Zellen zu der in der IL-2-Kontrolle war darüber hinaus für keinen weiteren Marker messbar. Die Rezeptordichte auf positiven Zellen war entweder ebenso nicht verschieden oder sogar verringert gegenüber der Stimulierung nur mit Il-2 (CD30 p=0,007; CD71 p < 0,05; CD86 p < 0,001; HLA-DR $\mathrm{p} \leq$ 0,001). A549-Stimulatorzellen in Anwesenheit von IL-2 führten damit zu keiner Aktivierung von $\mathrm{CD}^{+}$T-Zellen, sondern schienen im Gegenteil die durch IL-2 bedingte Aktivierung der CD8 ${ }^{+}$T-Zellen sogar zu verringern. Diese beschriebenen Effekte konnten jedoch nur nach 7 Tagen Stimulationsdauer gemessen werden, nach Restimulation bestanden keine signifikanten Unterschiede mehr zwischen A549-stimulierten T-Zellen und IL-2-Kontrolle.

Einfluss einer Vorstimulation der Stimulatorzellen auf die Aktivierungsmarkerexpression der CD8 ${ }^{+}$T-Zellen: In der Expression von Aktivierungsmarkern auf 

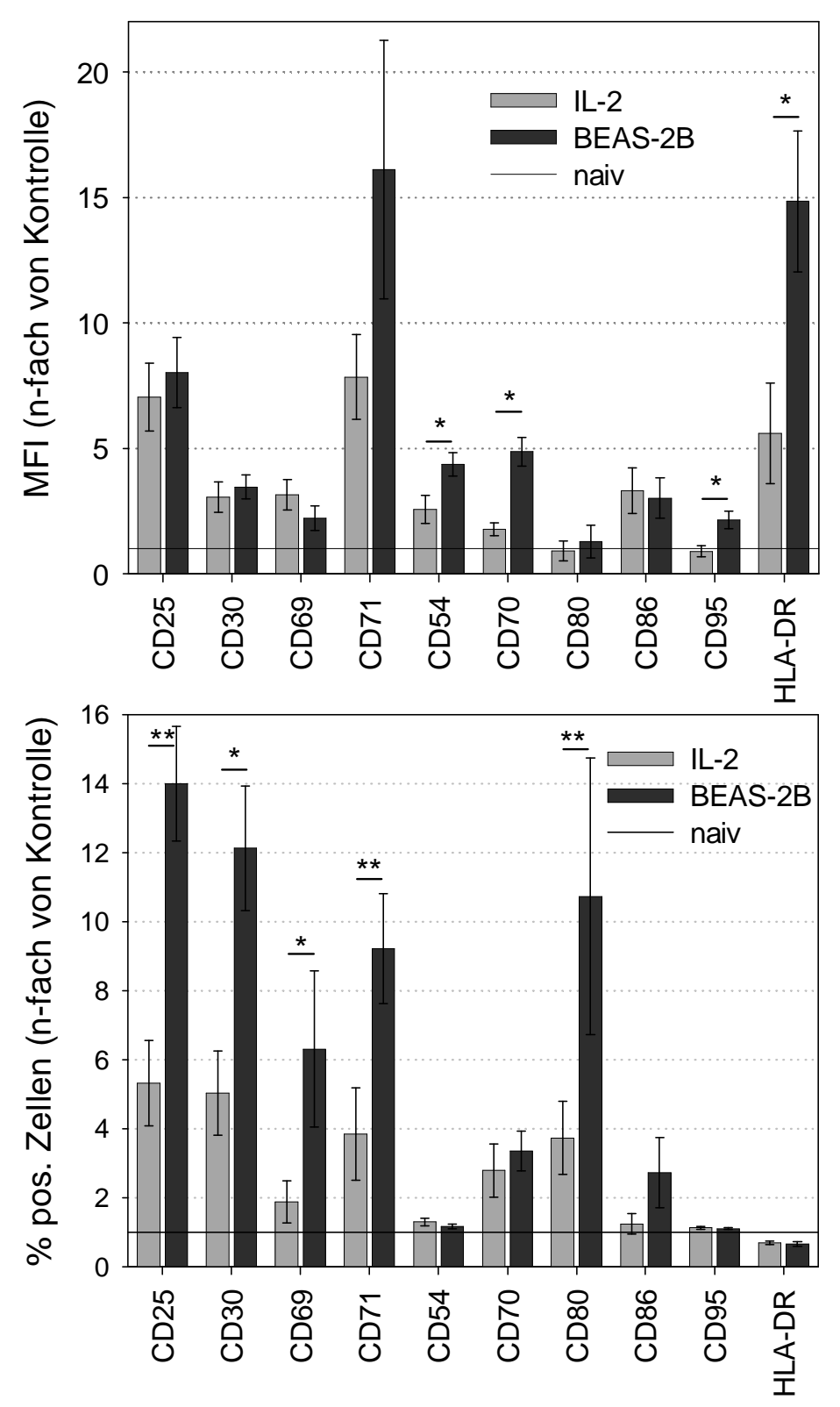

Abbildung 4.9: Regulation der Aktivierungsmarker CD25, CD30, CD69, CD70, CD71, CD54, CD80, CD86, CD95 und HLA-DR auf CD8 ${ }^{+}$T-Zellen nach IL-2- bzw. BEAS-2BStimulation. Die Anzahl positiver Zellen und die mittlere Fluoreszenzintensität der Marker wurden auf entsprechend fluoreszenzmarkierten CD8 ${ }^{+}$T-Zellen vor (naiv) und nach 7-tägiger Stimulation mit BEAS-2B bzw. IL-2 durchflusszytometrisch bestimmt und sind je als Vielfaches der Kontrolle (naive T-Zellen) dargestellt. Die absoluten Expressionswerte der naiven T-Zellen sind in Tabelle 4.1 zusammengefasst. $\mathrm{n}=7 ; * * \mathrm{p}<0,001, *$ $\mathrm{p}<0,01$. 
CD8 ${ }^{+}$T-Zellen bestand nach Kokultur mit A549(IFN- $\left.\gamma\right)$ kein signifikanter Unterschied zu den Ansätzen mit nicht vorstimulierten A549.

\subsection{Proliferation der $\mathrm{CD}^{+}{ }^{+} \mathrm{T}$-Zellen}

Wurde durch eine (Allo-)Antigenerkennung die Aktivierung erfolgreich initiiert, beginnen diese T-Zellen schließlich klonal zu expandieren, also sich zu teilen. Zur Messung dieser Proliferation in der Kultur wurden die T-Zellen vor der Aktivierungsphase mit dem Fluoreszenzfarbstoff CFSE wie beschrieben markiert und zunächst deren Ausgangsfluoreszenz einen Tag nach der CFSE-Markierung gemessen und damit gleichzeitig der Erfolg der Markierung überprüft. Alle Zellen zeigten zu diesem Zeitpunkt (d0) die für ungeteilte CFSE-markierte Zellen typische einheitlich sehr hohe Fluoreszenz, es bestand kein signifikanter Unterschied zwischen den verschiedenen Stimulierungsansätzen $(p=0,211)$ (Abbildung $4.10 \mathrm{~d} 0$ ).
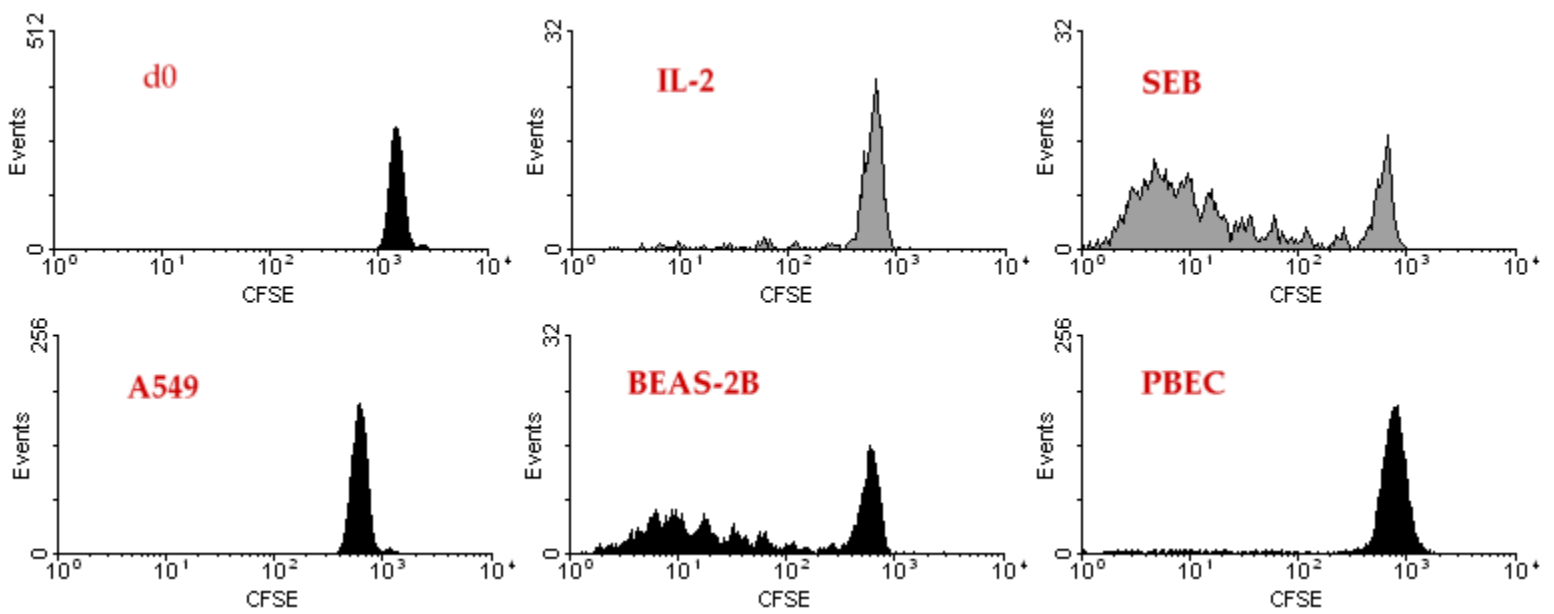

Abbildung 4.10: Proliferation CD ${ }^{+}$T-Zellen. Die Proliferation wurde mittels CFSEmarkierung der T-Zellen und anschließender durchflusszytometrischer Messung ihrer Fluoreszenzintensität bestimmt. Dargestellt sind Histogramme eines repräsentativen Versuches mit T-Zellen unmittelbar nach der CFSE-Markierung (d0) und nach 7d Stimulation nur mit IL-2, mit SEB oder mit den Stimulatorzellen A549, BEAS-2B oder PBEC.

Bei antigenunabhängiger Überstimulierung mit dem Superantigen SEB waren bereits nach drei bis vier Tagen einige Peaks jeweils geringerer, mittlerer Fluoreszenzintensität zu erkennen, d. h. die T-Zellen hatten begonnen, sich mehrfach zu teilen. Nach sieben Tagen Kultur waren bis zu mind. acht Peaks jeweils geringerer Fluoreszenz zu erkennen, von 
denen jeder für eine Generation proliferierender T-Zellen steht (Abbildung 4.10 SEB). Man kann daraus erkennen, dass während der Stimulationsdauer von sieben Tagen im Mittel insgesamt $41 \%( \pm 5,4 \%)$ der T-Zellen auf den SEB-Stimulus mit Proliferation reagierten, wobei sich am Ende der siebentägigen Stimulation die meisten dieser T-Zellen mindestens viermal geteilt hatten. Auch nach siebentägiger Kultur in IL-2-Medium alleine war bereits Proliferation messbar ( $p=0,002$ vs. Ko), die jedoch lediglich auf 2,8\% sich teilende T-Zellen zurückzuführen war (Tabelle 4.2; Abbildung 4.10 IL-2). Diese sehr geringe Proliferation muss als basale Hintergrund-Aktivierung der T-Zellen alleine durch das IL-2 betrachtet werden.

Eine Stimulierung mit bestrahlten BEAS-2B veranlasste eine große Anzahl der T-Zellen zu proliferieren, über ein Viertel hatte sich nach sieben Tagen mind. einmal geteilt $(28,4 \%( \pm 6,5 \%) ; \mathrm{p}<0,001$ vs. IL-2, Tabelle 4.2) und insgesamt waren ca. sieben bis acht Generationen erkennbar (Abbildung 4.10). Diese starke Proliferation nach BEAS-2BStimulation ist somit annähernd vergleichbar mit der nach SEB-Stimulation, was auf gute Stimulatoreigenschaften dieser bronchialen Epithelzellen hindeutet (Tabelle 4.2; Abbildung 4.11).

Zwar veranlassten auch bestrahlte A549 die T-Zellen zu proliferieren ( $\mathrm{p}=0,008$ vs. IL-2), mit gerade einmal 6,9\% $( \pm 1,5 \%)$ fiel diese Reaktion jedoch sehr niedrig aus im Gegensatz zu der mit BEAS-2B-Stimulatoren. Bestrahlte PBEC standen in ihrer Fähigkeit zur Proliferationsinduktion zwischen den Zellen der beiden untersuchten Zelllinien, sie initiierten eine Zellteilung bei $17,4 \%( \pm 2,1 \%)$ der T-Zellen (Tabelle 4.2; Abbildung 4.10 und 4.11).

\begin{tabular}{|c|c|c|c|c|}
\hline Stimulation & $7 \mathrm{~d}$ & p (vs. IL-2) & $7+3 \mathrm{~d}$ & $\mathrm{p}(\mathrm{vs} .7 \mathrm{~d})$ \\
\hline IL-2 & $2,83 \pm 0,42$ & & $5,10 \pm 1,02$ & 0,04 \\
\hline SEB & $41,03 \pm 5,36$ & $<0,001$ & $58,84 \pm 5,91$ & 0,06 \\
\hline BEAS-2B & $28,43 \pm 6,52$ & $<0,001$ & $55,81 \pm 7,24$ & 0,00 \\
\hline A 549 & $6,91 \pm 1,50$ & 0,008 & $13,24 \pm 2,45$ & 0,01 \\
\hline $\mathrm{A} 549^{(\mathrm{IFN}-\gamma)}$ & $5,00 \pm 1,16$ & 0,050 & $12,07 \pm 3,03$ & 0,03 \\
\hline PBEC & $17,42 \pm 2,14$ & $<0,001$ & $25,57 \pm 3,81$ & 0,09 \\
\hline $\mathrm{PBEC}^{(\mathrm{IFN}-\gamma)}$ & $14,30 \pm 3,12$ & $<0,001$ & $18,85 \pm 2,04$ & 0,21 \\
\hline
\end{tabular}

Tabelle 4.2: Anteile proliferierender CD8 ${ }^{+}$T-Zellen (in \%) nach 7- bzw. 7+3-tägiger Kultur in IL-2-Medium alleine, mit SEB oder den Stimulatorzellen BEAS-2B, A549 oder PBEC. Kontrolle direkt am Tag nach CFSE-Markierung (d0): 1,48 $\pm 0,16 \%$. n=7.

Einfluss der Stimulationsdauer auf die Proliferation der CD8 ${ }^{+}$T-Zellen: Auch während einer zusätzlichen dreitägigen Restimulation teilten sich die T-Zellen wei- 
terhin. In allen Ansätzen war nach dieser zusätzlichen Zeit der Anteil proliferierender T-Zellen gestiegen. Da es sich bei der gemessenen Größe allerdings um den prozentualen Anteil proliferierender Zellen handelt, kann nicht unterschieden werden, ob tatsächlich mehr Zellen proliferierten, oder ob während der Restimulationszeit nur mehr der nicht proliferierenden Zellen abgestorben sind. Der Anteil nur aufgrund des IL-2 proliferierender Zellen lag mit ca. 5,1 \% auch nach $7+3$ Tagen immer noch sehr niedrig. Die Restimulation des SEB-Ansatzes steigerte dessen Anteil proliferierender T-Zellen auf $58,8 \%$ ( $\pm 5,9 \%$ ), dieser Anstieg war jedoch nicht signifikant, möglicherweise weil die Zahl proliferierender Zellen bereits nach sieben Tagen sehr hoch war und schon alle aktivierten T-Zellen umfasste, da SEB ein sehr starkes Stimulans darstellt. Hochsignifikant fiel besonders die Steigerung der Proliferation mit BEAS-2B-Stimulatoren aus $(p=0,004)$, nach den zusätzlichen drei Tagen hatte sich die Anzahl geteilter BEAS-2B-stimulierter T-Zellen auf 55,8 \% ( $\pm 7,2 \%)$ annähernd verdoppelt. Bestrahlte A549 vermochten als ohnehin schwächere Stimulatoren die Proliferation auch nach der Restimulationszeit nur noch leicht zu steigern $(\mathrm{p}<0,05)$, vergleichbar mit IL-2-Medium alleine. Die gemessene Induktion der Proliferation durch Restimulation mit PBEC war dagegen nicht mehr signifikant. Dies ist zwar möglicherweise nur auf die geringere Stichprobengröße zurückzuführen, da ein Trend auch hier deutlich zu sehen war, ist aber erneut ein Hinweis auf das geringe Stimulatorpotential dieser Zellen zumindest im Vergleich zu BEAS-2B (Tabelle 4.2; Abbildung 4.11).

Einfluss einer IFN- $\gamma$-Vorstimulation der Stimulatorzellen auf die Proliferation der CD8 ${ }^{+}$T-Zellen: Obwohl eine erhöhte Allogenität der Stimulatorzellen durch IFN- $\gamma$-Vorstimulation nachgeweisen werden konnte (Abbildung 4.4), war kein signifikanter Unterschied in der T-Zell-Proliferation zwischen den Ansätzen mit nicht vorstimu-

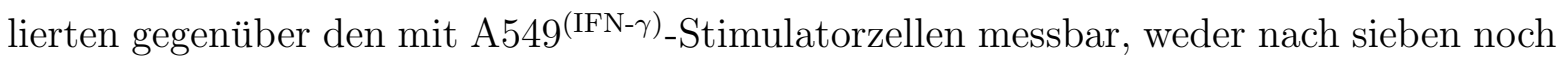
nach $7+3$ Tagen. In fast allen Einzelversuchen war dagegen sogar zumindest ein Trend zu erkennen, dass sich nach Stimulation mit A549(IFN- $\gamma)$ weniger T-Zellen teilten als mit nichtvorstimulierten. Ebenso war auch bei PBEC nach sieben Tagen der Trend zu sehen, dass die jeweiligen IFN- $\gamma$-vorstimulierten Stimulatorzellen im Gegensatz zu den unstimulierten sogar zu einer geringeren T-Zell-Proliferation führten, was sich für PBEC nach 7+3 Tagen Stimulationsdauer sogar als signifikant erwies ( $\mathrm{p}=0,037$, Abbildung 4.11).

Dieses Ergebnis ist bezüglich der T-Zell-Aktivierung vergleichbar mit der geringeren IFN- $\gamma$-Ausschüttung von T-Zellen in der Kokultur mit A549 $9^{(\mathrm{IFN}-\gamma)}$ bzw. PBEC ${ }^{(\mathrm{IFN}-\gamma)}$ gegenüber den entsprechenden nicht vorstimulierten Stimulatorzellen. Möglicherweise spielen hier Oberflächenmoleküle der Stimulatorzellen eine Rolle, deren Veränderungen 


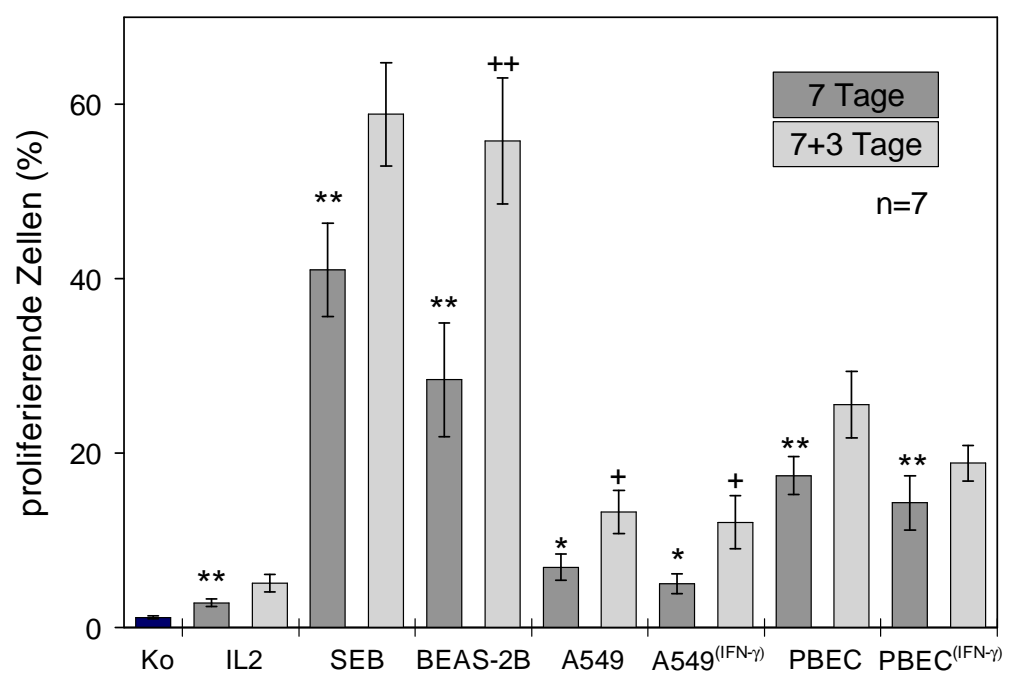

Abbildung 4.11: Anteile proliferierender T-Zellen in der Kultur am Tag nach der Markierung (Kontrolle d0: Ko) und nach 7- bzw. 7+3-tägiger Stimulation mit IL-2, SEB oder den Stimulatorzellen BEAS-2B, A549 und PBEC. Differenz vs. IL-2 (bzw. Ko): ** $\mathrm{p}<0,001, * \mathrm{p}<0,05$; Differenz vs. 7 Tage: $++\mathrm{p}<0,001,+\mathrm{p}<0,05$.

durch IFN- $\gamma$-Vorstimulation nicht erfasst wurden, die jedoch die Aktivierungsfähigkeit der Stimulatorzellen negativ beeinflussen konnten.

\subsection{Zytotoxizität aktivierter $\mathrm{CD8}^{+} \mathrm{T}$-Zellen gegen respiratorische Epithelzellen}

In den vorangehenden Experimenten hat sich bereits gezeigt, dass CD8 ${ }^{+} \mathrm{T}$-Zellen durch respiratorische Epithelzellen zur IFN- $\gamma$-Produktion (BEAS-2B und PBEC), Aktivierungsmarkerexpression und Proliferation (BEAS-2B) angeregt werden können. Ein weiteres Merkmal aktivierter CD8 ${ }^{+}$T-Zellen ist deren Zytotoxizität. Erkennt eine (allogen) aktivierte zytotoxische CD8 ${ }^{+}$T-Zelle (CTL, cytotoxic T-Lymphocyte) erneut eine Körperzelle, die dasselbe (,ihr“) (Allo-)Antigen trägt, kann sie diese abtöten. Die Frage, ob respiratorische Epithelzellen in der Lage sind, neben der bereits beschriebenen Aktivierung auch diese Zytotoxizität in CTL zu induzieren, bzw. ob die wie beschrieben allogen aktivierten CTL auch eine zytotoxische Effektorfunktion gegen die respiratorischen Epithelzellen zeigen, soll nun mit Hilfe eines funktionellen Zytotoxizitätstests, des ${ }^{51} \mathrm{Cr}$-Freisetzungstests, geklärt werden. Soweit nicht anders erwähnt, handelte es sich 
bei den angebotenen Zielzellen (Targets) stets um frische, unbehandelte Zellen desselben Typs, mit dem die CD8 ${ }^{+}$T-Zellen zuvor in der Regel über sieben Tage aktiviert wurden.

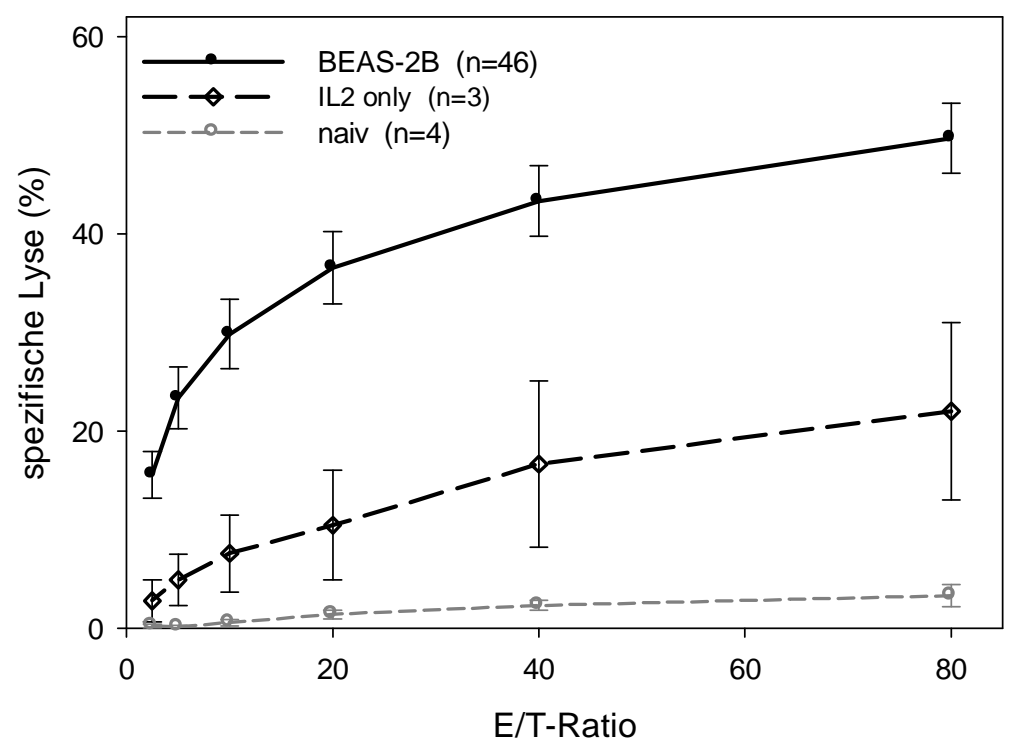

Abbildung 4.12: Lyse von BEAS-2B-Targetzellen durch stimulierte CD8 ${ }^{+}$T-Zellen. ${ }^{51}$ Cr-markierte BEAS-2B (Targets) wurden für vier Stunden mit BEAS-2B-stimulierten CTL, IL-2-stimulierten oder naiven $\mathrm{CD}^{+}{ }^{+} \mathrm{T}$-Zellen (Effektoren) kokultiviert und die spezifische Lyse der Targets über die freigesetzte Radioaktivität in Abhängigkeit vom E/T-Verhältnis bestimmt.

Innerhalb der vierstündigen Kokultur mit BEAS-2B-stimulierten CTL konnte eine hohe Lyse von BEAS-2B-Targets gemessen werden. Diese nahm in Abhängigkeit mit dem Effektor/Target (E/T)-Verhältnis zu und zeigte sich damit als spezifisch durch die CTL verursacht. Beim höchsten E/T-Verhältnis von 80:1 wurden im Mittel $50 \%$ der eingesetzten Targetzellen lysiert ( $\pm 3,5 \%$; bei $\mathrm{E} / \mathrm{T}=10$ im Mittel $30 \% \pm 3,5 \%$ ) (Abbildung 4.12). Frisch isolierte, nicht aktivierte, also naive T-Zellen waren dagegen nicht in der Lage, Zielzellen zu lysieren (Abbildung 4.12). Ohne Stimulatorzellen, also nur durch IL-2 vorstimulierte $\mathrm{CD}^{+} \mathrm{T}$-Zellen zeigten bereits eine geringe Lyse $(22 \% \pm 9 \%$ bei $\mathrm{E} / \mathrm{T}=80$; $7,6 \% \pm 3,9 \%$ bei $\mathrm{E} / \mathrm{T}=10$ ) der angebotenen BEAS-2B-Targets (Abbildung 4.12). Die BEAS-2B-Lyse durch BEAS-2B-stimulierte CTLs lag jedoch bei jedem E/T-Verhältnis deutlich über dieser unspezifischen, nur durch IL-2 bedingten Lyse $(\mathrm{p}=0,001)$.

Im Gegensatz zu BEAS-2B konnte in keinem Ansatz mit A549-stimulierten CTL eine 
Lyse von A549-Targets gemessen werden, weder nach sieben-, noch nach 7+3-tägiger Stimulationsdauer. Diese sehr geringe Lyse der A549-Targets lag damit sogar noch unter der durch die nur mit IL-2 stimulierten T-Zellen. Weder durch eine IFN- $\gamma$-Vorbehandlung der A549-Stimulatoren, noch der A549-Zielzellen konnte eine signifikante Lyse der A549 induziert werden, obwohl dadurch nachweislich deren Allogenität gesteigert worden war. Im Gegensatz war die Lyse der A549(IFN- $)$-Targets tendenziell sogar noch niedriger als die der nichtvorstimulierten Targets (Abbildung 4.13).

Da mit A549-Stimulatoren und -Targetzellen keinerlei Zytotoxizität messbar war, wurden die folgenden Experimente zunächst ausschließlich mit BEAS-2B durchgeführt. Im Anschluss sollen die mit dieser Zelllinie gefundenen Ergebnisse dann an PBEC bestätigt werden.

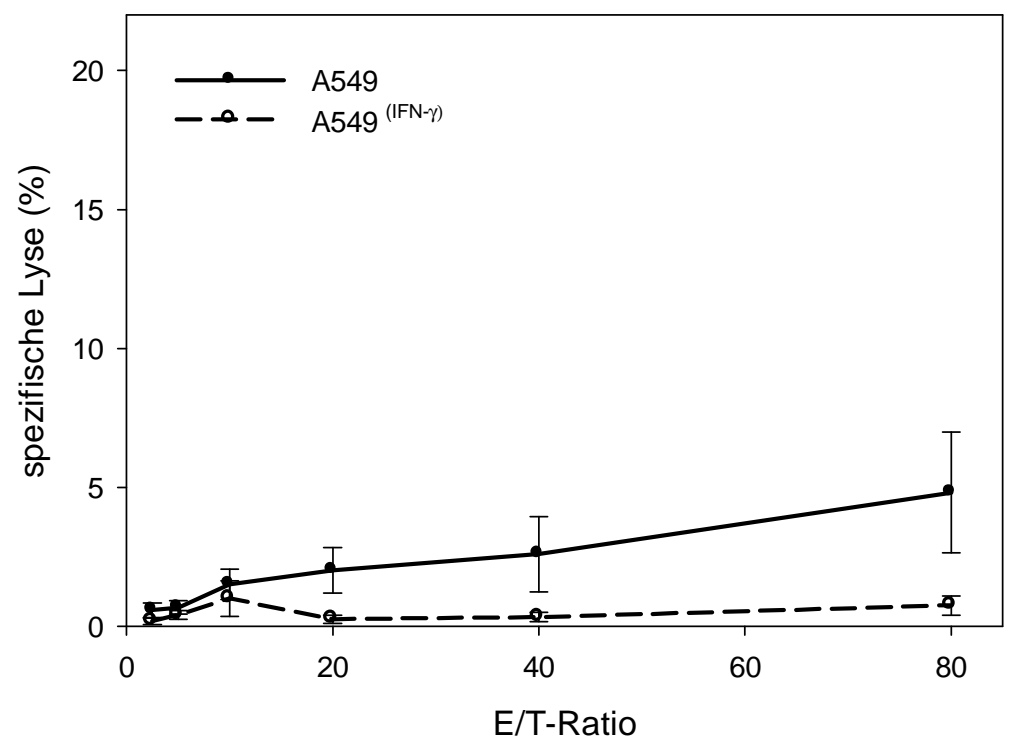

Abbildung 4.13: Lyse von A549-Targetzellen durch stimulierte CD8 ${ }^{+}$T-Zellen. ${ }^{51} \mathrm{Cr}-$ markierte A549 bzw. IFN- $\gamma$-Vorstimulierte A549 (A549(IFN- $\gamma)$ wurden als Targets für vier Stunden mit A549-stimulierten CD8 ${ }^{+}$T-Zellen (Effektoren) kokultiviert und die spezifische Lyse der Targets über die freigesetzte Radioaktivität in Abhängigkeit vom E/T-Verhältnis bestimmt. 


\subsubsection{Kontrolltargets: Bestätigung von Alloreaktivität und Target-Spezifität der Zytotoxizität aktivierter $\mathrm{CD8}^{+} \mathrm{T}$-Zellen}

Zur weiteren Kontrolle wurden den BEAS-2B-stimulierten CTLs B-Zellen (BLCL) desselben Spenders, von dem die T-Zellen stammten, also autologe Zielzellen angeboten [73]. Diese wurden erwartungsgemäß nicht lysiert. Dadurch war ausgeschlossen, dass die gemessene BEAS-2B-Lyse nur auf eine unspezifische Reaktion überaktivierter Effektoren zurückzuführen war, wie z. B. auf die Aktivität Lymphokin-aktivierter Killerzellen (LAK), die alleine durch IL-2 so aktiviert werden könnten, dass sie unspezifisch alle Targets, also auch körpereigene Zellen wie die BLCL in diesem Ansatz lysieren könnten (Abbildung 4.14).

Da die Effektorpopulation nachgewiesenermaßen zu über $90 \%$ aus CD8 ${ }^{+}$T-Zellen bestand und nur unter $1 \%$ NK-Zellen enthielt, ist die maßgebliche Beteiligung einer unspezifischen NK-Zell-Aktivität an der gemessenen Lyse von BEAS-2B bereits deshalb zumindest sehr unwahrscheinlich. Als zusätzliche Kontrolle, um eine unspezifische, NK-Zell-vermittelte Lyse auszuschließen, wurden in jedem Versuch K562, also MHC Inegative NK-Zell-Targets eingesetzt, die nur von NK-Zellen, nicht aber von klassischen CTL erkannt und lysiert werden durften. Die K562-Lyse durch BEAS-2B-aktivierte CTLs lag in allen Versuchen deutlich niedriger als die von BEAS-2B, nämlich bei 21,0 \% $\pm 2,9 \%$ bei $\mathrm{E} / \mathrm{T}=80$ bzw. bei $8,0 \% \pm 1,8 \%$ bei $\mathrm{E} / \mathrm{T}=10(\mathrm{p}=0,001$ im Mittel aus $\mathrm{n}=46$; Abbildung 4.14). Dieses Ergebnis sichert zumindest ab, dass es sich bei der messbaren BEAS-2B-Lyse nicht ausschließlich um eine Alloantigen-unspezifische Zytotoxizität von NK-Zellen, sondern zumindest überwiegend tatsächlich um eine BEAS-2B-spezifische bzw. Alloantigen-spezifische Lyse handelte.

Einfluss der Stimulationsdauer auf die Spezifität der BEAS-2B- und K562Lyse: Wie gezeigt stieg mit der Stimulationsdauer auch die IFN- $\gamma$-Produktion und Proliferation BEAS-2B-stimulierter CTLs (Abbildung 4.7 und 4.11), was auf eine stärkere Aktivierung hindeutet. Um zu untersuchen, ob eine längere Stimulationdauer auch eine höhere Spezifität der Lyse und damit verbunden eine geringere K562-Lyse induziert, wurden auch über $7+3$ Tage mit bestrahlten BEAS-2B stimulierte CD8 ${ }^{+}$T-Zellen in Zytotoxizitätsassays eingesetzt. Die BEAS-2B-Lyse erhöhte sich nur leicht (ns.) mit der Stimulationsdauer, während die K562-Lyse nur minimal niedriger wurde (ns.). Ein Experiment, bei dem je nach 7 und nach 7+3 Tagen aus dem selben Ansatz heraus eine Messung erfolgte, ist in Abbildung 4.15 dargestellt, die Lysewerte aus mehreren unabhängigen Experimenten zeigten keine signifikanten Unterschiede. Diese Tendenz 


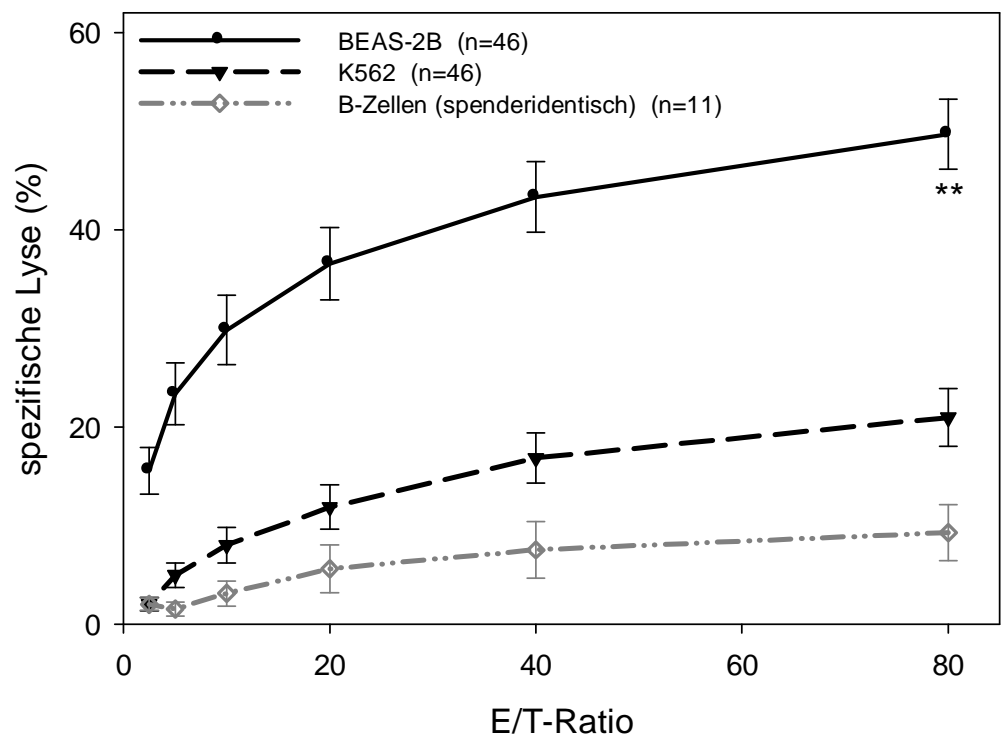

Abbildung 4.14: Spezifische lytische Aktivität BEAS-2B-aktivierter CTL gegen BEAS2B-, K562- bzw. körpereigene (B-) Targetzellen des T-Zell-Spenders. ${ }^{51}$ Cr-markierte Targetzellen wurden für vier Stunden mit BEAS-2B-stimulierten CTL (Effektoren) kokultiviert und die spezifische Lyse der verschiedenen Targets über die freigesetzte Radioaktivität in Abhängigkeit vom E/T-Verhältnis bestimmt.

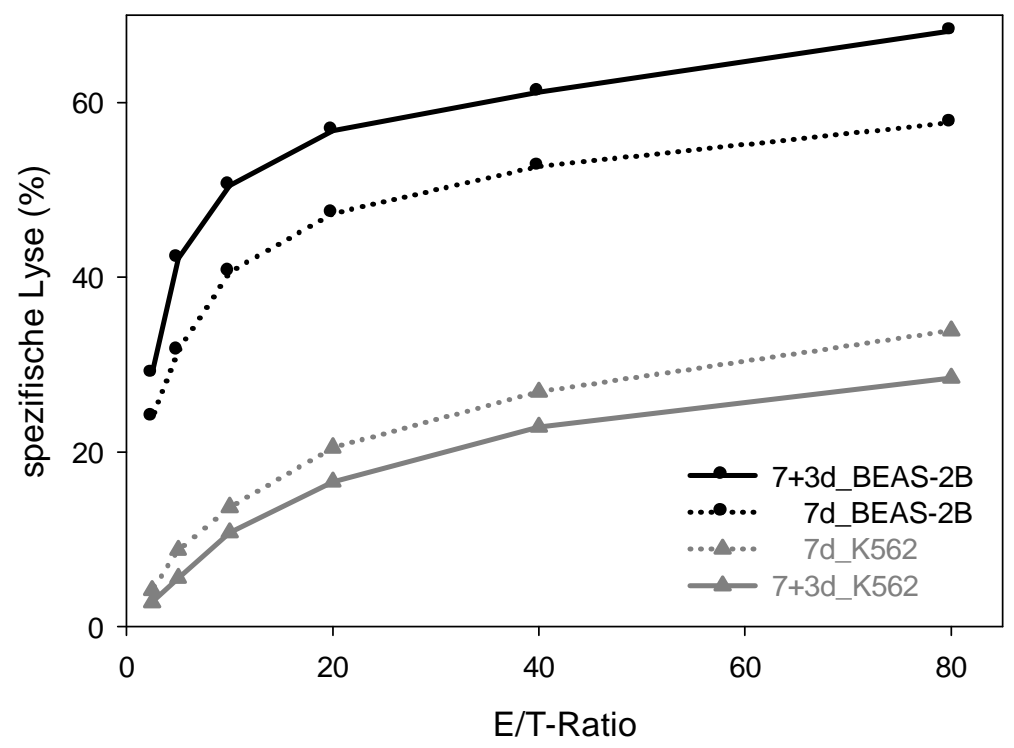

Abbildung 4.15: BEAS-2B- und K562-Lyse in Abhängigkeit von der Stimulationsdauer. ${ }^{51}$ Cr-markierte Targets (BEAS-2B oder K562) wurden mit BEAS-2B-aktivierten CTL (Effektoren) nach einer Stimulationsdauer von 7 bzw. $7+3$ Tagen kokultiviert. Die spezifische Lyse der Targets wurde über die freigesetzte Radioaktivität in Abhängigkeit vom E/T-Verhältnis bestimmt. Dargestellt ist das Ergebnis eines Experiments, bei dem die Messungen zu beiden Zeitpunkten im selben Ansatz erfolgten. Die Lyseergebnisse aus mehreren (unabhängigen) Experimenten zeigten keine signifikanten Unterschiede. 
spricht zwar dafür, dass die Reaktion nach längerer Stimulationsdauer tatsächlich spezifischer werden könnte, da der gefundene Effekt aber sehr klein und nicht statistisch abgesichert war, und da zusätzlich längere Stimulationsdauern von mehreren Wochen nicht praktikabel waren, u.a. auch deshalb, weil eine mehrwöchige Stimulation oftmals nur wenige oder keine $\mathrm{CD} 8^{+} \mathrm{T}$-Zellen überlebten, wurden die Versuche in der Regel mit 7- oder wenn möglich maximal 7+3-tägiger Stimulationsdauer durchgeführt.

\subsubsection{Cold-Target-Inhibition: Bestätigung der Target-Spezifität der Zytotoxizität aktivierter CD8 ${ }^{+}$T-Zellen}

Wie gezeigt, wurden in den Zytotoxizitätsassays in geringem und sehr unterschiedlichem Ausmaß (bis $53 \%$ bei $\mathrm{E} / \mathrm{T}=80$; bis $27 \%$ bei $\mathrm{E} / \mathrm{T}=10$ ) auch K562-Zellen von BEAS-2B-stimulierten CTL lysiert. Um diese messbare K562-Lyse weiter charakterisieren zu können, insbesondere um zu testen, ob die beiden Target-Zelltypen (BEAS-2B und K562) von ein und denselben Zellen innerhalb der Effektorpopulation getötet werden, oder ob während der Aktivierungsphase eine Mischung unterschiedlicher Effektorzellen generiert wurde, von denen die einen BEAS-2B und die andern K562 als Targets erkennen und lysieren, wurden hier sog. "Cold-Target-Inhibition-Assays" angeschlossen. Bei festem E/T-Vehältnis von 1:10 wurden in zunehmender Konzentration unmarkierte (=cold) Targetzellen als Kompetitoren zusätzlich zu den markierten (=hot) Targets in den 4h-51Cr-Release Assay eingesetzt. Als Kontrolle eingesetzte unmarkierte BEAS-2BZellen verringerten dabei die Lyse von markierten BEAS-2B-Targtes erwartungsgemäß. Die gleichzeitige Anwesenheit von (unmarkierten) K562-Zellen im Assay hatte jedoch keinen Einfluss auf die Höhe der Lyse der BEAS-2B-Targets, die unverändert blieb (Abbildung 4.16).

Dieses Ergebnis ließ entweder den Schluss zu, dass es sich um eine gemischte Population von Effektoren handelte, die jeweils nur eines der beiden gleichzeitig angebotenen Targets lysierten, oder ein und dieselben Effektoren lysierten beide Zelltypen mit unterschiedlicher Affinität. Um dies zu klären, wurden die Cold-Target-Inhibition-Assays im Folgenden bei ansonsten gleichen Bedingungen „umgekehrt" angeschlossen, also unmarkierte BEAS-2B zusätzlich zu markierten K562 in den Assay eingesetzt. Die Anwesenheit dieser unmarkierten BEAS-2B-Kompetitoren hatte einen hemmenden Einfluss auf die K562-Lyse, in gleicher Weise wie diese erwartungsgemäß auch durch zusätzlich anwesende unmarkierte K562-Zellen verringert werden konnte (Abbildung 4.16). Das zeigt, dass K562-Zellen von BEAS-2B-aktivierten CTL nur dann lysiert werden konnten, wenn 


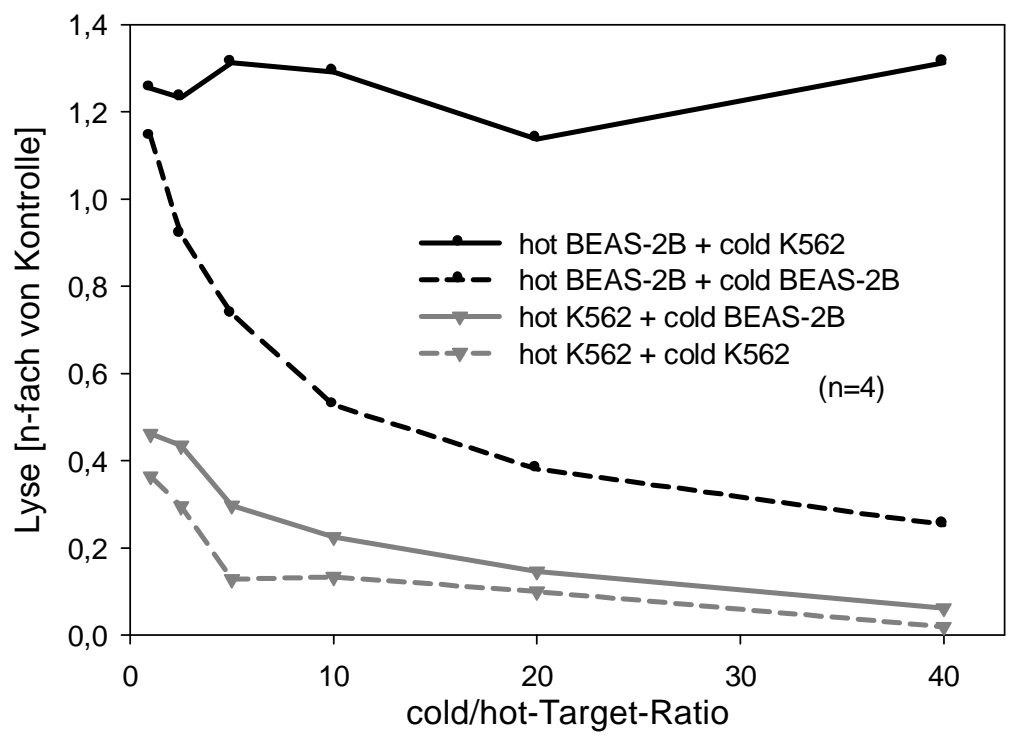

Abbildung 4.16: Cold-Target-Inhibition: Lyse von BEAS-2B und K562 durch BEAS2B-stimulierte CTL bei gleichzeitiger Anwesenheit beider Targets. BEAS-2B-stimulierte CTL (Effektoren) wurden mit festem E/T-Verhältnis für vier Stunden gleichzeitig mit ${ }^{51}$ Cr-markierten (hot) BEAS-2B und nicht ${ }^{51}$ Cr-markierten (cold) K562 (bzw. umgekehrt) kokultiviert und die spezifische Lyse der jeweils ${ }^{51}$ Cr-markierten Targets über die freigesetzte Radioaktivität in Abhängigkeit vom cold/hot-Verhältnis bestimmt.

sie alleine als einziges Target zur Verfügung standen. Sobald aber gleichzeitig BEAS-2B anwesend waren, wurden nur diese als Target erkannt und mit hoher Affinität spezifisch lysiert. Es handelte sich bei den Effektoren also um eine einheitliche Population, deren Zellen BEAS-2B mit höherer Affinität und Spezifität lysierten als K562. Neben einer NKZell-Aktivität der BEAS-2B-stimulierten CTL konnten damit auch weitere unspezifische lytische Aktivitäten bzw. Effektoren ausgeschlossen werden, durch die MHC I-negative Targetzellen erkannt und lysiert worden wären, wie z. B. eine LAK-Aktivität.

\subsection{Mechanismus der Lyse von BEAS-2B}

Um den der Lyse von BEAS-2B zugrunde liegenden Mechanismus aufzudecken, wurden zunächst die drei klassischen Systeme untersucht, durch die klassische CD8 ${ }^{+}$CTL eine Zytotoxizität vermitteln können: Perforin/Granzym B, FAS/FAS-Ligand und TNF. 


\subsubsection{Granzym B oder FAS/FAS-Ligand?}

Perforin und Granzym sind lösliche Enzyme, die zwar gezielt in die Richtung einer erkannten Zielzelle sezerniert werden, um diese abzutöten, trotzdem aber und gerade auch weil sie über den Extrazellularraum wirken, in zellfreien Mediumüberständen nachweisbar sind. Mittels ELISA konnte in den Überständen einer vierstündigen, zum Zytotoxizitätsassay analogen, nicht radioaktiven Kokultur Granzym B in signifikanten Konzentrationen gemessen werden (Abbildung 4.17). Die Granzym B-Konzentration nahm mit dem E/T-Verhältnis und damit mit der gleichzeitig messbaren Lyse zu, wobei im Überstand einer Kultur aus jeweils nur alloaktivierten CTL (entspricht E/T=0 in Abbildung 4.17) ebenso wie aus nur BEAS-2B alleine (nicht dargestellt) kein Granzym B nachweisbar war.

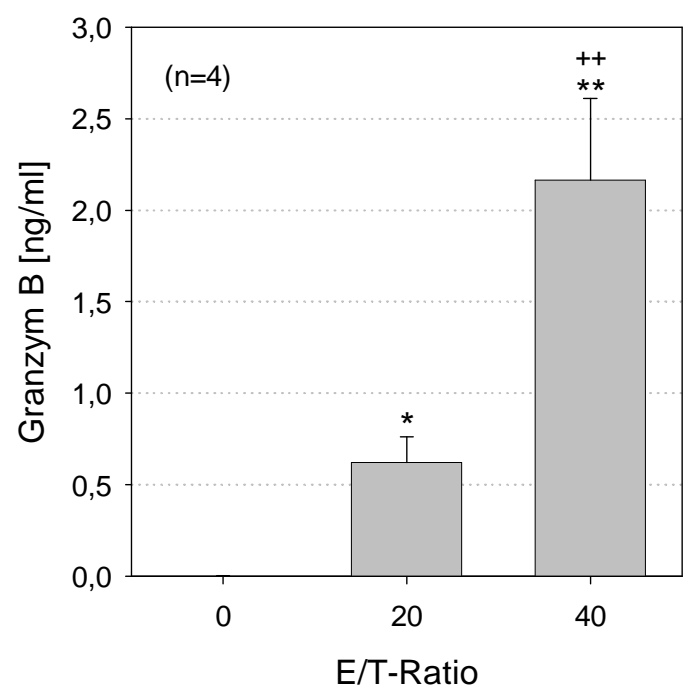

Abbildung 4.17: Granzym B-Ausschüttung während einer vierstündigen Kokultur aus BEAS-2B-Targets und BEAS-2B-aktivierten CTL (Effektoren) bei E/T-Verhältnissen von 40 und 20 bzw. einer vierstündigen Kultur von BEAS-2B-aktivierten CTL alleine ohne Targets (entspricht $\mathrm{E} / \mathrm{T}=0$ ). Die Granzym B-Konzentration wurde im Überstand der Kultur mittels ELISA bestimmt.

Der Einfluss eines durch FAS/FAS-Ligand vermittelten Todessignals auf die Lyse von BEAS-2B wurde im funktionalen Zytotoxozitätsassay mit Hilfe des blockierenden antiCD95-Antikörpers ZB4 untersucht [99]. Durch Präinkubation der Targtes mit dem Antikörper direkt vor dem Einsatz (und bei anschließend andauernder Anwesenheit des Antikörpers während des Tests) wurde die BEAS-2B-Lyse nicht vermindert, d. h. blockiert, 
gegenüber der Kontrolle ohne den Antikörper (Abbildung 4.18 links). Ebenso verringerte auch die Präinkubation der Targets mit einem blockierenden anti-TNF-Antikörper die Lyse von BEAS-2B nicht (Abbildung 4.18 rechts).

Im Zusammenhang mit der deutlich messbaren Granzym B-Ausschüttung während der Kokultur ist also davon auszugehen, dass die gemessene Lyse von BEAS-2B nicht über FAS-FAS-Ligand- oder z. B. alternative, TNF-vermittelte Apoptosesignale, sondern über den Perforin/Granzym B-Mechanismus vermittelt wurde.
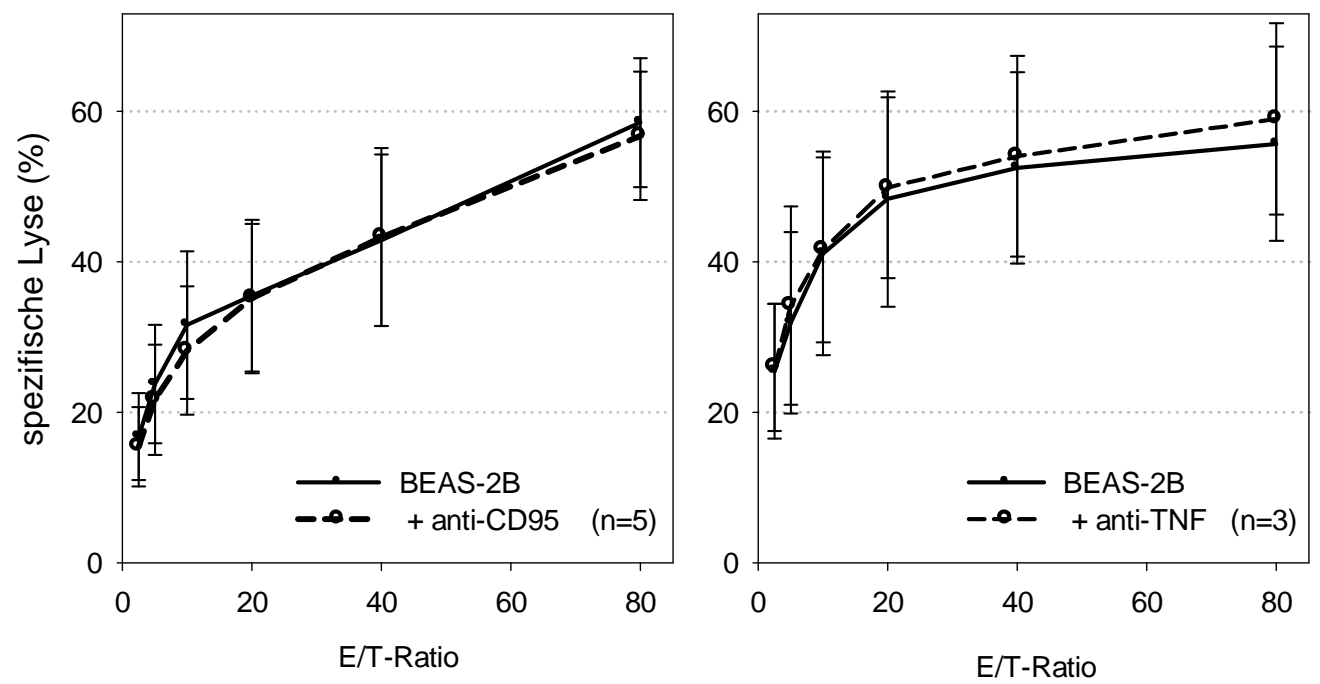

Abbildung 4.18: Einfluss eines durch FAS (CD95, links) oder TNF (rechts) vermittelten Apoptosesignals auf die BEAS-2B-Lyse. ${ }^{51}$ Cr-markierte BEAS-2B (Targets) wurden entweder nach Präinkubation mit einem anti-CD95- oder anti-TNF-Antikörper oder direkt für vier Stunden mit BEAS-2B-stimulierten CTL (Effektoren) kokultiviert und die spezifische Lyse über die freigesetzte Radioaktivität in Abhängigkeit vom E/T-Verhältnis bestimmt.

\subsubsection{Einfluss von MHC I auf die Lyse von BEAS-2B}

Der Zerstörung einer Zielzelle durch eine klassische $\mathrm{CD}^{+}{ }^{+}$zytotoxische T-Zellen geht klassischerweise zunächst die Erkennung ihrer Zielzelle über den spezifischen MHCKomplex voran. Der Einfluss dieses Prozesses bei der Lyse von BEAS-2B-Targets wurde durch die Blockade von MHC I durch Vorinkubation der Zielzellen mit anti-MHC IAntikörper und anschließender Anwesenheit des Antikörpers im Zytotoxizitätsassay untersucht. Anti-MHC I hatte in den Assays jedoch keinen Einfluss auf die Höhe der Lyse 
von BEAS-2B durch alloaktivierte CTL (Abbildung 4.19). Die Wirkung des eingesetzten W6/32-Antikörpers und seine blockierenden Eigenschaften wurden bereits in zahlreichen Versuchen und Veröffentlichungen beschrieben und nachgewiesen (z. B. [100, 101, 102]). Auch bindet der Antikörper an die BEAS-2B-Zellen, wie zuvor durchflusszytometrisch bestätigt werden konnte (Abbildung 4.4). Zusätzlich wurde jede in den Versuchen eingesetzte Charge des Antikörpers auch in parallelen Versuchen mit der Endothelzelllinie HMEC eingesetzt. Deren Lyse wurde, wie bei Eissner et al. [73] beschrieben, durch die den W6/32-Antikörper gehemmt, so dass jeweils erneut die blockierende Wirkung der eingesetzten Chargen des W6/32-Antikörpers bestätigt war (Abbildung 4.19).
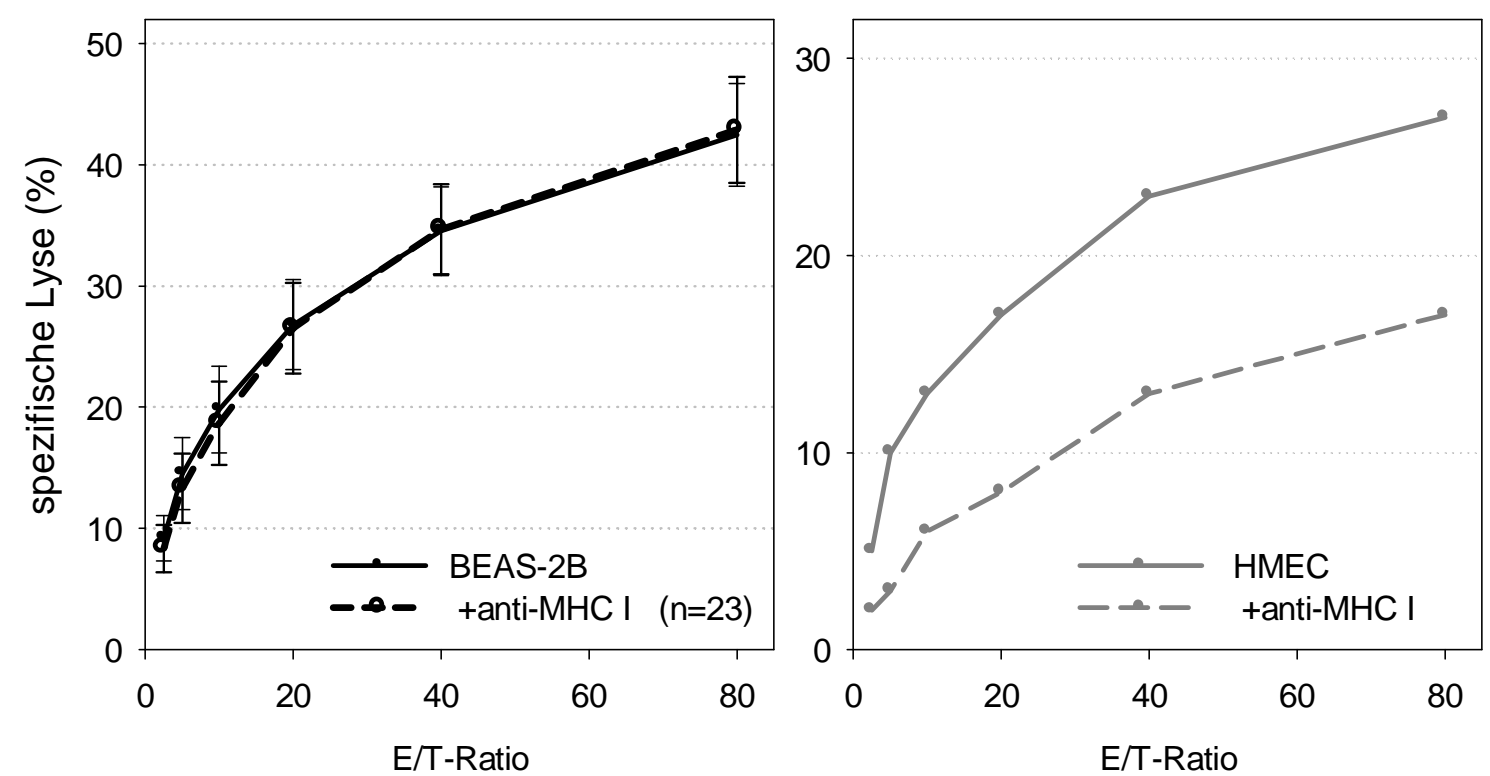

Abbildung 4.19: Einfluss von MHC I auf die BEAS-2B-Lyse (links). ${ }^{51} \mathrm{Cr}$-markierte BEAS-2B (Targets) wurden entweder nach Präinkubation mit einem anti-MHC IAntikörper (W6/32) oder direkt für vier Stunden mit BEAS-2B-stimulierten CTL (Effektoren) kokultiviert und die spezifische Lyse über die freigesetzte Radioaktivität in Abhängigkeit vom E/T-Verhältnis bestimmt. Rechts: Ein repräsentatives Kontrollexperiment mit HMEC als Stimulator- und Targetzellen bei ansonsten analoger Durchführung. Präinkubation mit dem anti-MHC I-Antikörper (W6/32) hemmt bei diesen Zellen die Targetlyse deutlich. 


\subsubsection{Einfluss von NKG2D und dessen Liganden auf die BEAS-2B-Lyse}

Aufgrund des vorherigen Ergebnisses, dass die Lyse der durch BEAS-2B-Stimulatoren generierten Effektoren, die aufgrund von Phänotyp, Zytokinexpression und Proliferation sowie ihrer Granzym B-vermittelten lytischen Aktivität klassischen CD8 ${ }^{+}$CTL entsprachen, nicht durch MHC I-Blockade beeinflussbar war, wurde nach alternativen Mechanismen gesucht und das Augenmerk im Folgenden auf NKG2D gerichtet, das zunächst als aktivierender Rezeptor auf NK-Zellen beschrieben worden war, aber auch auf überwiegend $\mathrm{CD}^{+} \mathrm{T}$-Zellen nachgewiesen ist.

Die Expression von NKG2D konnte sowohl auf den naiven, frisch isolierten CD8 ${ }^{+}$ T-Zellen (Abbildung 4.20) als auch auf BEAS-2B-aktivierten CTL nachgewiesen werden. Während der siebentägigen Stimulationsdauer wurde die Expressionsdichte von NKG2D auf den $\mathrm{CD}^{+}{ }^{+}$T-Zellen zudem hochreguliert $(\mathrm{p}<0,01, \mathrm{n}=5$; von MFI $40 \pm 6$ auf $97 \pm 19$; Abbildung 4.21), wie auch von Verneris et al. [67] bereits gezeigt werden konnte.

Ebenso konnten auf BEAS-2B zwei der Liganden von NKG2D, MIC A und B, durchflusszytometrisch nachgewiesen werden (Abbildung 4.22). Demzufolge wurde anschließend der Einfluss dieses alternativen Lysemechanismus durch die Blockade der NKG2DMIC-Interaktion untersucht.

Eine Inkubation der CTL-Effektoren mit anti-NKG2D-Antikörper unmittelbar vor deren Einsatz in den Zytotoxizitätsassay führte zu einer signifikanten Verringerung der BEAS-2B-Lyse bei jedem E/T-Verhältnis, bei $\mathrm{E} / \mathrm{T}=20 \mathrm{im}$ Mittel insgesamt um ca. $30 \%$ gegenüber der Isotyp-Kontrolle, die keinen Einfluss auf die Höhe der Lyse hatte $(\mathrm{p}=0,017$; Abbildung 4.23). Ebenso wurde auch die K562-Lyse durch den Einsatz des anti-NKG2D-Antikörpers reduziert (um gut $30 \%$ bei $\mathrm{E} / \mathrm{T}=20 ; \mathrm{p}=0,005$ gegenüber der Isotyp-Kontrolle).

Dies ist zwar keine komplette Blockade, auch wenn man ohnehin keine 100 \%ige Blockade erwarten kann, da nie an alle Epitope auf der Zelloberfläche während der gesamten vierstündigen Kokultlur Antikörper gebunden sein können (Internalisation). Der eingesetzte Antikörper kann laut Hersteller allerdings auch aktivierend wirken. Sofern diese beiden Funktionen gleichzeitig auftreten, könnte ein Teil des (z. B. vor allem anfänglich auftretenden) blockierenden Effektes von einer gleichzeitig stattfindenden Aktivierung wieder aufgehoben bzw. überdeckt werden. 


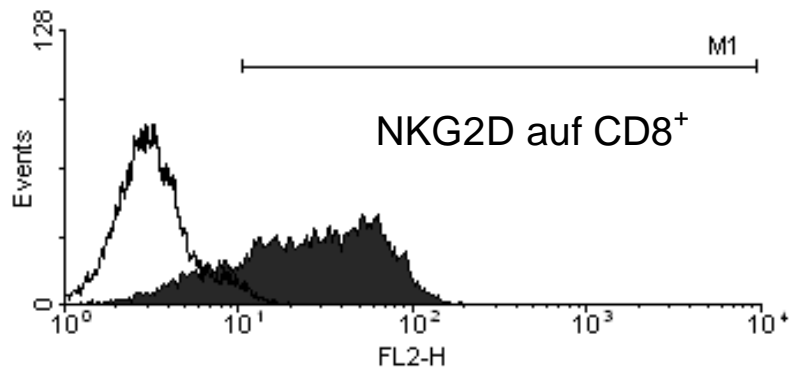

Abbildung 4.20: NKG2D-Expression auf CD8 ${ }^{+}$T-Zellen. CD8 ${ }^{+}$T-Zellen wurden mit PE-konjugiertem anti-NKG2D-Antikörper markiert und die Fluoreszenz durchflusszytometrisch gemessen. Dargestellt ist ein repräsentatives Histogramm; $n=5$.

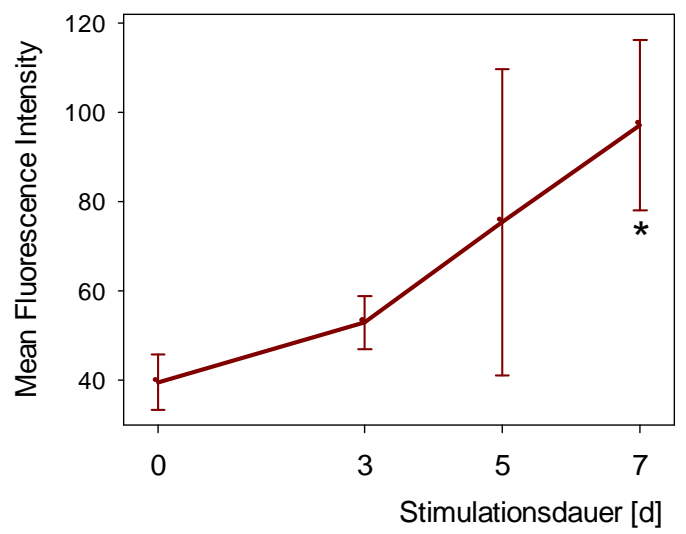

Abbildung 4.21: Regulation der NKG2D-Expression auf CD8 ${ }^{+}$T-Zellen während der siebentägigen Kokultur mit BEAS-2B-Stimulatoren. Die T-Zellen wurden mit PE-konjugiertem anti-NKG2D-Antikörper markiert und die Fluoreszenzintensität der positiven Zellen durchflusszytometrisch gemessen; $\mathrm{n}=5$.

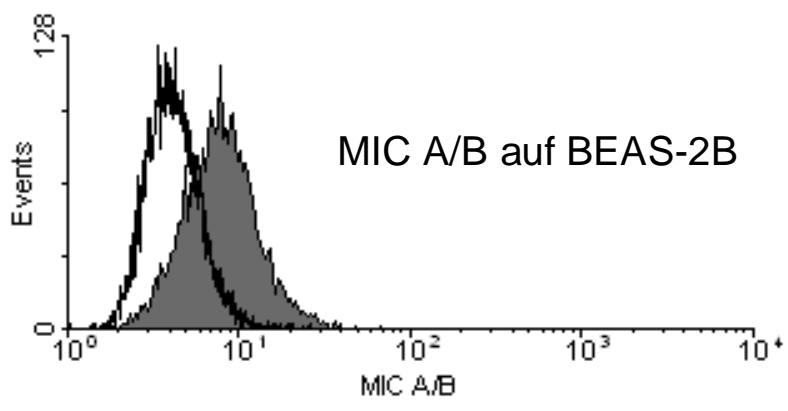

Abbildung 4.22: MIC A/B-Expression auf BEAS-2B. BEAS-2B wurden mit anti-MIC A/B-Antikörper FITC-markiert und die Fluoreszenz durchflusszytometrisch gemessen. Dargestellt ist ein repräsentatives Histogramm; $\mathrm{n}=5$. 


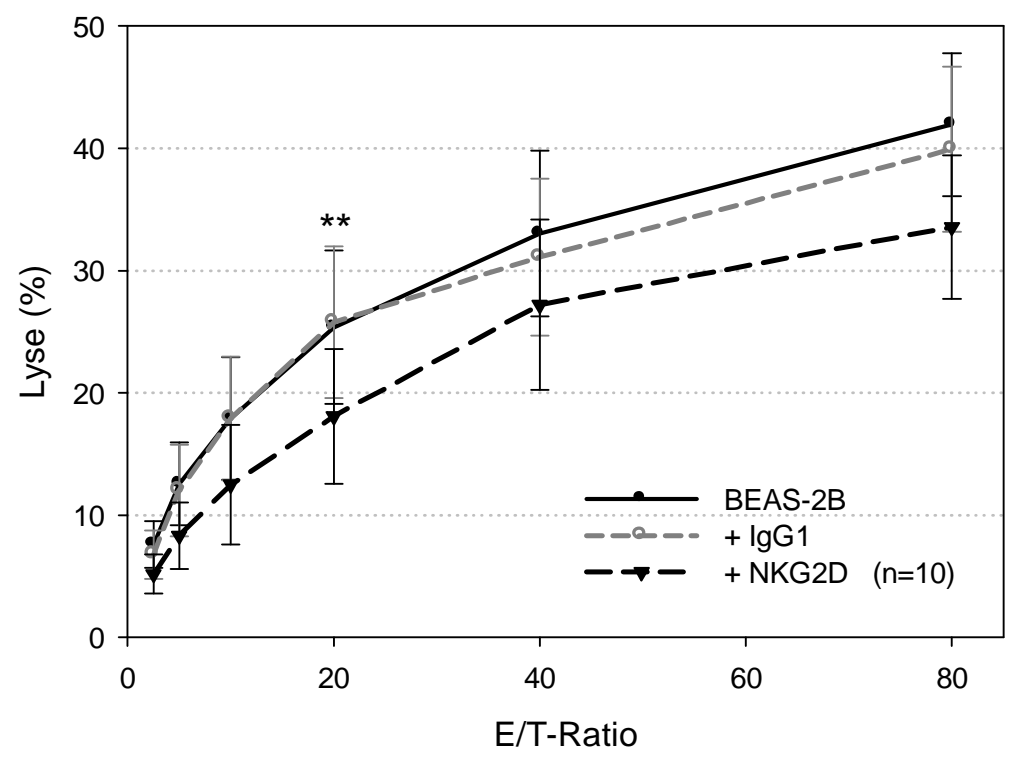

Abbildung 4.23: Einfluss von NKG2D auf die BEAS-2B-Lyse. ${ }^{51}$ Cr-markierte BEAS2B (Targets) wurden entweder nach Präinkubation mit einem anti-NKG2D-Antikörper oder mit IgG 1 Isotypkontrolle oder direkt für vier Stunden mit BEAS-2B-stimulierten CTL (Effektoren) kokultiviert und die spezifische Lyse über die freigesetzte Radioaktivität in Abhängigkeit vom $\mathrm{E} / \mathrm{T}$-Verhältnis bestimmt; $* * \mathrm{p}<0,005$.

\section{Lyse NKG2D-positiver gegenüber der NKG2D-negativer CTL nach Zell-} sortierung: FACS-Daten haben gezeigt, dass am Ende der siebentägigen Stimulationszeit $77 \%( \pm 5,7 \%)$ aller CTL positiv für NKG2D waren, der andere Teil jedoch negativ (Abbildung 4.24). Um den Einfluss des NKG2D auf die Lyse genauer einschätzen zu können, sollten die Lyse-Eigenschaften dieser beiden Subpopulationen im Folgenden getrennt voneinander untersucht werden. Mit PE-markiertem anti-NKG2D-Antikörper gefärbte CTL wurden dazu in einem Durchflusszytometer in die zwei Subpopulationen aufgetrennt und die NKG2D-positiven und die NKG2D-negativen CD8 ${ }^{+}$T-Zellen anschließend unabhängig voneinander in Zytotoxizitätsassays eingesetzt.

Tatsächlich zeigte sich eine deutliche Abhängigkeit der Höhe der Lyse von der NKG2DExpression. NKG2D-negative CTL zeigten nur eine sehr geringe Lyse von unter $10 \%$. NKG2D-positive CTL zeigten dagegen bei allen E/T-Verhältnissen eine deutlich höhere Lyse von BEAS-2B als die unbehandelten Kontrollzellen $(\mathrm{n}=1$ ) (Abbildung 4.25). Um den Einfluss des Färbe- und Sortiervorgangs auf die Aktivität der CTL einschätzen zu können, wurde eine Versuchsreihe mit gefärbten, aber nicht sortierten CTL mitgeführt. 


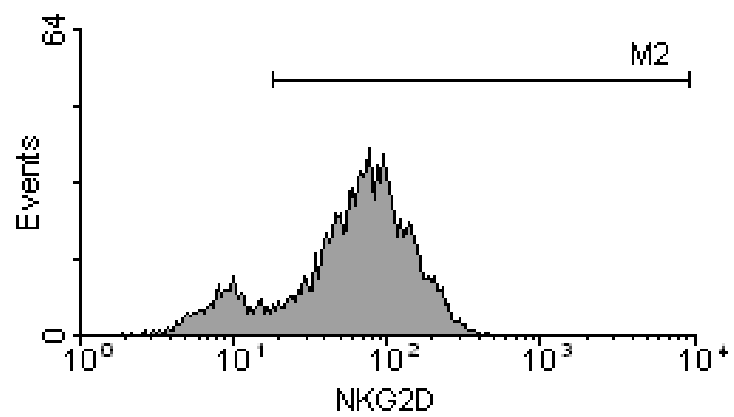

Abbildung 4.24: NKG2D-Expression auf CTL nach BEAS-2B-Stimulation. BEAS-2Bstimulierte CTL wurden mit PE-konjugiertem anti-NKG2D-Antikörper markiert und die Fluoreszenz durchflusszytometrisch gemessen. Dargestellt ist ein repräsentatives Histogramm. Der Marker (M2) ist so gesetzt, dass die unspezifische Färbung der Isotypkontrolle ausgeschlossen, also nur NKG2D-positive Zellen eingeschlossen sind.
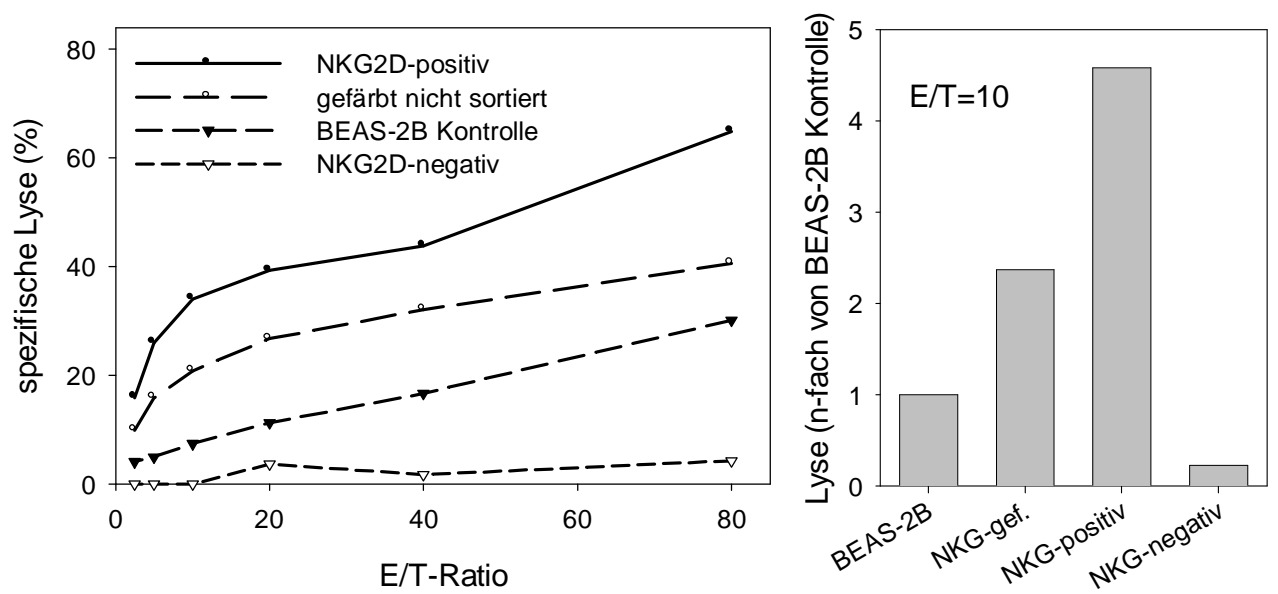

Abbildung 4.25: Abhängigkeit der BEAS-2B-Lyse von der NKG2D-Expression auf CTL. BEAS-2B-stimulierte CTL wurden mit spezifischem, PE-konjugiertem NKG2DAntikörper markiert, im Cell-Sorter in NKG2D-negative und NKG2D-positive Zellen getrennt und anschließend jeweils einzeln für vier Stunden mit ${ }^{51} \mathrm{Cr}$-markierten BEAS-2B kokultiviert und die spezifische Lyse über die freigesetzte Radioaktivität in Abhängigkeit vom E/T-Verhältnis bestimmt. Als Kontrolle dienten nicht behandelte CTL (BEAS-2BKontrolle) und NKG2D-markierte aber nicht aufgetrennte CTL.

Diese zeigten bereits eine erhöhte lytische Aktivität gegenüber dem normalen Ansatz, was möglicherweise auf den aktivierenden Einfluss des gebundenen NKG2D-Antikörpers zurückgeführt werden kann. Die Lyse durch diese Kontrollzellen lag aber immer noch 
deutlich unter der der NKG2D-positiven CTL, so dass nicht das gesamte Ausmaß der Lyse dieser auf einen bloßen aktivierenden Antikörpereffekt zurückzuführen ist. Dass die Lyse der positiv-sortierten CTL im Gegensatz zu der im Kontrollansatz mit normalen CTL durch den Einsatz des NKG2D-blockierenden Antikörpers nicht mehr gehemmt werden konnte, mag darauf zurückzuführen sein, dass der PE-markierte NKG2DAntikörper aus dem Färbe- und Sortiervorgang bereits an den NKG2D-Epitopen der Oberfläche aller CTL in diesem Ansatz gebunden hat. Dieser ist lt. Hersteller selbst nicht blockierend, verhindert aber offensichtlich die weitere Bindung und damit die blockierende Wirkung des unmarkierten, blockierenden Antikörpers an die Zellen.

\subsection{Zytotoxizität aktivierter $\mathrm{CD8}^{+}{ }^{+}$-Zellen gegen primäre bronchiale Epithelzellen}

Da die gezeigten Ergebnisse zur Zytotoxizität aktivierter CD8 ${ }^{+}$T-Zellen bisher nur auf Experimenten mit einer Zelllinie beruhen (BEAS-2B) und mit den Zellen einer zweiten Linie (A549) auch nicht eindeutig bestätigt werden konnten, war es nun wichtig zu zeigen, dass es sich bei den Effekten nicht bloß um Artefakte handelte, die auf die Eigenschaften der Zelllinie bzw. auf deren Immortalisierung mit Virusantigenen zurückzuführen waren. Dazu wurden die Kernexperimente zu Zytotoxizität und Mechanismus im Folgenden mit PBEC durchgeführt. PBEC-stimulierte CTL wurden dazu mit PBEC-Targetzellen in Standard- ${ }^{51}$ Cr-Release Assays kokultiviert, wobei es sich bei Stimulator- und TargetPBEC immer um Zellen des selben Spenders handelte.

Im Gegensatz zu den Versuchen mit der Zelllinie zeigten PBEC-stimulierte CTL sehr unterschiedliche Ausmaße von Lysen. Dies mag darauf zurückzuführen sein, dass die Zellen von verschiedenen Spendern mit jeweils unterschiedlicher Vorgeschichte „life-history“ gewonnen wurden. Zellen einiger Spender wurden während der vierstündigen Kokultur mit aktivierten CTL im Zytotoxizitätsassay zu einem hohen Prozentsatz lysiert (max. $20 \%$ bis $45 \%$ bei $\mathrm{E} / \mathrm{T}=80$ ). Die Zellen weiterer Spender zeigten zwar jeweils nur eine recht geringe Lyse (max. $8 \%$ bis $12 \%$ bei $\mathrm{E} / \mathrm{T}=80$ ), diese war aber auch bei $\mathrm{E} / \mathrm{T}=40$ und $\mathrm{E} / \mathrm{T}=20$ noch deutlich messbar und nahm wie bei ersteren Patienten auch kontinuierlich mit dem E/T-Verhältnis ab, erwies sich dadurch also bereits als spezifisch (Abbildung 4.26 oben). Bei den Zellen anderer Spender konnte unter selben Bedingungen keinerlei spezifische Lyse festgestellt werden, d.h. die maximale, bei $\mathrm{E} / \mathrm{T}=80$ gemessene Lyse lag nur im Bereich weniger Prozent (unter 7\%) und bereits bei $\mathrm{E} / \mathrm{T}=40$ war keine signifikante Lyse mehr messbar. Außerdem fand keine regelmäßige Titrierung 

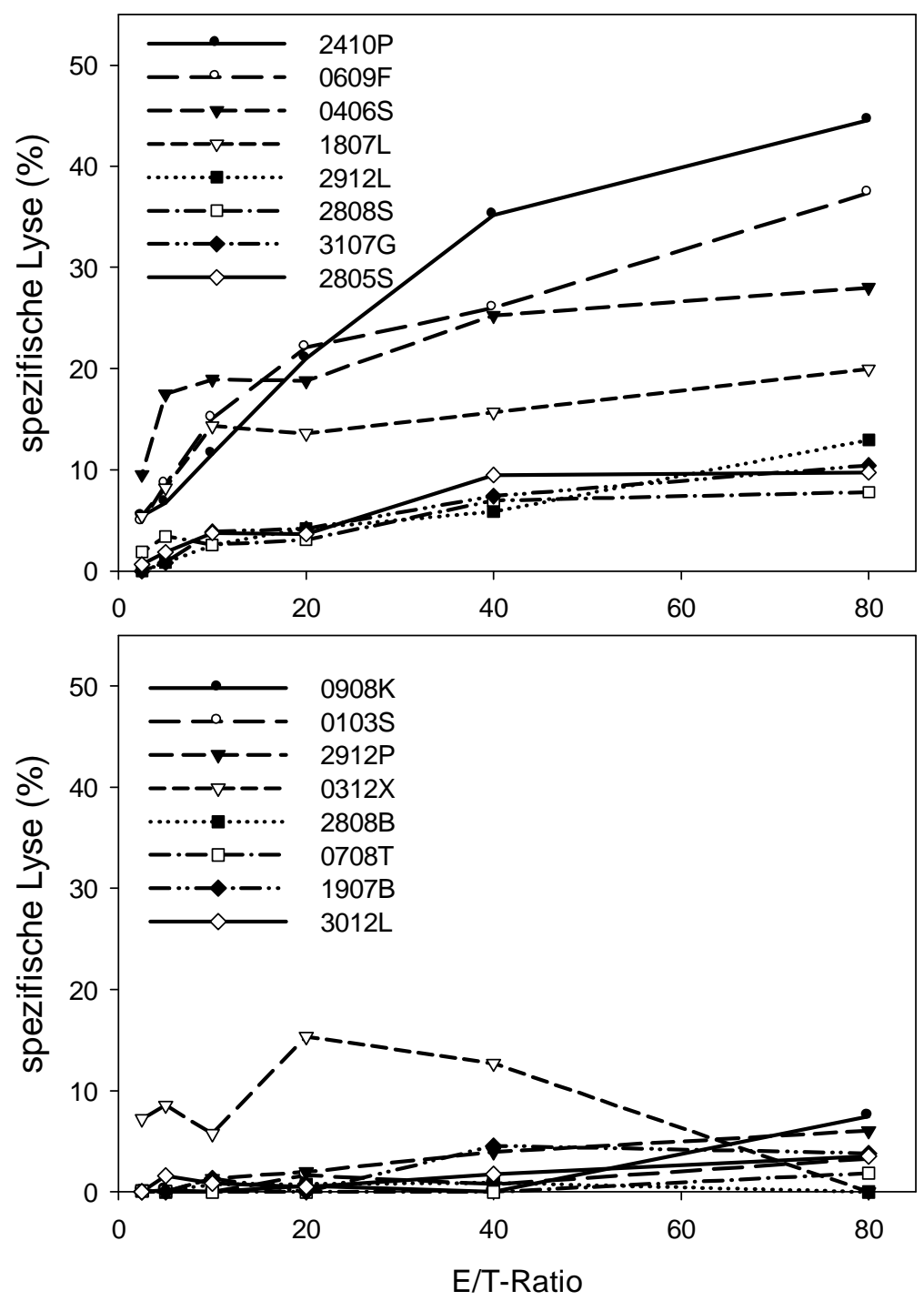

Abbildung 4.26: Spezifische Lyse von PBEC durch PBEC-stimulierte CTL. ${ }^{51} \mathrm{Cr}-$ markierte PBEC (Targets) wurden mit PBEC-stimulierten CTL für vier Stunden kokultiviert und die spezifische Lyse über die freigesetzte Radioaktivität in Abhängigkeit vom E/T-Verhältnis bestimmt $(\mathrm{n}=16)$. Die PBEC von acht Spendern wurden spezifisch lysiert (oben), PBEC-Targetzellen acht weiterer Spender wurden nicht oder nicht spezifisch lysiert (unten).

in Abhängigkeit vom E/T-Verhältnis statt (Abbildung 4.26 unten).

Eine standardmäßige HLA-Typisierung aller Patienten wurde in dieser Studie nicht durchgeführt, es ist allerdings nicht davon auszugehen, dass alle acht Patienten mit dem/den Spendern der CD8 ${ }^{+}$T-Zellen HLA-identisch sind und die Epithelzellen dieser 
Patienten aus diesem Grund nicht lysiert wurden. Für die weiteren Untersuchungen und Auswertungen wurden nur die Epithelzellen derjenigen Spender herangezogen, die zur ersten beschriebenen Gruppe von PBEC gehören (mit mehr oder weniger hoher, spezifischer Lyse statt unspezifischer, sehr niedriger bzw. keiner Lyse), zum einen, weil die unspezifischen Lysen selbst nicht erklärbar sind und zum andern, weil bei sehr niedrigen Lysen nicht ausgeschlossen werden kann, dass es sich dabei nur um Hintergrundartefakte handelt. Darüber hinaus wären auch Lysen von wenigen Prozent nicht mehr sinnvoll in weitergehenden, z. B. Blockierungsexperimenten einzusetzen.

Einfluss einer IFN- $\gamma$-Vorstimulation der PBEC: Auch PBEC waren zur Steigerung ihrer Allogenität mit IFN- $\gamma$ vorstimuliert worden (vgl. Abbildung 4.4; PBEC ${ }^{(\mathrm{IFN}-\gamma)}$ ), was zu unterschiedlichen Effekten auf das Lyseverhalten führte, je nach dem, ob die Stimulator- oder die Targetzellen IFN- $\gamma$-behandelt wurden.

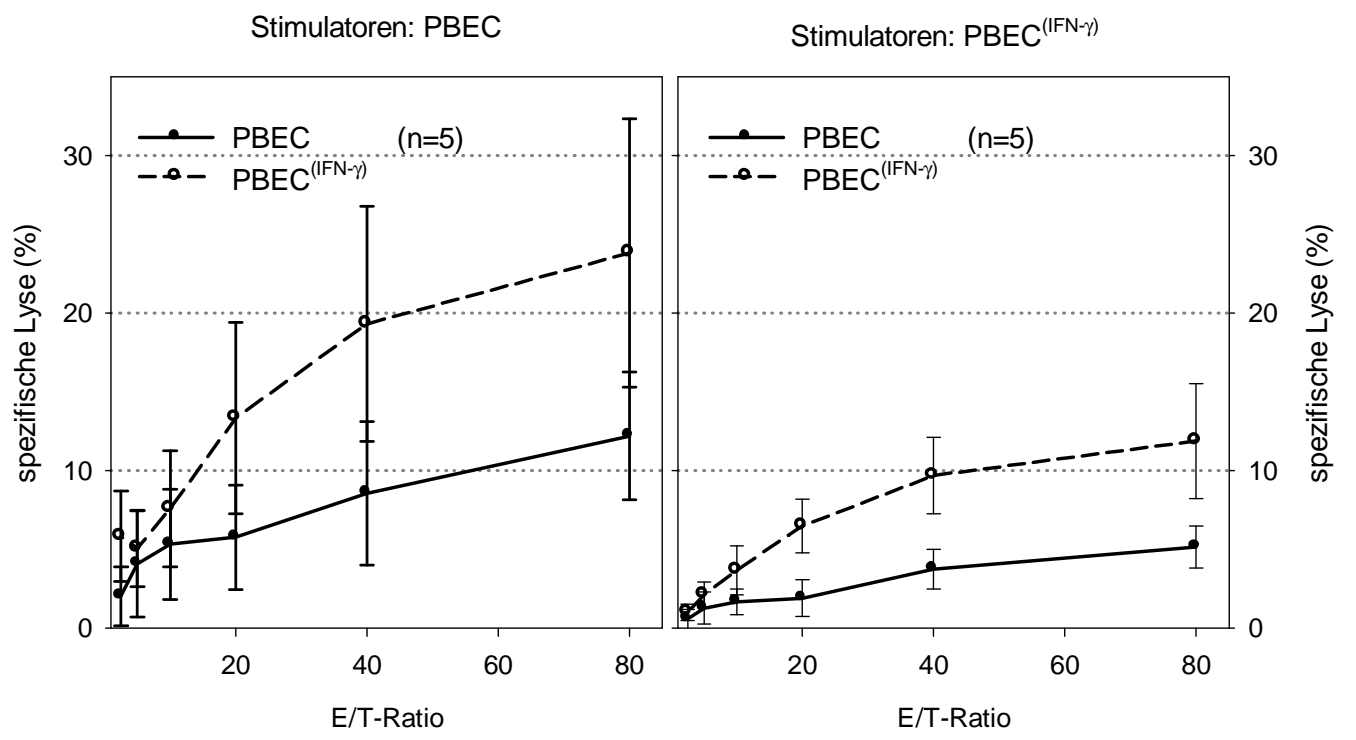

Abbildung 4.27: Einfluss einer IFN- $\gamma$-Vorbehandlung der Stimulator- und/oder Target-PBEC auf die spezifische Lyse. ${ }^{51} \mathrm{Cr}$-markierte PBEC wurden mit PBECstimulierten CTL für vier Stunden kokultiviert und die spezifische Lyse über die freigesetzte Radioaktivität in Abhängigkeit vom E/T-Verhältnis bestimmt. Als Targets und Stimulatoren wurden entweder unbehandelte (PBEC) oder IFN- $\gamma$-vorstimulierte PBEC $\left(\mathrm{PBEC}^{(\mathrm{IFN}-\gamma)}\right)$ eingesetzt.

Waren die Stimulatorzellen vorbehandelt, führte dies zu einer insgesamt geringeren Induktion der Lyse von Zielzellen durch die aktivierten CTL, wobei der Unterschied nicht groß genug war, um statistisch bestätigt werden zu können. Vorstimulierte Targetzellen wurden dagegen immer stärker lysiert als nicht vorstimulierte unter denselben 
Bedingungen (Abbildung 4.27). Dieser Effekt zeigte sich nur im gleichzeitigen Ansatz mit Stimulator-PBEC ${ }^{(\mathrm{IFN}-\gamma)}$ bei $\mathrm{E} / \mathrm{T}=40$ als signifikant $(\mathrm{p}<0,01$, Abbildung 4.27 rechts). Diese unterschiedliche Wirkung einer gesteigerten Allogenität von Stimulator- bzw. Zielzellen auf die Lyse könnte darauf hindeuten, dass Aktivierung und Lyse verschiedene Mechanismen zugrunde liegen.

Mechanismus der spezifischen Lyse von PBEC: Wie oben dargelegt, werden hier nur die Epithelzellen der in Abbildung 4.26 oben aufgeführten Spender weiter berücksichtigt, die eine messbare und spezifisch titrierbare Lyse zeigten. Durch Präinkubation der Targetzellen mit anti-MHC I-Antikörper (W6/32) direkt vor dem Einsatz in den Zytotoxizitätsassay konnte die Lyse der PBEC nicht reduziert werden (Abbildung 4.28 links). Nur bei vier von sechs Spendern war überhaupt ein minimaler hemmender Effekt erkennbar, der jedoch so gering war, dass er sich kaum im Mittelwert niederschlägt und entsprechend nicht signifikant ist. Deutlich stärker und bei den höchsten E/T-Verhältnissen (40 und 80) sogar signifikant fiel dagegen bei PBEC die Blockade der Lyse durch Präinkubation der Effektoren mit anti-NKG2D aus $(\mathrm{p}<0,05$, Abbildung 4.28 rechts). Sie lag im Mittel bei ca. 50 \%, und überstieg damit sogar deutlich das Ausmaß der für BEAS-2B gefundenen Hemmung.

Um diese Bedeutung des NKG2D für die Zytotoxizität der PBEC in diesem System zu bestärken, ist es sinnvoll, die NKG2D-Liganden-Interaktion auch auf der anderen Seite zu blockieren. Aus Mangel an verfügbarem Primärzellmaterial konnten entsprechende Experimente im Rahmen dieser Arbeit nur mit Zellen eines Patienten und für zwei der NKG2D-Liganden, MIC A/B, durchgeführt werden. Dazu wurden die Targets zunächst direkt vor dem Einsatz in den Assay mit einem anti-MIC A/B-Antikörper inkubiert. Diese PBEC-Targets wurden anschließend weniger lysiert, als die nicht mit Antikörper vorbehandelten PBEC (Abbildung 4.29). Um eine Aussage treffen zu können, ob diese Hemmung durch Blockade der Interaktion auf Seiten des MIC A/B ebenso signifikant ist, so wie durch die Blockade des NKG2D auf Effektorseite, bedarf es weiterer Experimente. Ebenso können auch blockierende Antikörper gegen weitere Liganden des NKG2D eingesetzt werden, um differenzierte Aussagen ableiten zu können. 


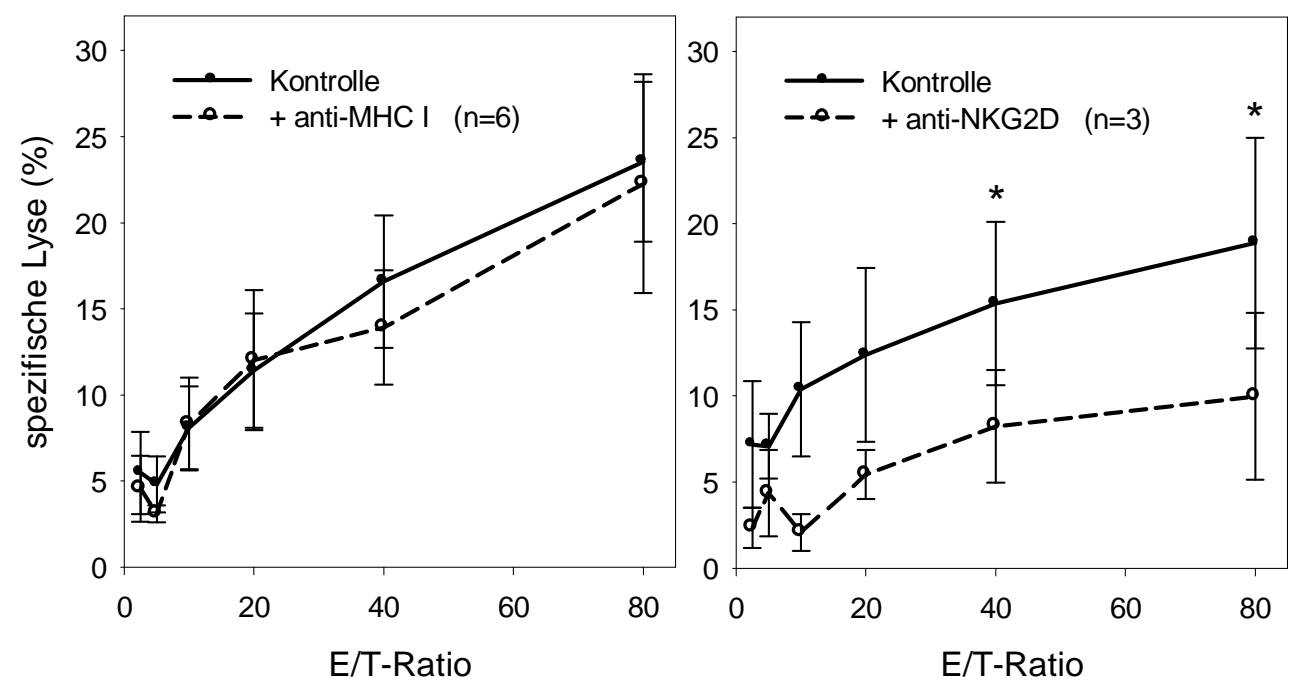

Abbildung 4.28: Einfluss von MHC I und NKG2D auf die PBEC-Lyse. ${ }^{51}$ Cr-markierte PBEC wurden entweder nach Präinkubation mit einem anti-MHC I- (links) oder NKG2D-Antikörper (rechts) oder direkt mit PBEC-stimulierten CTL für vier Stunden kokultiviert und die spezifische Lyse über die freigesetzte Radioaktivität in Abhängigkeit vom E/T-Verhältnis bestimmt; $* \mathrm{p}<0,05$.

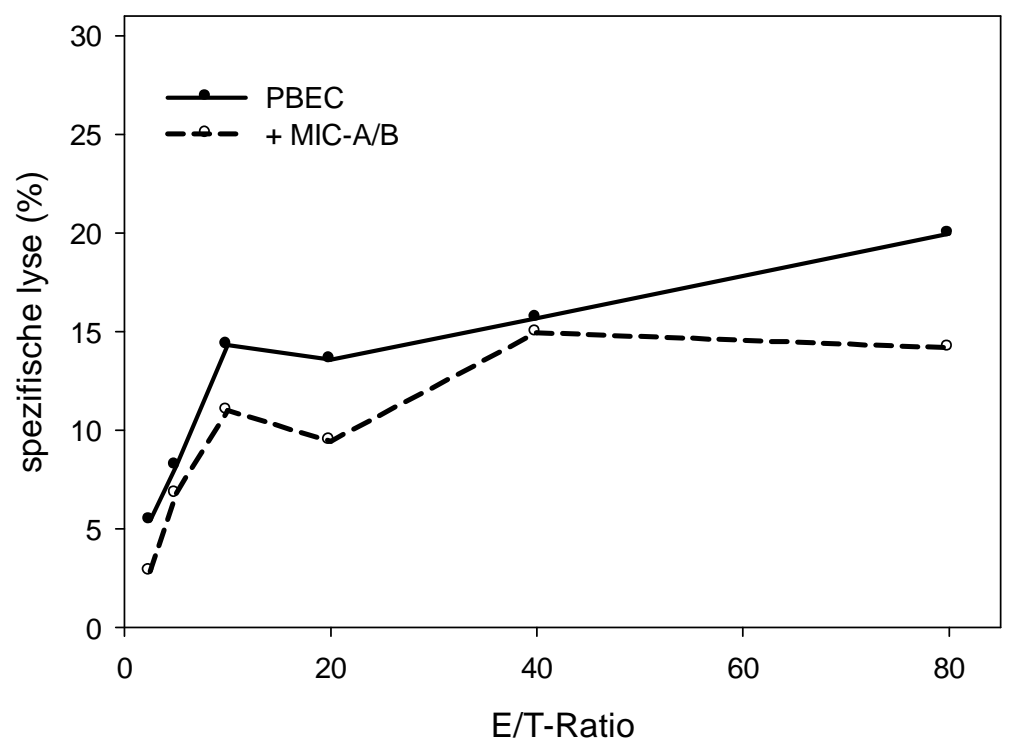

Abbildung 4.29: Einfluss von MIC auf die PBEC-Lyse. ${ }^{51}$ Cr-markierte PBEC wurden entweder nach Präinkubation mit einem anti-MIC A/B-Antikörper oder direkt mit PBEC-stimulierten CTL für vier Stunden kokultiviert und die spezifische Lyse über die freigesetzte Radioaktivität in Abhängigkeit vom E/T-Verhältnis bestimmt. Aus Mangel an verfügbarem Primärzellmaterial konnte das Experiment im Rahmen dieser Arbeit nur mit Zellen eines Patienten durchgeführt werden, die Wiederholung dieses und analoge Experimente mit weiteren NKG2D-Liganden wären sinnvoll. 


\section{Diskussion}

In der vorliegenden Arbeit wurde die Beteiligung einer allogen vermittelten, zytotoxischen Reaktion im Sinne einer GvHD an der Entstehung nichtinfektiös bedingter Lungenschäden nach allogener SZT untersucht. Im Einzelnen wurde die Frage bearbeitet, ob respiratorische Epithelzellen als direkte Aktivatoren für zytotoxische CD8 ${ }^{+}$T-Zellen fungieren können, ob solche allogen aktivierten zytotoxischen CD8 ${ }^{+}$T-Zellen die respiratorischen Epithelzellen in der Folge als Targets erkennen und zerstören können und welche Mechanismen einer solchen Reaktion zugrunde liegen. Dazu wurde ein Zellkulturmodell der GvHD benutzt, in dem CD8 ${ }^{+}$T-Zellen mit respiratorischen Epithelzellen kokultiviert wurden. In $\mathrm{CD}^{+} \mathrm{T}$-Zellen konnte in vitro durch die bronchialen Epithelzellen BEAS-2B sowie PBEC Zytokinproduktion (IFN- $\gamma$ ), Proliferation, verstärkte Expression von Aktivierungsmarkern sowie eine spezifische Zytotoxizität gegen Epithelzelltargets initiiert werden. Damit konnte in vitro gezeigt werden, dass humane bronchiale Epithelzellen sowohl direkte Aktivatoren zytotoxischer $\mathrm{CD}^{+}$T-Zellen als auch Targets für alloaktivierte $\mathrm{CD} 8^{+}$T-Zellen in einer zytotoxischen Reaktion im Sinne einer GvHD sein können.

\subsection{Zellkulturmodell der GvHD}

Es mag zunächst als Nachteil erscheinen, statt eines tierexperimentellen in vivo-Ansatzes ein in vitro Modell zur Untersuchung der komplexen Vorgänge im Zusammenhang mit GvHD-Reaktionen heranzuziehen. Ein entscheidender Vorteil des in dieser Arbeit entwickelten Modells ist jedoch der Einsatz von ex vivo frisch isolierten und kultivierten humanen primären bronchialen Epithelzellen. Deren Reaktionen kommen dem menschlichen System wiederum näher als Tierversuche. Außerdem stimmt in diesem System die komplexe humane HLA-Struktur mit der in vivo überein und die spezifischen Reaktionen einzelner Zelltypen können unterschieden und differenziert untersucht werden. Darüber hinaus besteht die Möglichkeit, ein solches Modell derart weiter zu entwickeln, dass mit dessen Hilfe individuelle patientenspezifische Unterschiede in der Ausprägung einer GvHD an der Lunge z. B. bereits im Vorfeld einer Transplantation erkannt bzw. 
eingeschätzt werden können. Somit könnte dieses Kokulturmodell sogar prädiktiv eingesetzt werden, um vor einer SZT die Verträglichkeit zwischen Spender und Empfänger im Hinblick auf Lungenkomplikationen abschätzten und zumindest die Therapie, wie z. B. die Höhe einer Immunsuppression in der Folge optimal abstimmen zu können.

Zytotoxische T-Zellen sind die Zellen, die klassischerweise für zytotoxische Reaktionen im Rahmen von Abstoßungsreaktionen bzw. einer GvHD verantwortlich gemacht werden [38]. Deshalb wurden isolierte CD8 ${ }^{+}$T-Zellen mit einer Reinheit von $90 \%$ in die Versuche eingesetzt. Die Kontamination dieser Effektorpopulation durch NK-Zellen lag in allen Versuchen bei unter $1 \%$ - sowohl vor als auch nach der Aktivierungsphase sodass unspezifische, antigenunabhängige Reaktionen, die die Effekte einer CD8 ${ }^{+}$T-Zellspezifischen Reaktion überdecken könnten, alleine dadurch minimiert wurden. Entgegen der früheren Annahme wurde inzwischen gezeigt, dass hochaffine CD8 ${ }^{+}$T-Zellen auch unabhängig von professioneller Hilfe, z.B. von CD4 ${ }^{+}$Helfer-T-Zellen, aktiviert werden können [38, 42, 43, 103]. Da aber nicht von vornherein davon ausgegangen werden konnte, dass es sich bei den in diesem Kulturmodell herangezogenen Zellen um ausreichend starke Stimulatoren bzw. hochaffine CD8 ${ }^{+}$T-Zellen handelte, wurde zur Unterstützung von deren Überleben und Wachstum der T-Zell-Wachstumsfaktor IL-2 ins Medium gegeben. Die niedrige eingesetzte IL-2-Konzentration von $100 \mathrm{U} / \mathrm{ml}$ verhinderte jedoch, dass unspezifische Effektoren wie natürliche Killer (NK)-, NK-ähnliche T-Zellen (NKTZellen), Zytokin-induzierte Killerzellen (CIK) oder Zellen mit Lymphokin-aktivierter Killeraktivität (LAK) heranwachsen oder sich entwickeln konnten [104, 105]. Obwohl das Verhältnis von Effektoren zu Targetzellen im geschädigten Gewebe in vivo vermutlich geringer als die hier maximal eingesetzte E/T-Ratio von 80:1 ist, ließ sich zumindest durch die Titration der Effektor/Target-Verhältnisse in den Zytotoxizitätsassays von 2:1 bis 80:1 eine Dosis-Wirkungs-Abhängigkeit und damit Spezifität der Lyse aufzeigen. Außerdem wurden zur Berechnung der E/T-Ratio alle nach der Stimulationszeit noch lebenden $\mathrm{CD}^{+}$T-Zellen des Stimulationsansatzes ausgezählt, unter denen sich natürlich auch die aktivierten Effektoren befanden. Wie jedoch aus den FACS-Diagrammen des Proliferationsansatzes zu sehen ist (Abbildung 4.10), sind darin ebenso zusätzliche nicht aktivierte T-Zellen enthalten, so dass das effektive Verhältnis aktivierter Effektoren zu Targetzellen sicherlich unter dem rein rechnerisch ermittelten lag.

Als Stimulatoren und als Targets wurden zunächst Zellen der bronchialen Zelllinie BEAS-2B und der alveolären Zelllinie A549 eingesetzt, da diese in großem Umfang zur Verfügung stehen. Unter den üblichen Unsicherheiten, die Versuchsansätze in in vitroSystemen generell mit sich bringen, muss hier besonders die Herkunft der beiden Zell- 
linien berücksichtigt bleiben - bei den BEAS-2B handelt es sich um virustransfizierte Zellen, bei A549 um eine Krebszelllinie. Für beide Zelllinien wurden aber die typischen Epithelzell-Eigenschaften nachgewiesen, weshalb sie als Modellzellen für das respiratorische Epithel gelten und als solche bereits vielfach erfolgreich eingesetzt wurden (z. B. $[77,88])$. Zur Reproduktion der wichtigsten Experimente wurden in dieser Arbeit anschließend frisch isolierte und kultivierte primäre bronchiale Epithelzellen herangezogen, deren epithelialer Charakter als Zytokeratin-positiv zuvor bestätigt, sowie Kontamination mit Fibroblasten, Endothelzellen oder Makrophagen ausgeschlossen werden konnte. Die Zellen beider Linien exprimierten so wie auch PBEC zu 100 \% MHC I auf ihrer Oberfläche, während MHC II nur auf wenigen Prozent der Zellen nachzuweisen war (Abbildung 4.4). Auch diese Tatsache argumentiert erneut für den Einsatz von isolierten $\mathrm{CD}^{+} \mathrm{T}$-Zellen in das Kokulturmodell, da CD4 ${ }^{+}$T-Zellen nur über eine Interaktion mit MHC II aktiviert werden können. Adhäsions- (ICAM-1) und kostimulatorische Moleküle wurden auf den eingesetzten Epithelzellen exprimiert. Die klassischen kostimulatorischen Moleküle CD80 und CD86 waren zwar auf beiden Zelllinien kaum nachweisbar (nur auf maximal $1 \%$ der Zellen), wie für BEAS-2B auch bereits von Tanaka [92] und Kurosawa [94] beschrieben, CD70 war aber auf ca. $20 \%$ der Zellen beider Linien, CD95 auf über $50 \%$ (BEAS-2B) bis $80 \%$ (A549) nachweisbar. Beide Moleküle können alternative Wege der Kostimulation vermitteln, so dass damit wichtige phänotypische Voraussetzungen für eine Antigenpräsentation und direkte Aktivierung von $\mathrm{CD} 8^{+}$T-Zellen zumindest theoretisch erfüllt sind.

\subsection{Aktivierung $\mathrm{CD8}^{+} \mathrm{T}$-Zellen durch respiratorische Epithelzellen}

In dem verwendeten Zellkulturmodell konnte gezeigt werden, dass die bronchialen Epithelzellen BEAS-2B als Stimulatoren - im Gegensatz zu A549 - isolierte CD8 ${ }^{+}$T-Zellen direkt und ohne professionelle Hilfe (allo-)antigenspezifisch aktivieren und zu IFN- $\gamma$ Produktion, Proliferation und Zytotoxizität anregen können. Zumindest die Ergebnisse bezüglich Proliferationsinduktion und Zytotoxizität konnten auch durch PBEC belegt werden.

Bereits während einer Woche BEAS-2B-Stimulation bildeten die aktivierten T-Zellen in signifikanter Menge das Zytokin IFN- $\gamma$, was durch eine Restimulation noch verstärkt wurde (Abbildung 4.7). Zudem zeigten sie einen Phänotyp aktivierter zytotoxischer TZellen, indem die Expression (Anteil positiver Zellen oder MFI) von neun der zehn 
untersuchten Aktivierungsmarker auf ihrer Oberfläche verstärkt war (Abbildung 4.9). Bei sieben der zehn Marker war sogar sowohl der Anteil positiver Zellen als auch die MFI nach BEAS-2B-Stimulation stärker erhöht als nach IL-2-Stimulierung. Selbst wenn die Steigerung der Anteile positiver Zellen ausschließlich auf einer Selektion während der Stimulationsdauer beruhen würde, bliebe zumindest noch die im Gegensatz zum IL-2Ansatz stärkere Erhöhung der Expressionsdichte von CD54, CD70, CD95 und HLA-DR, die alleine schon für das Vorliegen aktivierter T-Zellen in der Population sprechen. Das Ergebnis deutet somit auf eine nicht nur durch das Zytokin bewirkte, sondern antigenspezifische Stimulierung des T-Zell-Rezeptors durch die BEAS-2B-Stimulatorzellen hin. Wie in verschiedenen klinischen und tierexperimentellen Studien v.a. nach Transplantation solider Organe gezeigt werden konnte [38], kann dabei insbesondere die verstärkte Expression der Marker CD25, CD30, CD69 und HLA-DR auf eine alloantigen vermittelte Reaktion hindeuten. CD30 wurde auf zytotoxischen T-Zellen in Herzbiopsien beschrieben, auch wenn kein signifikanter Zusammenhang der Höhe der CD30-Expression mit der Schwere einer Abstoßungsreaktion nachgewiesen werden konnte. Für CD25 konnte ein solcher Zusammenhang in derselben Studie dagegen auch belegt werden [95]. Martinez [96] beschrieb $\mathrm{CD}^{+} \mathrm{CD}^{+} 0^{+}$T-Zellen sogar als eine wichtige Teilpopulation alloaktivierter T-Zellen und die Hauptquelle von IFN- $\gamma$ in gemischten Lymphozytenkulturen in vitro. Die Korrelation einer CD69-Expression auf CD8 ${ }^{+}$T-Zellen im Blut als auch auf antigenspezifischen $\mathrm{CD} 8^{+} \mathrm{T}$-Zellen in den Infiltraten in Herzen mit schweren AbstoBungsreaktionen ist belegt und für CD69 sowie HLA-DR ist eine verstärkte Expression besonders auch nach Alloaktivierung bekannt [38, 97, 106, 107, 98].

Diese Zeichen (allogener) Aktivierung waren von einer starken proliferativen Antwort der CD8 ${ }^{+}$T-Zellen während der Stimulation mit BEAS-2B begleitet (zehnfach höher als im IL-2-Ansatz; Abbildung 4.10). Diese Proliferation spiegelt sich auch in der Beobachtung wider, dass die Anzahl nur in IL-2-Medium kultivierter CD8 ${ }^{+}$T-Zellen während der siebentägigen Stimulationsdauer auf unter die Hälfte zurückging, während die Zellzahl im BEAS-2B-Ansatz nahezu konstant blieb, was wohl auf die Ersetzung der nicht stimulierten, absterbenden T-Zellen durch Tochterzellen der aktivierten, sich teilenden T-Zellen zurückgeführt werden kann.

IFN- $\gamma$-Produktion, Aktivierungsmarkerexpression und Proliferation fielen zu jedem Zeitpunkt signifikant stärker aus, als bei nur durch IL-2-stimulierten CD8 ${ }^{+}$T-Zellen. Zudem waren die Stimulatorzellen durch Bestrahlung stoffwechselinaktiviert, konnten also selbst auch keine zusätzlichen T-Zell-stimulierenden Proteine produzieren oder ins Medium sezernieren. Das gibt einen zusätzlichen Hinweis darauf, dass der Aktivierung 
ein (Alloantigen-)spezifischer, über den TCR der Stimulatorzellen vermittelter Mechanismus zugrunde liegt und nicht ausschließlich durch die Anwesenheit eines Zytokins bewirkt wurde.

Im Gegensatz dazu waren A549 nicht in der Lage, CD8 ${ }^{+}$T-Zellen zu aktivieren. Die IFN- $\gamma$-Produktion war ebenso wie die Expression von Aktivierungsmarkern nach A549-Stimulation nicht signifikant von der durch IL-2 alleine bedingten verschieden. Im Gegenteil war die Expression der Aktivierungsmarker CD30, CD71, CD86 und HLA-DR sogar signifikant verringert gegenüber der IL-2-Kontrolle, ebenso wie auch die IFN- $\gamma$ Produktion nach Restimulation. Nur eine sehr schwache Proliferierten A549-stimulierter $\mathrm{CD}^{+}$T-Zellen gegenüber der IL-2-Kontrolle war zu beobachten, die nach sieben bzw. $7+3$ Tagen insgesamt aber immer noch nur $7 \%$ bzw. $13 \%$ aller CD8 ${ }^{+}$T-Zellen (Abbildung 4.10) und damit nur knapp ein Viertel so viele Zellen wie nach BEAS2B-Stimulation betraf.

Wie A549 konnten PBEC-Stimulatorzellen die CD8 ${ }^{+}$T-Zellen zu keiner signifikanten IFN- $\gamma$-Produktion veranlassen, weder nach sieben Tagen noch nach Restimulation. Nur eine leichte Proliferation der $\mathrm{CD} 8^{+}$T-Zellen konnten PBEC gegenüber der IL-2Kontrolle induzieren, diese lag in der Höhe zwischen der durch A549 (zwei- bis zweieinhalbmal so hoch) und der durch BEAS-2B induzierten (ca. zwei Drittel so hoch; Abbildung 4.11), war aber wie bei A549 nicht von der IL-2-Kontrolle verschieden.

Diese Ergebnisse deuten auf ein wesentlich stärkeres Potential zur Aktivierung von $\mathrm{CD}^{+}$T-Zellen der BEAS-2B gegenüber A549-Zellen und PBEC hin. Dies belegt aber auch, dass die hier gefundenen aktivierenden Eigenschaften der untersuchten respiratorischen Epithelzellen nicht bloß ein Zelllinienartefakt sind oder auf Auswirkungen des Virus, mit welchem BEAS-2B immortalisiert wurden, zurückzuführen sind, was der gefundene Unterschied in der Stärke der Aktivatoreigenschaften zwischen BEAS-2B und A549 hätte vermuten lassen können.

\subsection{Zytotoxizität $\mathrm{CD8}^{+} \mathrm{T}$-Zellen gegen respiratorische Epithelzellen}

Auch eine spezifische zytotoxische Aktivität konnte durch die respiratorischen Epithelzellen BEAS-2B in CD8 ${ }^{+}$T-Zellen induziert werden. Umgekehrt ausgedrückt bedeutet das, dass die respiratorischen Epithelzellen von aktivierten CTL spezifisch als Targets erkannt und lysiert werden konnten. A549 waren zwar nicht in der Lage eine Zytotoxizität in $\mathrm{CD}^{+}$T-Zellen zu induzieren (Abbildung 4.13), mit PBEC konnte dieses Ergebnis 
jedoch bestätigt werden (Abbildung 4.26 oben).

BEAS-2B-stimulierte CD8 ${ }^{+}$T-Zellen lysierten BEAS-2B-Targetzellen in starkem Ausmaß (von bis zu $50 \%$ im Mittel). Mit niedrigen Werten beginnend stieg die Lyse in zunehmendem Maße mit dem Effektor/Target-Verhältnis. Naive frisch isolierte CD8 ${ }^{+}$ T-Zellen waren nicht in der Lage BEAS-2B zu lysieren und auch die Lyse durch nur in IL-2-Medium kultivierte CD8 ${ }^{+}$T-Zellen lag nur bei wenigen Prozent und damit immer deutlich unter der BEAS-2B-stimulierter CTLs (Abbildung 4.12). Aus diesen Gründen kann davon ausgegangen werden, dass es sich bei der gemessenen Lyse um eine spezifisch durch BEAS-2B induzierte Zytotoxizität handelte. Auch wurden angebotene körpereigene Targetzellen des jeweiligen T-Zell-Spenders nicht lysiert (Abbildung 4.14), was einerseits wiederum die Allospezifität der zytotoxischen Reaktion selbst bestätigt, da die CTLs offensichtlich zwischen körpereigenen und fremden Targets unterscheiden. Andererseits ist dadurch gleichzeitig auch wiederum eine unspezifische (Über-)Aktivierung der Effektoren ausgeschlossen, wie sie z. B. für die Generierung von LAK- oder CIK-Zellen beschrieben ist, da diese alle Zelltypen MHC-unabhängig lysieren würden.

K562, also MHC I-negative Kontrolltargets, wurden von BEAS-2B-stimulierten CTLs $\mathrm{zu}$ einem unterschiedlichen, wenn auch geringen und immer niedrigeren Prozentsatz als BEAS-2B lysiert. Dass NK Zellen oder NKT-Zellen in der Effektorpopulation für diese Lyse der klassischen NK-Zell-Targets K562 verantwortlich sind, kann jedoch bereits durch den Phänotyp $\left(\mathrm{CD}^{+}, \mathrm{CD}^{+}, \mathrm{CD} 4^{-}, \mathrm{CD} 16 / 56^{-}\right)$der hier eingesetzten Effektoren, der auch während der Stimulationsdauer konstant blieb, nahezu ausgeschlossen werden (Abbildung 4.5). NK-Zellen sind dagegen charakterisiert als CD3 ${ }^{-}$CD16/56 ${ }^{+}$. NKTZellen sind unter humanen Gesamt-PBMC überhaupt nur zu ca. 0,1\% bis $1 \%$ vertreten und fast ausschließlich CD8 ${ }^{-}$. Sie sind zwar wie T-Zellen $\mathrm{CD} 3^{+}$, tragen jedoch auch NKMarker (CD161, CD16/56) auf ihrer Oberfläche [108, 109, 110]. Solche CD3 ${ }^{+}$CD16/56 ${ }^{+}$ Zellen würden in dem entsprechenden FACS-Diagramm im oberen rechten Quadranten erscheinen (Abbildung 4.5 ganz rechts), wo allerdings nur ein sehr geringer Anteil der Effektoren tatsächlich gemessen wurde - im Mittel unter $1 \%$. Dies alles in Betracht gezogen, macht die Beteiligung einer signifikanten NK- oder NKT-vermittelten Lyse sehr unwahrscheinlich.

Auch LAK- oder CIK-Zellen (1 \% bis $5 \%$ aller T-Zellen) könnten für eine Lyse von MHC I-negativen Targetzellen wie den K562 verantwortlich sein, da sie jeden Zelltyp, auf den sie treffen, besonders auch Tumorzellen, mit vergleichbarer Effektivität lysieren können. Da sie aber unabhängig von einer MHC I-Expression, damit (allo)antigenunabhängig und somit also unspezifisch lysieren, müssten solche Effektoren 
ebenso auch körpereigene Zellen lysieren, was wie gezeigt nicht der Fall war [104, 105]. Auch die Tatsache, dass hohe IL-2-Konzentrationen (300 U/ml bis $1000 \mathrm{U} / \mathrm{ml}$ ) benötigt werden, um LAK-Aktivität in einer Kultur aus isolierten CD8 ${ }^{+}$T-Zellen zu induzieren bzw. bei zusätzlicher Anwesenheit von IFN- $\gamma$ CIK-Zellen aus v.a. doppelnegativen (CD4- CD8 ${ }^{-}$) T-Zellen generieren zu können [104, 105, 111], macht die Beteiligung einer LAK- oder CIK-Aktivität an der Lyse unwahrscheinlich. Ebenso spricht auch erneut deren Phänotyp dagegen, dass LAK- oder CIK-Zellen (je CD3 ${ }^{+}$CD16/56 ${ }^{+}$) einen signifikanten Anteil an der Effektorpopulation haben.

Die Ergebnisse der Cold-Target-Inhibition-Assays (Abbildung 4.16) zeigten darüber hinaus, dass K562-Zellen nur in Abwesenheit von BEAS-2B lysiert werden konnten. Sobald den Effektoren die beiden Targetzelltypen gleichzeitig angeboten wurden, wurden spezifisch nur BEAS-2B lysiert. Das ist einerseits ein weiterer Hinweis auf die Spezifität der BEAS-2B-Lyse und legt andererseits den Schluss nahe, dass es sich bei den BEAS-2B-stimulierten CTLs um eine homogene Population handelt, in der die einzelnen Effektorzellen jeweils beide Targets (BEAS-2B und K562) lysieren können - BEAS-2B jedoch mit deutlich höherer Affinität. Beim Vorliegen verschiedener Effektorzellen in einer gemischten, ,verunreinigten“ Population müsste man erwarten, dass sie auch die gemischten Targetzellen gleichzeitig lysieren könnten.

PBEC-stimulierte CD8 ${ }^{+}$T-Zellen zeigten in sehr unterschiedlichem Ausmaß Zytotoxizität gegen PBEC-Targets (0 \% bis maximal $45 \%$ ). PBEC von acht der 16 Spender waren dabei nicht in der Lage eine spezifische, zytotoxische Antwort bei CD ${ }^{+} \mathrm{T}$-Zellen auszulösen (Abbildung 4.26 unten) bzw. wurden nicht als Targets erkannt. PBEC acht weiterer Spender induzierten eine zytotoxische Reaktion, diese PBEC wurden von den aktivierten CTLs als Targets erkannt und spezifisch lysiert (Abbildung 4.26 oben). Die Höhe der Lyse war unabhängig von der Person des Spenders der CD8 ${ }^{+}$T-Zellen, so dass die starken Unterschiede in der Zytotoxizität auf individuelle Unterschiede der Epithelzellen bzw. -Spender zurückzuführen sein müssen. Das klingt plausibel, wenn man berücksichtigt, dass es sich bei den Spendern um Individuen mit unterschiedlichen Vorgeschichten und Vorerkrankungen handelt, wodurch die Epithelzellen vor der Gewinnung unterschiedlichen Milieus ausgesetzt waren bzw. verschiedene Vorstimulierungsniveaus erfahren haben. Auch die genetische Veranlagung der Spender könnte einen Einfluss auf die Allogenität bzw. Empfänglichkeit für Zytotoxizität haben.

Ob diese Unterschiede der in vitro messbaren PBEC-Lyse damit korrelieren, ob ein Patient anfällig für nachtransplantliche, nichtinfektiöse immunologische Komplikationen ist oder nicht, kann aufgrund der Ergebnisse dieser Arbeit nicht abschließend beantwor- 
tet werden. Für eine genauere Beleuchtung dieser interessanten Fragestellung müssten weitergehende Untersuchungen angeschlossen werden, die die in vitro Ergebnisse direkt mit Langzeitbeobachtungen an transplantierten Patienten korrelieren könnten.

\subsection{IFN- $\gamma$-Vorstimulation der schwachen Stimulatoren A549 und PBEC}

Auf A549 waren MHC I und das Adhäsionsmolekül ICAM-1 deutlich schwächer exprimiert als auf BEAS-2B (ein sechstel bzw. ein viertel so stark). PBEC trugen zwar tendenziell mehr CD80/86 und weniger CD70 als die beiden Zelllinien, entsprachen mit ihrer vergleichbar niedrigen mittleren MHC I- und ICAM-1-Expression aber den A549. Beides deutet auf schlechtere Stimulatoreigenschaften von A549 und PBEC im Vergleich zu BEAS-2B hin und könnte theoretisch für deren geringe Lyse verantwortlich sein. Durch eine Vorstimulierung mit IFN- $\gamma$ konnte auf A549 und PBEC eine signifikante Steigerung der Expression von ICAM-1 auf ein vergleichbares Niveau zu BEAS-2B, sowie von MHC I gemessen werden (Abbildung 4.4). Aufgrund dessen ließe sich eine gesteigerte Fähigkeit zur Aktivierung von $\mathrm{CD} 8^{+} \mathrm{T}$-Zellen und damit eine erhöhte Allogenität dieser vorstimulierten gegenüber den basalen Zellen erwarten.

Dies zeigte sich jedoch nicht für A549. IFN- $\gamma$-Produktion, Aktivierungsmarkerexpression und Lyse waren infolge der Stimulation mit A549(IFN- $\gamma)$ unverändert gegenüber der mit A549 oder sogar niedriger. Ebenso blieb mit PBEC-Stimulatoren die Höhe der IFN- $\gamma$-Produktion durch CD8 ${ }^{+}$T-Zellen unbeeinflusst von der Vorstimulierung der Stimulatorzellen, wenn auch die Proliferation leicht erhöht war. Die durch PBEC ${ }^{(\operatorname{IFN}-\gamma)}$ Stimulatoren induzierte Lyse war dagegen deutlich verringert gegenüber der durch PBEC (Abbildung 4.27).

Die Höhe der Expression von MHC I und ICAM-1 hatte auf A549 und PBEC also einen uneinheitlichen bzw. keinen Einfluss auf die Aktivierung von CD8 ${ }^{+}$T-Zellen. Es muss daher postuliert werden, dass es weitere, in der vorliegenden Arbeit nicht untersuchte Moleküle gibt, die Aktivierung und/oder Zytotoxizität beeinflussen. Dies könnten entscheidende aktivierende oder kostimulierende Faktoren sein, die den A549 auch nach IFN- $\gamma$-Vorstimulation noch fehlten. Denkbar wären in diesem Zusammenhang auch „dominant" wirkende, hemmende/inhibitorische Faktoren, deren Expression ebenfalls durch IFN- $\gamma$-Vorstimulation gesteigert wird und die dann einen aktivierungssteigernden Effekt durch mehr ICAM-1 und MHC I wieder aufheben bzw. sogar umkehren könnten. Ähnliches muss auch für die Stimulierungsphase mit PBEC als Stimulatorzellen (Induktion 
von IFN- $\gamma$-Produktion und Zytotoxizität) in Betracht gezogen werden. Da PBEC(IFN- $\gamma)_{-}$ Targets mit gesteigerter MHC I-Expression dagegen zu einem höheren Prozentsatz lysiert wurden als PBEC-Kontrolltargets, scheinen aber zumindest bei den PBEC während Aktivierungsphase und zytotoxischer Reaktion unterschiedliche Mechanismen von Bedeutung zu sein.

\subsection{Mechanismus der Lyse bronchialer Epithelzellen}

Die Bedeutung der drei Haupteffektormechanismen, über die CD8 ${ }^{+}$T-Zellen in ihren antigenspezifischen Targetzellen das Apoptoseprogramm auslösen und diese dadurch abtöten, wurde in dieser Arbeit untersucht: die Freisetzung der Proteasen Perforin und Granzym, die Bindung der Membranmoleküle FAS und FAS-Ligand und die von direktem Zellkontakt unabhängige Wirkung von TNF. Da die Blockade sowohl von FAS als auch von TNF in der vierstündigen Kultur von CTL mit BEAS-2B keinen Einfluss auf die Höhe der Lyse hatte, kann die Vermittlung eines Todessignals durch diese Mediatoren ausgeschlossen werden (Abbildung 4.18). Da Granzym B in hoher Konzentration in der Kokultur nachweisbar war (Abbildung 4.17), muss dagegen die Sezernierung der Proteasen Perforin und Granzym B als verantwortlich für die gemessene Zelllyse angenommen werden. Das ist gleichzeitig auch der für CD8 ${ }^{+}$CTL typische und als vorherrschend beschriebene Mechanismus der zytotoxischen Wirkung [53].

Da der Zerstörung von Zielzellen durch klassische CTL die Erkennung ihres spezifischen Antigen-MHC I-Komplexes auf den Zielzellen üblicherweise vorausgeht, kommt MHC I-Molekülen auch bei der Zytotoxizität eine Schlüsselrolle zu. In den Kokulturen von BEAS-2B-Targetzellen mit BEAS-2B-stimulierten CTLs konnte durch Präinkubation der Targets und anschließender Anwesenheit eines anti-MHC I-Antikörpers im Versuch allerdings keine Reduzierung der Lyse erreicht werden (Abbildung 4.19). Der eingesetzte Antikörper W6/32 bindet unabhängig von individuellen genetischen Variationen an nichtpolymorphe Abschnitte in der alpha-2-Domäne des HLA-A-, -Bund -C-Glycoproteins und wurde bereits in vielen Ansätzen als blockierend beschrieben $[101,102,100]$. Auch konnte durchflusszytometrisch bestätigt werden, dass der Antikörper an die BEAS-2B-Zellen bindet (Abbildung 4.4). Jede in den Versuchen eingesetzte Charge des Antikörpers wurde außerdem auch in parallelen Versuchen mit der endothelialen Zelllinie HMEC eingesetzt, wodurch jeweils erneut die blockierende Wirkung bestätigt werden konnte (Abbildung 4.19; vgl. [73]). Diese Beobachtungen sprechen alle dafür, dass eine MHC I-Erkennung auf die Lyse von BEAS-2B keinen Einfluss 
hat. Über den Mechanismus während der Aktivierungsphase erlauben die Ergebnisse dieser Experimente dagegen keine Aussage. Die Tatsache, dass im Gegensatz zur Aktivierungsphase während der Effektorphase eine Interaktion zwischen antigenspezifischem Rezeptor auf den CTL mit auf MHC I präsentiertem Antigen nicht unbedingt notwendig ist, haben Teshima et al. [55] bereits gezeigt. Dies war allerdings weniger auf die Perforin/Granzym-, also zellulär vermittelte Zytotoxizität bezogen, sondern vielmehr auf eine antigenunspezifische, durch Zytokine vermittelte Zytotoxizität.

Als alternativer, für die Zytotoxizität von $\mathrm{CD} 8^{+} \mathrm{T}$-Zellen beschriebener Mechanismus wurde die Interaktion von NKG2D mit seinen Liganden untersucht. Durch Blockierung dieser Interaktion während der zytotoxischen Reaktion mit anti-NKG2D-Antikörpern lässt sich die Lyse von BEAS-2B durch BEAS-2B-stimulierte CTL verringern, was den Einfluss dieses Mechanismus im untersuchten Modell verdeutlicht (Abbildung 4.23). Das trotz guter Reproduzierbarkeit dieses Ergebnisses relativ geringe Ausmaß der Reduzierung der Lyse um ca. 30\% mag darauf zurückzuführen sein, dass der Antikörper laut Hersteller gleichzeitig auch aktivierend wirken kann. Außerdem muss hier auch der zusätzliche Einfluss weiterer Mechanismen für Kostimulation, Targeterkennung oder -lyse in Betracht gezogen werden. Hierfür käme z. B. die CD70-CD27-Interaktion in Frage, deren Bedeutung für die $\mathrm{CD}^{+}$T-Zell-vermittelte Transplantatabstoßung Yamada bereits zeigen konnte [62].

Dass die Expression von NKG2D auf CTL eine wichtige Rolle bei der Lyse der BEAS2B spielt, bestätigte auch ein Experiment mit sortierten CTL, in dem die NKG2Dpositiven eine sehr starke lytische Aktivität gegen BEAS-2B aufwiesen, NKG2D-negative CTL dagegen annähernd zu keiner Lyse von BEAS-2B-Targets fähig waren (Abbildung 4.25).

Auch mit PBEC konnte sowohl der fehlende Einfluss von MHC I als auch der signifikante Einfluss von NKG2D auf die Lyse bestätigt werden, wobei letzterer sogar noch deutlicher als bei den Zellen der Zelllinie zu sehen war (Abbildung 4.28 rechts). Dies bestätigt eindrucksvoll, dass es sich bei den gefundenen Ergebnissen mit BEAS-2B nicht bloß um Virus-induzierte Zelllinienartefakte handelte. Vielmehr zeigten die gegen respiratorische Epithelzellen spezifischen zytotoxischen $\mathrm{CD} 8^{+} \mathrm{T}$-Zellen in diesem Modell eine nichtklassische Effektorfunktion, die teilweise NKG2D-vermittelt, aber nicht MHC Iabhängig war - trotz ihrer ansonsten klassischen CD8 ${ }^{+}$T-Zelltypischen Eigenschaften wie Zytokinproduktion, Aktivierungsmarkerexpression, Proliferation und Zytotoxizität.

Dieser gefundene Einfluss von NKG2D auf die Lyse eröffnet darüber hinaus auch eine zusätzliche Erklärungsmöglichkeit für die sehr heterogene Lyse der PBEC. Denn zumin- 
dest einer der Liganden des NKG2D, das MIC A, besitzt eine dem MHC I vergleichbare polymorphe Genstruktur und -expression, wobei die verschiedenen Varianten eine unterschiedliche Bindungsaffinität zum NKG2D aufweisen [112]. Den Einfluss dieser Tatsache auf die Höhe der Lyse von PBEC und in der Konsequenz möglicherweise auch auf die Ausprägung einer GvHD nach SZT könnte möglicherweise durch eine Sequenzierung der MIC-Genotypen der jeweiligen Patientenzellen und die Korrelation mit deren Lyse aufgeklärt werden. 


\section{Zusammenfassung}

Die Stammzelltransplantation (SZT) ist eine gut etablierte und verbreitete Behandlungsmethode von einer Reihe lebensbedrohlicher Krankheiten, die trotz inzwischen hoher Heilungschancen immer noch häufig mit lebensbedrohlichen Nebenwirkungen verbunden ist. Aufgrund verbesserter antibiotischer Prophylaxe stehen dabei heute akute und chronische nichtinfektiös bedingte Nebenwirkungen im Vordergrund, die sich nicht nur an den Organen Haut, Leber und Darm, sondern sehr häufig auch an der Lunge manifestieren. Dort machen sie sich u. a. durch Entzündungsreaktionen zusammen mit einer abnormalen Lungenfunktion bemerkbar und sind histopathologisch mit einem diffusen Alveolarschaden, bronchiolärer Entzündung und Epithelschäden assoziiert. Durch die Maßnahmen des Konditionierungsregimes lassen sich diese Befunde jedoch nicht ausreichend erklären. Die direkte Beteiligung zytotoxischer Reaktionen im Sinne einer graftversus-host disease (GvHD) könnte deshalb eine weitere Erklärungsmöglichkeit für die Entstehung nichtinfektiös bedingter Schädigungen des Lungenepithels nach allogener SZT darstellen. Deren Nachweis steht aber noch aus und war Untersuchungsgegenstand dieser Arbeit.

Zur Untersuchung der Fragestellung, ob und wie solche zytotoxischen Reaktionen an der Schädigung des Lungenepithels nach allogener SZT beteiligt sind, wurden isolierte zytotoxische T-Zellen (CD8 $\left.{ }^{+} \mathrm{CD}^{-} \mathrm{CD} 16 / 56^{-}\right)$mit respiratorischen Epithelzellinien (BEAS-2B bzw. A549) bzw. primären bronchialen Epithelzellen (PBEC) in einem Zellkulturmodell kokultiviert. MHC I, ICAM-1 und zumindest die nichtklassischen kostimulatorischen Moleküle CD70 und CD95 wurden - im Gegensatz zu den klassischen CD80 und CD86 - als Voraussetzung zur Antigenpräsentation und T-Zell-Aktivierung auf den respiratorischen Epithelzellen exprimiert. Die in der Kokultur erhobenen Daten zeigen, dass die bronchialen Epithelzellen in vitro in der Lage waren, allogene CD8 ${ }^{+}$ T-Zellen direkt und ohne professionelle Hilfe zu Zytokinproduktion (IFN- $\gamma$ ), Proliferation, verstärkter Expression von Aktivierungsmarkern und einer spezifischen Zytotoxizität gegen Epithelzelltargets zu aktivieren. Diese Ergebnisse konnten sowohl mit Zellen der Linie BEAS-2B, als auch mit PBEC (IFN- $\gamma$-Produktion und Zytotoxizität) gezeigt werden, nicht aber für A549. Die gemessene Aktivierung erwies sich als spezifisch durch 
die Epithelzellen (nicht z. B. durch Zytokine wie IL-2) induziert. Sowohl für die respiratorische Epithelzelllinie BEAS-2B als auch für frisch gewonnene primäre bronchiale Epithelzellen konnte damit eine „nichtprofessionelle antigenpräsentierende“ Funktion nachgewiesen werden.

Die derart (allo)aktivierten CD8 ${ }^{+}$T-Zellen waren in der Lage, die entsprechenden respiratorischen Epithelzellen als Targets zu erkennen und zu zerstören. Diese gegen BEAS-2B bzw. PBEC nachweisbare Zytotoxizität war spezifisch gegen die entsprechenden Targets gerichtet und durch Granzym B vermittelt. Eine Apoptoseinduktion über FAS- oder TNF-vermittelte Signale war dagegen nicht nachweisbar. Auch sprechen die in dieser Arbeit gefundenen Ergebnisse aus Blockierungsexperimenten mit anti-MHC IAntikörpern gegen eine MHC I-Abhängigkeit der Epithelzelllyse, eine Aussage über die MHC I-Abhängigkeit in der Aktivierungsphase erlauben diese Ergebnisse allerdings nicht. Dagegen konnte der Einfluss eines alternativen Mechanismus zur Vermittlung von Zytotoxizität aufgezeigt werden: in den Versuchsansätzen mit BEAS-2B und PBEC wurde die Lyse der Epithelzelltargets durch Blockade des Rezeptors NKG2D signifikant reduziert.

In dem Zellkulturmodell konnten also zytotoxische Reaktionen, die als typische Mechanismen einer GvHD gelten, an respiratorischem Epithel nachgewiesen werden. Humane bronchiale Epithelzellen dienten dabei sowohl als direkte Aktivatoren zytotoxischer $\mathrm{CD}^{+}$T-Zellen als auch als Targets für alloaktivierte CD8 ${ }^{+}$T-Zellen. Eine offenbar zentrale Rolle für die Zytotoxizität der CD8 ${ }^{+}$T-Zellen spielte hierbei die nichtklassische Signalvermittlung über NKG2D. Dies eröffnet neue Ansätze für vorbeugende Maßnahmen bzw. eine Therapie zur Reduzierung zytotoxisch bedingter Schäden des respiratorischen Epithels nach allogener SZT. 


\section{Anhang}

\section{Aus der Arbeit ging folgende Veröffentlichung hervor:}

K. Krätzel, B. Stoelcker, G. Eissner, G. Multhoff, M. Pfeifer, E. Holler, C. Schulz. NKG2D-dependent Effector Function of Bronchial Epithelium Activated Alloreactive T Cells. Accepted for publication in Eur Respir J.

Weitere Publikationen, die im Zusammenhang mit dieser Arbeit entstanden:

C. Schulz, L. Farkas, K. Wolf, K. Krätzel, G. Eissner, and M. Pfeifer. Differences in LPS-Induced Activation of Bronchial Epithelial Cells (BEAS-2B) and Type II-Like Pneumocytes (A-549). Scandinavian Journal of Immunology, 56: 294-302, 2002.

C. Schulz, K. Wolf, M. Harth, K. Krätzel, L. Kunz-Schughart, and M. Pfeifer. Expression and Release of Interleukin-8 by Human Bronchial Epithelial Cells from Patients with Chronic Obstructive Pulmonary Disease, Smokers, and Never-Smokers. Respiration, 70: 254-261, 2003.

C. Schulz, V. Petrig, K. Wolf, K. Krätzel, M. Köhler, B. Becker, M. Pfeifer. Upregulation of MCAM in primary bronchial epithelial cells from patients with COPD. Eur Respir J., 22: 450-456, 2003.

C. Schulz, K. Krätzel, K. Wolf, S. Schroll, M. Köhler, and M. Pfeifer. Activation of Bronchial Epithelial Cells in Smokers Without Airway Obstruction and Patients With COPD. Chest, 125: 1706-1713, 2004.

L. Farkas, M.C. Hahn, M. Schmoczer, N. Jentsch, K. Krätzel, M. Pfeifer, C. Schulz. Expression of CXC Chemokine Receptors 1 and 2 in Human Bronchial Epithelial Cells. Chest, 128: 3724-34, 2005.

\section{Vorarbeiten und Teile der Arbeit wurden in Vorträgen oder Postern auf folgenden Kongressen präsentiert:}

K. Krätzel, G. Eissner, C. Schulz, S. Haffner, E. Holler, M. Pfeifer. Konditionierungsbedingte Schädigung respiratorischer Epithelzellen in einem zellkulturellen Modell der 
Graft versus Host-Reaktion nach allogener Stammzelltransplantation. 44. Kongress der Deutschen Gesellschaft für Pneumologie, München (2003).

K. Wolf, C. Schulz, K. Krätzel, S. Schroll, M. Pfeifer. CD70 und Interleukin 7 Rezeptor Genexpression in primären humanen Bronchialepithelzellen. 44. Kongress der Deutschen Gesellschaft für Pneumologie, München (2003).

C. Schulz, K. Krätzel, K. Wolf, S. Schroll, M. Pfeifer. Verstärkte bronchoepitheliale Aktivierung in COPD-Patienten gegenüber gesunden Rauchern mit gleicher Anzahl an Packyears. 44. Kongress der Deutschen Gesellschaft für Pneumologie, München (2003).

Conditioning mediated damage of respiratory epithelial cells after allogeneic stem cell transplantation in a cell culture model of the graft-versus-host disease. Kongress der American Thoracic Society (2003).

K. Krätzel, G. Eissner, E. Holler, M. Pfeifer, C. Schulz. Damage of Respiratory Epithelial Cells after Allogenic Stem Cell Transplantation in a Cell Culture Model of GraftVersus-Host Disease. European Respiratory Society, 14th Annual Congress (2004).

K. Krätzel, G. Eissner, E. Holler, M. Pfeifer, C. Schulz. Schädigung respiratorischer Epithelzellen nach allogener Stammzelltransplantation in einem Zellkulturmodell der Graft versus Host Reaktion. 46. Kongress der Deutschen Gesellschaft für Pneumologie, Berlin (2005).

K. Krätzel, B. Stoelcker, B. Griener, M. Pfeifer, G. Eissner, C. Schulz. Different activation of $\mathrm{CD}^{+}$T-cells by bronchial and alveolar epithelial cells in a cell culture model of graft-versus-host disease. European Respiratory Society, 16th Annual Congress (2006). European Respiratory Journal 28, Supplement 50, September 2006.

K. Krätzel, G. Eissner, E. Holler, M. Pfeifer, C. Schulz. MHC I-unabhängige Schädigung respiratorischer Epithelzellen in einem Zellkulturmodell der Graft versus Host Reaktion. 4\%. Kongress der Deutschen Gesellschaft für Pneumologie, Nürnberg (2006).

B. Stoelcker, K. Krätzel, G. Eissner, M. Pfeifer, C. Schulz. NKG2D-triggered effector function of bronchial epithelial cell activated alloreactive $\mathrm{CD}^{+} \mathrm{T}$ cells. Deutsche Gesellschaft für Immunologie, Heidelberg (2007). 


\section{Dank}

An dieser Stelle möchte ich mich bei allen bedanken, die zum Gelingen dieser Arbeit beigetragen haben:

PD Dr. C. Schulz und Prof. Dr. M. Pfeifer, Innere Medizin II, sowie PD Dr. G. Eißner und Prof. Dr. E. Holler, Abteilung für Hämatologie und Internistische Onkologie, danke ich für die Ermöglichung dieser Arbeit an der Klinik und Poliklinik für Innere Medizin II der Universität Regensburg und die zahlreichen damit verbundenen Besprechungen.

Darüberhinaus möchte ich mich besonders bei PD Dr. C. Schulz für die Betreuung und sein unerschütterliches Interesse am Voranschreiten der Arbeit, sowie bei Prof. Dr. G. Hauska für die fakultätsinterne Betreuung und für zahlreiche alternative Impulse und Denkansätze herzlich bedanken.

PD Dr. Gaby Multhoff bin ich ebenso wie Dr. Benjamin Stoelcker für Ihre große Diskussionsbereitschaft und sehr hilfreiche und weiterbringende Ideen und Anregungen zu großem Dank verpflichtet.

Für die Unterstützung beim Cell Sorting bedanke ich mich bei PD Dr. Leoni KunzSchughart, Lehrstuhl für Pathologie des Uniklinikums Regensburg. Den Mitarbeitern der Hämatologie danke ich besonders für die zur Verfügungstellung von Leukaphereseblut, T-Zellen und die Überlassung von Kontrollzelllinien.

Ohne das gute Arbeitsklima in der pneumologischen/nephrologischen Arbeitsgruppe hätte die Arbeit der letzten Jahre aber höchstens halb so viel Spaß gemacht. Für ihre freundliche Zusammenarbeit, Hilfsbereitschaft, ihre guten Anregungen und die angenehme Arbeitsatmosphäre möchte ich mich deshalb besonders herzlich bedanken bei Benjamin, Nico, Britta, Gitte, Sabine, Tobias, Lisa, Roland und allen anderen, die ich möglicherweise vergessen habe, namentlich zu erwähnen!

Besonders danken möchte ich an dieser Stelle auch meinen Eltern, Großeltern, meinem Bruder sowie meinem Freund, die mich immer und in jeder Hinsicht unterstützt und gefördert haben. 


\section{Eidesstattliche Erklärung}

Ich erkläre hiermit an Eides statt, dass ich die vorliegende Arbeit ohne unzulässige Hilfe Dritter und ohne Benutzung anderer als der angegebenen Hilfsmittel angefertigt habe; die aus anderen Quellen direkt oder indirekt übernommenen Daten und Konzepte sind unter Angabe des Literaturzitats gekennzeichnet.

Die in der Danksagung aufgeführten Personen haben mir in der jeweils beschriebenen Weise unentgeltlich geholfen.

Weitere Personen waren an der inhaltlich-materiellen Herstellung der vorliegenden Arbeit nicht beteiligt. Insbesondere habe ich hierfür nicht die entgeltliche Hilfe eines Promotionsberaters oder anderer Personen in Anspruch genommen. Niemand hat von mir weder unmittelbar noch mittelbar geldwerte Leistungen für Arbeiten erhalten, die im Zusammenhang mit dem Inhalt der vorgelegten Dissertation stehen.

Die Arbeit wurde bisher weder im In- noch im Ausland in gleicher oder ähnlicher Form einer anderen Prüfungsbehörde vorgelegt. 


\section{Literaturverzeichnis}

[1] C.A. Janeway, P. Travers, M. Walport, and M.J. Shlomchik. Immunologie. Spektrum Akademischer Verlag, Heidelberg, Berlin, 5. edition, 2002.

[2] P. Reddy. Pathophysiology of acute graft-versus-host disease. Hematol Oncol, 21:149-161, 2003.

[3] P. Reddy and J.L. Ferrara. Immunobiology of acute graft-versus-host disease. Blood Rev, 17:187-194, 2003.

[4] J.L. Ferrara. Pathogenesis of acute graft-versus-host disease: cytokines and cellular effectors. J Hematother Stem Cell Res, 9:299-306, 2000.

[5] J.L. Ferrara and J.E. Levine. Graft-versus-host disease in the 21st century: new perspectives on an old problem. Semin Hematol, 43:1-2, 2006.

[6] D.W. Kufe, R.E. Pollock, R.R. Weichselbaum, R.C. Bast, T.S. Gansler, J.F. Holland, and E. Frei. Cancer Medicine. BC Decker, 6th edition, 2003.

[7] F. Baron and Y. Beguin. Nonmyeloablative allogeneic hematopoietic stem cell transplantation. J Hematother Stem Cell Res, 11:243-263, 2002.

[8] E. Holler. Progress in acute graft versus host disease. Curr Opin Hematol, 14:625$631,2007$.

[9] J.M. Hahn. Checkliste Innere Medizin. Thieme, Stuttgart, 5. edition, 2007.

[10] Herold. Innere Medizin. Herold, Köln, 2003.

[11] K.R. Cooke. Acute lung injury after allogeneic stem cell transplantation: From the clinic, to the bench and back again. Pediatr Transplant, 9:25-36, 2005.

[12] G. Yanik and K.R. Cooke. The lung as a target organ of graft-versus-host disease. Semin Hematol, 43:42-52, 2006. 
[13] C.K. Chan, R.H. Hyland, and M.A. Hutcheon. Pulmonary complications following bone marrow transplantation. Clin Chest Med, 11:323-332, 1990.

[14] S.W. Crawford and R.C. Hackman. Clinical course of idiopathic pneumonia after bone marrow transplantation. Am Rev Respir Dis, 147:1393-1400, 1993.

[15] K. Quabeck. The lung as a critical organ in marrow transplantation. Bone Marrow Transplant, 14 Suppl 4:19-28, 1994.

[16] S.P. Kantrow, R.C. Hackman, M. Boeckh, D. Myerson, and S.W. Crawford. Idiopathic pneumonia syndrome: changing spectrum of lung injury after marrow transplantation. Transplantation, 63:1079-1086, 1997.

[17] A. Palmas, A. Tefferi, J.L. Myers, J.P. Scott, S.J. Swensen, M.G. Chen, D.A. Gastineau, M.A. Gertz, D.J. Inwards, M. Q. Lacy, and M.R. Litzow. Late-onset noninfectious pulmonary complications after allogeneic bone marrow transplantation. Br J Haematol, 100:680-687, 1998.

[18] G. Yanik, B. Hellerstedt, J. Custer, R. Hutchinson, D. Kwon, J.L. Ferrara, J. Uberti, and K.R. Cooke. Etanercept (enbrel) administration for idiopathic pneumonia syndrome after allogeneic hematopoietic stem cell transplantation. Biol Blood Marrow Transplant, 8:395-400, 2002.

[19] B. Afessa, M.R. Litzow, and A. Tefferi. Bronchiolitis obliterans and other late onset non-infectious pulmonary complications in hematopoietic stem cell transplantation. Bone Marrow Transplant, 28:425-434, 2001.

[20] J.G. Clark, J.A. Hansen, M.I. Hertz, R. Parkman, L. Jensen, and H.H. Peavy. NHLBI workshop summary. idiopathic pneumonia syndrome after bone marrow transplantation. Am Rev Respir Dis, 147:1601-1606, 1993.

[21] A.P. Schwarer, J.M. Hughes, B. Trotman-Dickenson, T. Krausz, and J.M. Goldman. A chronic pulmonary syndrome associated with graft-versus-host disease after allogeneic marrow transplantation. Transplantation, 54:1002-1008, 1992.

[22] G. Shankar and D.A. Cohen. Idiopathic pneumonia syndrome after bone marrow transplantation: the role of pre-transplant radiation conditioning and local cytokine dysregulation in promoting lung inflammation and fibrosis. Int $J$ Exp Pathol, 82:101-113, 2001. 
[23] S. Sharma, H.F. Nadrous, S.G. Peters, A. Tefferi, M.R. Litzow, M.C. Aubry, and B. Afessa. Pulmonary complications in adult blood and marrow transplant recipients: autopsy findings. Chest, 128:1385-1392, 2005.

[24] J.R. Wingard, E.D. Mellits, M.B. Sostrin, D.Y. Chen, W.H. Burns, G.W. Santos, H.M. Vriesendorp, W.E. Beschorner, and R. Saral. Interstitial pneumonitis after allogeneic bone marrow transplantation. nine-year experience at a single institution. Medicine, 67:175-186, 1988.

[25] S.A. Yousem. The histological spectrum of pulmonary graft-versus-host disease in bone marrow transplant recipients. Hum Pathol, 26:668-675, 1995.

[26] T. Fukuda, R.C. Hackman, K.A. Guthrie, B.M. Sandmaier, M. Boeckh, M.B. Maris, D.G. Maloney, H.J. Deeg, P.J. Martin, R.F. Storb, and D.K. Madtes. Risks and outcomes of idiopathic pneumonia syndrome after nonmyeloablative and conventional conditioning regimens for allogeneic hematopoietic stem cell transplantation. Blood, 102:2777-2785, 2003.

[27] J.L. Ferrara and H.J. Deeg. Graft-versus-host disease. N Engl J Med, 324:667-674, 1991.

[28] J.L. Ferrara, K.R. Cooke, L. Pan, and W. Krenger. The immunopathophysiology of acute graft-versus-host-disease. Stem Cells, 14:473-489, 1996.

[29] H.J. Deeg and J.H. Antin. The clinical spectrum of acute graft-versus-host disease. Semin Hematol, 43:24-31, 2006.

[30] W.E. Beschorner, R. Saral, G.M. Hutchins, P.J. Tutschka, and G.W. Santos. Lymphocytic bronchitis associated with graft-versus-host disease in recipients of bonemarrow transplants. N Engl J Med, 299:1030-1036, 1978.

[31] T. Watanabe, T. Kawamura, H. Kawamura, M. Haga, K. Shirai, H. Watanabe, S. Eguchi, and T. Abo. Intermediate TCR cells in mouse lung: their effector function to induce pneumonitis in mice with autoimmune-like graft-versus-host disease. J Immunol, 158:5805-5814, 1997.

[32] J.G. Clark, D.K. Madtes, R.C. Hackman, W. Chen, M.A. Cheever, and P.J. Martin. Lung injury induced by alloreactive Th1 cells is characterized by host-derived mononuclear cell inflammation and activation of alveolar macrophages. J Immunol, 161:1913-1920, 1998. 
[33] D.D. Ralph, S.C. Springmeyer, K.M. Sullivan, R.C. Hackman, R. Storb, and E.D. Thomas. Rapidly progressive air-flow obstruction in marrow transplant recipients. possible association between obliterative bronchiolitis and chronic graft-versushost disease. Am Rev Respir Dis, 129:641-644, 1984.

[34] H.K. Holland, J.R. Wingard, W.E. Beschorner, R. Saral, and G.W. Santos. Bronchiolitis obliterans in bone marrow transplantation and its relationship to chronic graft-v-host disease and low serum IgG. Blood, 72:621-627, 1988.

[35] M.M. Bortin, O. Ringden, M.M. Horowitz, C. Rozman, R.S. Weiner, and A.A. Rimm. Temporal relationships between the major complications of bone marrow transplantation for leukemia. Bone Marrow Transplant, 4:339-344, 1989.

[36] K.R. Cooke, L. Kobzik, T.R. Martin, J. Brewer, Jr. Delmonte, J., J.M. Crawford, and J.L. Ferrara. An experimental model of idiopathic pneumonia syndrome after bone marrow transplantation: I. the roles of minor $\mathrm{H}$ antigens and endotoxin. Blood, 88:3230-3239, 1996.

[37] K.R. Cooke, W. Krenger, G. Hill, T.R. Martin, L. Kobzik, J. Brewer, R. Simmons, J.M. Crawford, M.R.M. van den Brink, and J.L. Ferrara. Host reactive donor T cells are associated with lung injury after experimental allogeneic bone marrow transplantation. Blood, 92:2571-2580, 1998.

[38] V. Bueno and J.O.M. Pestana. The role of CD8+ t cells during allograft rejection. Braz J Med Biol Res, 35:1247-1258, 2002.

[39] W.D. Shlomchik, M.S. Couzens, C.B. Tang, J. McNiff, M.E. Robert, J. Liu, M.J. Shlomchik, and S.G. Emerson. Prevention of graft versus host disease by inactivation of host antigen-presenting cells. Science, 285:412-415, 1999.

[40] J. Nakajima, N.J. Poindexter, P.B. Hillemeyer, E.P. Trulock, J.D. Cooper, G.A. Patterson, T. Mohanakumar, and R.S. Sundaresan. Cytotoxic T lyhocytes directed against donor HLA class I antigens on airway epithelial cells are present in bronchoalveolar lavage fluid from lung transplant recipients during acute rejection. J Thorac Cardiovasc Surg, 117:565-571, 1999.

[41] A.C. Cunningham, J.G. Zhang, J.V. Moy, S. Ali, and J.A. Kirby. A comparison of the antigen-presenting capabilities of class II MHC-expressing human lung epithelial and endothelial cells. Immunology, 91:458-463, 1997. 
[42] D. Kreisel, A.S. Krupnick, A.E. Gelman, F.H. Engels, S.H. Popma, A.M. Krasinskas, K.R. Balsara, W.Y. Szeto, L.A. Turka, and B.R. Rosengard. Nonhematopoietic allograft cells directly activate CD8 $+\mathrm{T}$ cells and trigger acute rejection: An alternative mechanism of allorecognition. Nat Med, 8:233-239, 2002.

[43] C.R. Smith, A. Jaramillo, B.F. Duffy, and T. Mohanakumar. Airway epithelial cell damage mediated by antigen-specific $\mathrm{T}$ cells: implications in lung allograft rejection. Hum Immunol, 61:985-992, 2000.

[44] J. Dausset. Presence of A \& B antigens in leukocytes disclosed by agglutination tests. C R Seances Soc Biol Fil, 148:1607-1608, 1954.

[45] M.H. Sayegh and L.A. Turka. The role of T-cell costimulatory activation pathways in transplant rejection. N Engl J Med, 338:1813-1821, 1998.

[46] A. Le Moine and M. Goldman. Non-classical pathways of cell-mediated allograft rejection: New challenges for tolerance induction? Am J Transplant, 3:101-106, 2003.

[47] S. Oehen and K. Brduscha-Riem. Differentiation of naive CTL to effector and memory CTL: Correlation of effector function with phenotype and cell division. $J$ Immunol, 161:5338-5346, 1998.

[48] E.R. Podack, N. Strbo, V. Sotosec, and H. Muta. CD30-governor of memory T cells? Ann N Y Acad Sci, 975:101-113, 2002.

[49] S.R. Wiley, R.G. Goodwin, and C.A. Smith. Reverse signaling via CD30 ligand. J Immunol, 157:3635-3639, 1996.

[50] H. Nishimura, T. Yajima, H. Muta, E.R. Podack, K. Tani, and Y. Yoshikai. A novel role of CD30/CD30 ligand signaling in the generation of long-lived memory CD8+ T cells. J Immunol, 175:4627-4634, 2005.

[51] S.Y. Nam, K.S. Cho, Y.M. Heo, J.C. Ha, Y.H. Kim, Y.H. Keun, H.P. Han, H.M. Kim, and E.R. Podack. Regulation of lymphocyte clustering by CD30-mediated ICAM-1 up-regulation. Cell Immunol, 219:38-47, 2002.

[52] G. Ferlazzo, C. Semino, M. Meta, F. Procopio, B. Morandi, and G. Melioli. T lymphocytes express B7 family molecules following interaction with dendritic cells and acquire bystander costimulatory properties. Eur J Immunol, 32:3092-3101, 2002. 
[53] S. Shresta, C.T. Pham, D.A. Thomas, T.A. Graubert, and T.J. Ley. How do cytotoxic lymphocytes kill their targets? Curr Opin Immunol, 10:581-587, 1998.

[54] M.J. Smyth and J.D. Sedgwick. Delayed kinetics of tumor necrosis factor-mediated bystander lysis by peptide-specific CD8+ cytotoxic T lymphocytes. Eur J Immunol, 28:4162-4169, 1998.

[55] T. Teshima, R. Ordemann, P. Reddy, S. Gagin, C. Liu, K.R. Cooke, and J.L. Ferrara. Acute graft-versus-host disease does not require alloantigen expression on host epithelium. Nat Med, 8:575-581, 2002.

[56] T.H. Watts and M.A. DeBenedettet. T cell co-stimulatory molecules other than CD28. Cur Opin Immunol, 11:286-293, 1999.

[57] J. Tanaka, M. Imamura, M. Kasai, S. Kobayashi, S. Hashino, T. Higa, K. Sakurada, and M. Asaka. Possible role of T-cell surface molecule gene expression in the mixed lymphocyte culture for predicting transplantation-related complications after allogeneic bone marrow transplantation. Eur J Haematol, 55:282-284, 1995.

[58] J. Tanaka, M. Asaka, and M. Imamura. T-cell co-signalling molecules in graftversus-host disease. Ann Hematol, 79:283-290, 2000.

[59] A.S. Rosenberg and A. Singer. Cellular basis of skin allograft rejection: an in vivo model of immune-mediated tissue destruction. Annu Rev Immunol, 10:333-358, 1992.

[60] K.A. Newell, G. He, Z. Guo, O. Kim, G.L. Szot, I. Rulifson, P. Zhou, J. Hart, J.R. Thistlethwaite, and J.A. Bluestone. Cutting edge: blockade of the CD28/B7 costimulatory pathway inhibits intestinal allograft rejection mediated by CD4+ but not CD8+ T cells. J Immunol, 163:2358-2362, 1999.

[61] A. Shustov, P. Nguyen, F. Finkelman, K.B. Elkon, and C.S. Via. Differential expression of Fas and Fas ligand in acute and chronic graft-versus-host disease: Up-regulation of Fas and Fas ligand requires CD8+ T cell activation and IFNgamma production. J Immunol, 161:2848-2855, 1998.

[62] A. Yamada, A.D. Salama, M. Sho, N. Najafian, T. Ito, J.P. Forman, R. Kewalramani, S. Sandner, H. Harada, M.R. Clarkson, D.A. Mandelbrot, A.H. Sharpe, H. Oshima, H. Yagita, G. Chalasani, F.G. Lakkis, Jr. Auchincloss, H., and M.H. 
Sayegh. CD70 signaling is critical for CD28-independent CD8+ T cell-mediated alloimmune responses in vivo. J Immunol, 174:1357-1364, 2005.

[63] I. Suzuki and P.J. Fink. Maximal proliferation of cytotoxic T lymphocytes requires reverse signaling through Fas ligand. J Exp Med, 187:123-128, 1998.

[64] S. Bauer, V. Groh, J. Wu, A. Steinle, J.H. Phillips, L.L. Lanier, and T. Spies. Activation of NK cells and T cells by NKG2D, a receptor for stress-inducible MICA. Science, 285:727-729, 1999.

[65] V. Groh, R. Rhinehart, J. Randolph-Habecker, M.S. Topp, S.R. Riddell, and T. Spies. Costimulation of CD $8 \alpha \beta$ T cells by NKG2D via engagement by MIC induced on virus-infected cells. Nat Immunol, 2:255-260, 2001.

[66] A.I. Roberts, L. Lee, E. Schwarz, V. Groh, T. Spies, E.C. Ebert, and B. Jabri. Cutting edge: NKG2D receptors induced by IL-15 costimulate CD28-negative effector CTL in the tissue microenvironment. J Immunol, 167:5527-5530, 2001.

[67] M.R. Verneris, M. Karami, J. Baker, A. Jayaswal, and R.S. Negrin. Role of NKG2D signaling in the cytotoxicity of activated and expanded CD8+ T cells. Blood, 103:3065-3072, 2004.

[68] K. Maasho, J. Opoku-Anane, A.I. Marusina, J.E. Coligan, and F. Borrego. Cutting edge: NKG2D is a costimulatory receptor for human naive CD8+ T cells. $J$ Immunol, 174:4480-4484, 2005.

[69] J.L. Upshaw and P.J. Leibson. NKG2D-mediated activation of cytotoxic lymphocytes: Unique signaling pathways and distinct functional outcomes. Semin Immunology, 18:167-175, 2006.

[70] M.T. Borchers, N.L. Harris, S.C. Wesselkamper, M. Vitucci, and D. Cosman. NKG2D ligands are expressed on stressed human airway epithelial cells. Am J Physiol Lung Cell Mol Physiol, 291:222-231, 2006.

[71] S. Gonzalez, V. Groh, and T. Spies. Immunobiology of human NKG2D and its ligands. Curr Top Microbiol Immunol, 298:121-138, 2006.

[72] R.A. Eagle and J. Trowsdale. Promiscuity and the single receptor: NKG2D. Nat Rev Immunol, 7:737-744, 2007. 
[73] G. Eissner, G. Multhoff, A. Gerbitz, S. Kirchner, S. Bauer, S. Haffner, D. Sondermann, R. Andreesen, and E. Holler. Fludarabine induces apoptosis, activation, and allogenicity in human endothelial and epithelial cells: protective effect of defibrotide. Blood, 100:334-340, 2002.

[74] R.R. Reddel, Y. Ke, B.I. Gerwin, M.G. McMenamin, J.F. Lechner, R.T. Su, D.E. Brash, J.B. Park, J.S. Rhim, and C.C. Harris. Transformation of human bronchial epithelial cells by infection with SV40 or adenovirus-12 SV40 hybrid virus, or transfection via strontium phosphate coprecipitation with a plasmid containing SV40 early region genes. Cancer Res, 48:1904-1909, 1988.

[75] Y. Ke, R.R. Reddel, B.I. Gerwin, M. Miyashita, M. McMenamin, J.F. Lechner, and C.C. Harris. Human bronchial epithelial cells with integrated SV40 virus T antigen genes retain the ability to undergo squamous differentiation. Differentiation, 38:60$66,1988$.

[76] C.D. Albright, R.T. Jones, E.A. Hudson, J.A. Fontana, B.F. Trump, and J.H. Resau. Transformed human bronchial epithelial cells (BEAS-2B) alter the growth and morphology of normal human bronchial epithelial cells in vitro. Cell Biol Toxicol, 6:379-398, 1990.

[77] T.L. Noah, A.M. Paradiso, M.C. Madden, K.P. McKinnon, and R.B. Devlin. The response of a human bronchial epithelial cell line to histamine: intracellular calcium changes and extracellular release of inflammatory mediators. Am J Respir Cell Mol Biol, 5:484-492, 1991.

[78] D.J. Giard, S.A. Aaronson, G.J. Todaro, P. Arnstein, J.H. Kersey, H. Dosik, and W.P. Parks. In vitro cultivation of human tumors: establishment of cell lines derived from a series of solid tumors. J Natl Cancer Inst, 51:1417-1423, 1973.

[79] M. Lieber, B. Smith, A. Szakal, W. Nelson-Rees, and G. Todaro. A continuous tumor-cell line from a human lung carcinoma with properties of type ii alveolar epithelial cells. Int J Cancer, 17:62-70, 1976.

[80] E. Klein, H. Ben-Bassat, H. Neumann, P. Ralph, J. Zeuthen, A. Polliack, and F. Vanky. Properties of the K562 cell line, derived from a patient with chronic myeloid leukemia. Int J Cancer, 18:421-431, 1976.

[81] B.B. Lozzio and C.B. Lozzio. Properties and usefulness of the original K-562 human myelogenous leukemia cell line. Leuk Res, 3:363-370, 1979. 
[82] C.B. Lozzio and B.B. Lozzio. Human chronic myelogenous leukemia cell-line with positive philadelphia chromosome. Blood, 45:321-334, 1975.

[83] A.T. Ichiki, C.B. Lozzio, M.A. Barnhill, C.J. Wust, E.G. Bamberger, D.J. Trent, P.B. Lucas, J.C. Bray, and J.E. Fuhr. Interferon-gamma-induced expression of class I HLA antigens on K-562 cells grown in serum-free medium. J Interferon Res, 7:87-93, 1987.

[84] C. Schulz, K. Wolf, M. Harth, K. Krätzel, L. Kunz-Schughart, and M. Pfeifer. Expression and release of interleukin- 8 by human bronchial epithelial cells from patients with chronic obstructive pulmonary disease, smokers, and never-smokers. Respiration, 70:254-261, 2003.

[85] A.B. Lyons and C.R. Parish. Determination of lymphocyte division by flow cytometry. J Immunol Methods, 171:131-137, 1994.

[86] A.B. Lyons. Analysing cell division in vivo and in vitro using flow cytometric measurement of cfse dye dilution. Journal of Immunological Methods, 243:147$154,2000$.

[87] A.B. Lyons, J. Hasbold, and P.D. Hodgkin. Flow cytometric analysis of cell division history using dilution of carboxyfluorescein diacetate succinimidyl ester, a stably integrated fluorescent probe. Methods Cell Biol, 63:375-398, 2001.

[88] C. Schulz, L. Farkas, K. Wolf, K. Kätzel, G. Eissner, and M. Pfeifer. Differences in LPS-induced activation of bronchial epithelial cells (BEAS-2B) and type II-like pneumocytes (A-549). Scand J Immunol, 56:294-302, 2002.

[89] S.M. Albelda. Endothelial and epithelial cell adhesion molecules. Am J Respir Cell Mol Biol, 4:195-203, 1991.

[90] P.G. Bloemen, M.C. van den Tweel, P.A. Henricks, F. Engels, S.S. Wagenaar, A.A. Rutten, and F.P. Nijkamp. Expression and modulation of adhesion molecules on human bronchial epithelial cells. Am J Respir Cell Mol Biol, 9:586-593, 1993.

[91] J. Atsuta, S.A. Sterbinsky, J. Plitt, L.M. Schwiebert, B.S. Bochner, and R.P. Schleimer. Phenotyping and cytokine regulation of the BEAS-2B human bronchial epithelial cell: Demonstration of inducible expression of the adhesion molecules VCAM-1 and ICAM-1. Am J Respir Cell Mol Biol, 17:571-582, 1997. 
[92] H. Tanaka, K. Maeda, Y. Nakamura, M. Azuma, H. Yanagawa, and S. Sone. CD40 and IFN-gamma dependent T cell activation by human bronchial epithelial cells. J Med Invest, 48:109-117, 2001.

[93] K. Wolf, C. Schulz, G.A.J. Riegger, and M. Pfeifer. Tumour necrosis factor-alpha induced CD70 and interleukin-7R mRNA expression in BEAS-2B cells. Eur Respir $J, 20: 369-375,2002$.

[94] S. Kurosawa, A.C. Myers, L. Chen, S. Wang, J. Ni, J.R. Plitt, N.M. Heller, B.S. Bochner, and R.P. Schleimer. Expression of the costimulatory molecule B7-H2 (inducible costimulator ligand) by human airway epithelial cells. Am J Respir Cell Mol Biol, 28:563-573, 2003.

[95] P.L. Wijngaard, W.B. Tuijnman, F.H. Gmelig Meyling, A. van der Meulen, M. Huytink, G. Jambroes, and H.J. Schuurman. Endomyocardial biopsies after heart transplantation. the presence of markers indicative of activation. Transplantation, 55:103-110, 1993.

[96] O.M. Martinez, J. Villanueva, S. Abtahi, P.R. Beatty, C.O. Esquivel, and S.M. Krams. CD30 expression identifies a functional alloreactive human T-lymphocyte subset. Transplantation, 65:1240-1247, 1998.

[97] K.O. Schowengerdt, F.J. Fricker, K.S. Bahjat, and S.T. Kuntz. Increased expression of the lymphocyte early activation marker CD69 in peripheral blood correlates with histologic evidence of cardiac allograft rejection. Transplantation, 69:21022107,2000 .

[98] M. Paz Morante, J. Briones, E. Canto, H. Sabzevari, R. Martino, J. Sierra, J.L. Rodriguez-Sanchez, and S. Vidal. Activation-associated phenotype of CD3+ T cells in acute graft-versus-host disease. Clin Exp Immunol, 145:36-43, 2006.

[99] Y. Komada and M. Sakurai. Fas receptor (CD95)-mediated apoptosis in leukemic cells. Leuk Lymphoma, 25:9-21, 1997.

[100] G. Multhoff, C. Botzler, M. Wiesnet, G. Eissner, and R. Issels. CD3- large granular lymphocytes recognize a heat-inducible immunogenic determinant associated with the $72-\mathrm{kD}$ heat shock protein on human sarcoma cells. Blood, 86:1374-1382, 1995. 
[101] F.M. Brodsky, P. Parham, C.J. Barnstable, M.J. Crumpton, and W.F. Bodmer. Monoclonal antibodies for analysis of the HLA system. Immunol Rev, 47:3-61, 1979.

[102] R.T. Maziarz, J. Fraser, J.L. Strominger, and S.J. Burakoff. The human HLAspecific monoclonal antibody W6/32 recognizes a discontinuous epitope within the alpha 2 domain of murine H-2Db. Immunogenetics, 24:206-208, 1986.

[103] M.J. Deeths, R.M. Kedl, and M.F. Mescher. Cd8+ t cells become nonresponsive (anergic) following activation in the presence of costimulation. J Immunol, 163:102-110, 1999.

[104] R.L. Geller, M.J. Smyth, S.L. Strobl, F.H. Bach, F.W. Ruscetti, D.L. Longo, and A.C. Ochoa. Generation of lymphokine-activated killer activity in T cells. possible regulatory circuits. J Immunol, 146:3280-3288, 1991.

[105] M.R. Verneris, J. Baker, M. Edinger, and R.S. Negrin. Studies of ex vivo activated and expanded CD8+ NK-T cells in humans and mice. J Clin Immunol, 22:131-136, 2002.

[106] S. Rutella, C. Rumi, M.B. Lucia, T. Barberi, P.L. Puggioni, M. Lai, A. Romano, R. Cauda, and G. Leone. Induction of CD69 antigen on normal CD4+ and CD8+ lymphocyte subsets and its relationship with the phenotype of responding T-cells. Cytometry, 38:95-101, 1999.

[107] B.J. Gilot, M. Hara, N.D. Jones, Maurik A. van, M. Niimi, V. Hadjianastassiou, P.J. Morris, and K.J. Wood. Visualization of the in vivo generation of donor antigen-specific effector CD8+ T cells during mouse cardiac allograft rejection: in vivo effector CD8+ T cell generation during allograft rejection. Transplantation, 69:639-648, 2000.

[108] D.I. Godfrey, K.J.L. Hammond, L.D. Poulton, M.J. Smyth, and A.G. Baxter. NKT cells: facts, functions and fallacies. Immunol Today, 21:573-583, 2000.

[109] S.P. Berzins, M.J. Smyth, and D.I. Godfrey. Working with NKT cells - pitfalls and practicalities. Cur Opin Immunol, 17:448-454, 2005.

[110] M. Kronenberg. Toward an understanding of NKT cell biology: Progress and paradoxes. Annu Rev Immunol, 23:877-900, 2005. 
[111] Z. Reiter. Dual effects of cytokines in regulation of MHC-unrestricted cell mediated cytotoxicity. Crit Rev Immunol, 13:1-34, 1993.

[112] A. Steinle, P. Li, D.L. Morris, V. Groh, L.L. Lanier, R.K. Strong, and T. Spies. Interactions of human NKG2D with its ligands MICA, MICB, and homologs of the mouse RAE-1 protein family. Immunogenetics, 53:279-287, 2001. 